\title{
CN TOWER LIGHTNING FLASH CHARACTERISTICS BASED ON HIGH-SPEED IMAGING
}

\author{
by \\ Ishmeen Sra \\ M. Eng., McMaster University, Hamilton, ON, Canada, 2016 \\ B. Tech., Guru Nanak Dev Engineering College, Punjab, India, 2014 \\ A thesis \\ presented to Ryerson University \\ in partial fulfilment of the \\ requirements for the degree of \\ Master of Applied Science \\ in the program of \\ Electrical and Computer Engineering
}

Toronto, Ontario, Canada, 2018

(C) Ishmeen Sra, 2018 


\section{AUTHOR'S DECLARATION}

I hereby declare that I am the sole author of this thesis. This is a true copy of the thesis, including any required final revisions, as accepted by my examiners.

I authorize Ryerson University to lend this thesis to other institutions or individuals for the sole purpose of scholarly research.

I further authorize Ryerson University to reproduce this thesis by photocopying or by other means, in total or in part, at the request of other institutions or individuals for the sole purpose of scholarly research.

I understand that my thesis may be made electronically available to the public. 


\author{
ABSTRACT \\ CN Tower Lightning Flash Characteristics Based on High-Speed Imaging \\ Ishmeen Sra \\ Master of Applied Science \\ Department of Electrical and Computer Engineering \\ Ryerson University, Toronto \\ 2018
}

The thesis emphasizes the analysis of fifty-eight flashes that struck the $\mathrm{CN}$ Tower during the last five years (2013-2017), based on video records of Phantom v5.0 digital high-speed imaging system, operating at $1 \mathrm{~ms}$ resolution. (A Sony HDR PJ790VB digital camera, operating at 16.67 ms resolution, provided a continuous recording of each $\mathrm{CN}$ Tower lightning storm.) It was observed that every recorded flash contained initial-stage current, confirming that all analyzed flashes were upward initiated. It was also observed that only 27 flashes out of the 58 contained return strokes. The number of strokes per flash varied between 1 and 9 , with an average multiplicity of 2.16. The time variation of the channel luminosity of each flash was precisely analyzed for the characterization of flash components. A yearly statistical comparison regarding $\mathrm{CN}$ Tower lightning macroscopic (number of flashes, inter-flash times and flash durations) and microscopic (initial-stage current durations, number of the return strokes per flash, M-components and inter-stroke times) characteristics was conducted. The analysis of these extensive data (20132017) clearly showed that the 50\% cumulative probability distribution (CPD) of flash duration in 2017 was found to be the largest in comparison with other data (2013-2016). Whereas, the 50\% CPD of inter-flash time duration in 2015 was the shortest. Furthermore, the 2014 data showed the longest 50\% CPD of the initial-stage current duration as well as the inter-stroke time duration. In 
2016, one flash was found to contain the highest number of return strokes. 2015 was distinguished by having the longest $50 \% \mathrm{CPD}$ of the continuing current duration. It was also noted that two significantly major storms were captured during the nights of September 5, 2014 and September 4, 2017. During the storm of September 5, 2014, the CN Tower imaging systems recorded 13 flashes. The storm lasted for 111.4 minutes, resulting on average a flash to the tower every 9.28 minutes. Whereas, the September 4, 2017 storm continued for 49.35 minutes, producing 11 flashes for the tower every 4.9 minutes. The characterisation of $\mathrm{CN}$ Tower lightning is pivotal to the protection of tall structures against lightning hazards. It's worth mentioning that flashes with longer flash duration, containing high number of return strokes and have shorter inter-stroke time durations pose severe threats to tall structures, electrical and communication systems. 


\section{ACKNOWLEDGMENTS}

I would like to express my sincere appreciation to my supervisor Professor Dr. Ali Hussein for his continuous guidance and support during my research work. I would like to thank you for your encouragement and your financial support. Also, the numerous discussions we had during these years proved invaluable.

I would like to express my gratitude to Mr. Petros Liatos for his help in operating the highspeed imaging system and the continually recording Sony camera during 2013-2017.

I would like to thank Natural Sciences and Engineering Research Council (NSERC) and Ryerson University for the financial support during my research work.

A special thank you goes to the graduate program administrator, Ms. Dawn Wright, for her help and encouragement during my MASc program.

I would surely like to thank the Department of Electrical and Computer Engineering and Yeates School of Graduate Studies for giving me the opportunity to pursue my fruitful research work. 


\section{TABLE OF CONTENT}

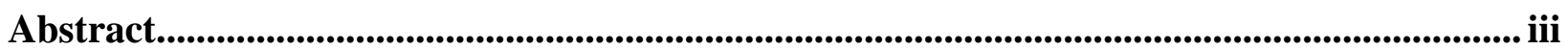

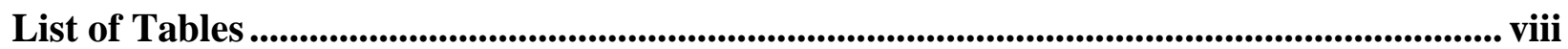

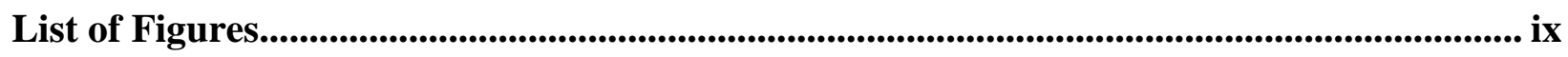

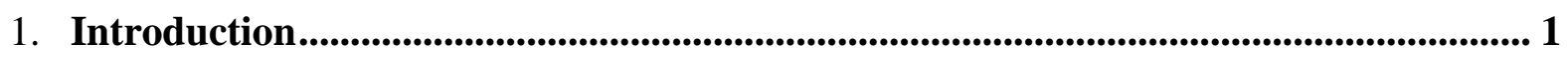

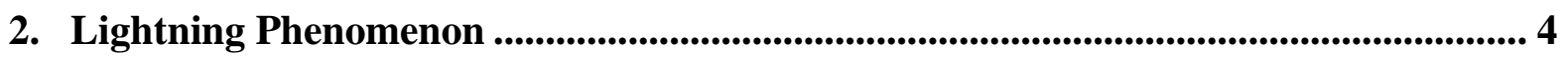

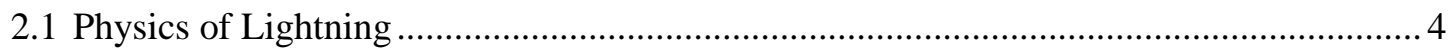

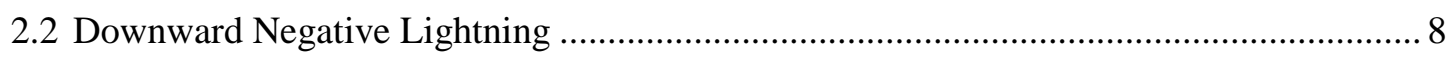

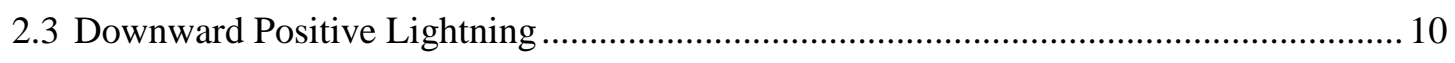

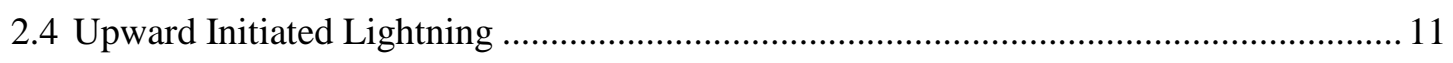

3. CN Tower Lightning Measurement Systems ...................................................... 13

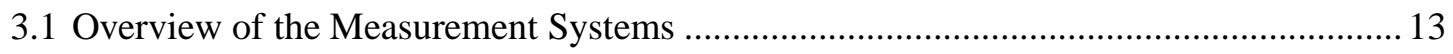

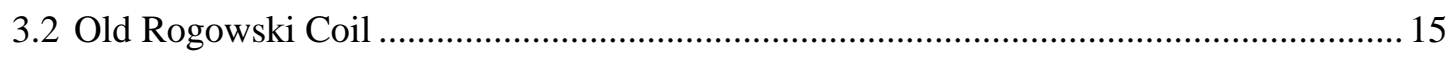

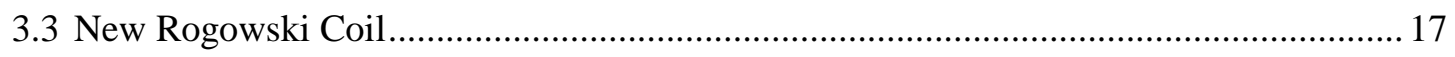

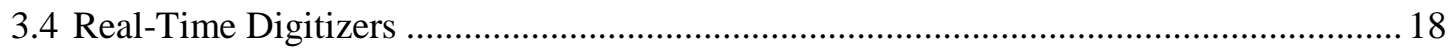

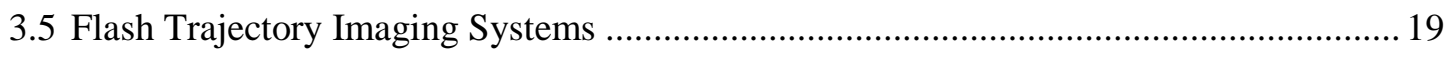

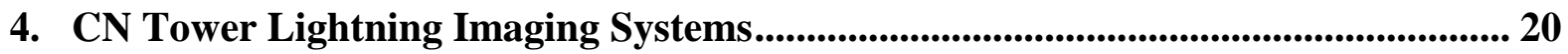

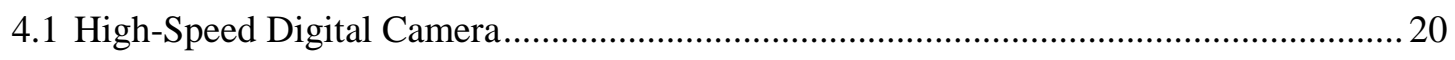

4.2 September 5, 2014 Storm Captured by HSC ….......................................................... 27

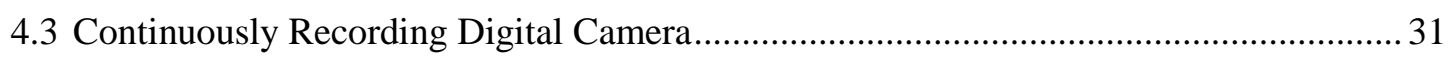

5. Lightning Storm Observed at CN Tower on September 4, 2017 ............................... 36

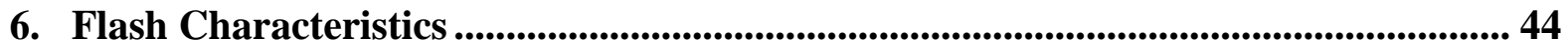

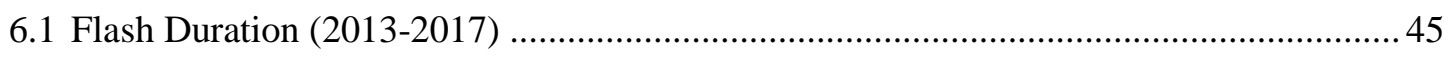

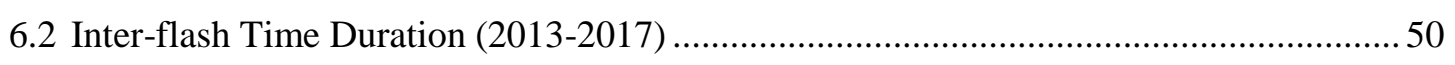

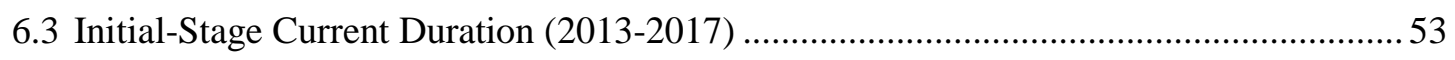

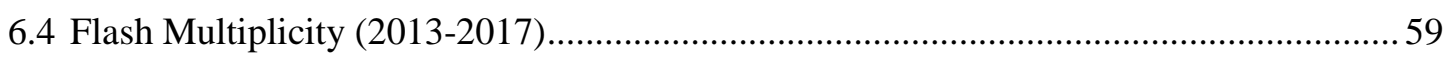

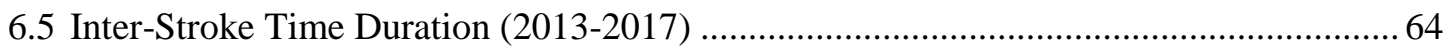




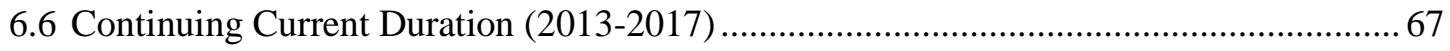

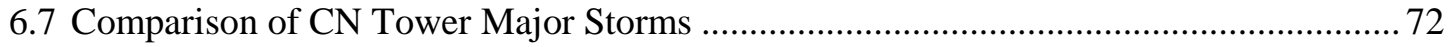

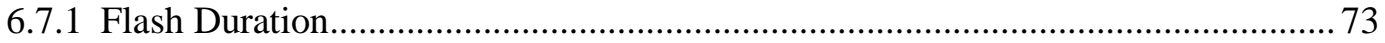

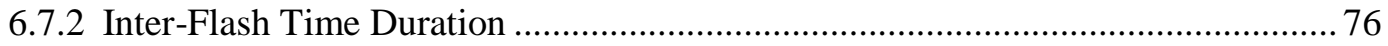

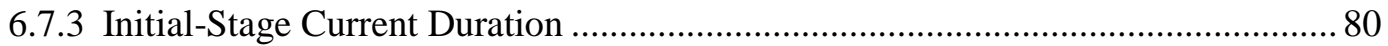

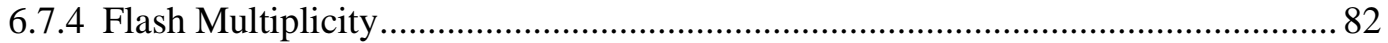

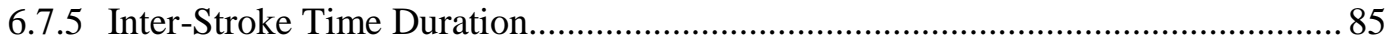

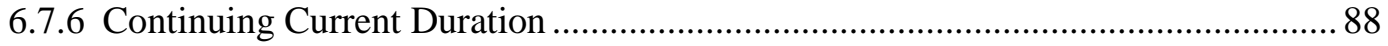

7. Conclusions and Future recommendations ........................................................................... 92

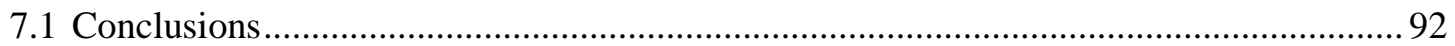

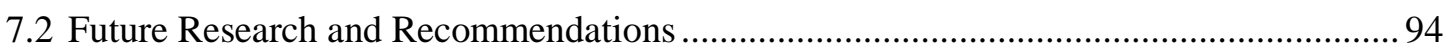

References........................................................................................................................................................... 96

Glossary .................................................................................................................................................... 99 


\section{List of Tables}

Table 6.1 Flash durations and inter-flash time durations of all 58 flashes based on video records (2013-2017) f....45

Table 6.2 Statistics of flash durations based on video records (2013-2017) ......................................................50

Table 6.3 Statistics of inter-flash time duration based on the video records (2013-2017).....................................53

Table 6.4 Initial-stage current durations based on video records (2013-2017) .....................................................54

Table 6.5 Statistics of initial-stage current durations based on video records (2013-2017) ...................................58

Table 6.6 Flash multiplicity and inter-stroke time duration based on video records (2013-2017) ..........................59

Table 6.7 Statistics of flash multiplicity for 27 flashes based on video records (2013-2017) ................................64

Table 6.8 Statistics of inter-stroke time durations based on video records (2013-2017) .......................................67

Table 6.9 Continuing current time durations based on video records (2013-2017)..............................................68

Table 6.10 Statistics of continuing current time durations based on video records (2013-2017) ............................72

Table 6.11 Statistical summary of flash durations of flashes recorded during major storms

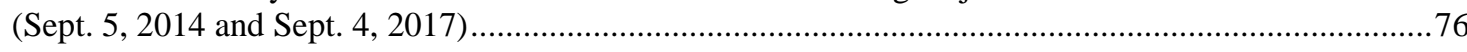

Table 6.12 Statistical summary of inter-flash time durations of flashes recorded during major storms

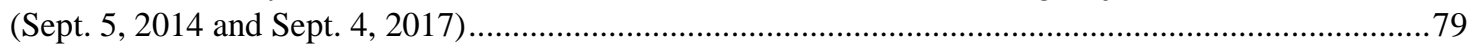

Table 6.13 Statistical summary of initial-stage current durations of flashes recorded during major storms (Sept. 5, 2014 and Sept. 4, 2017).

Table 6.14 Statistical summary of a flash multiplicity of flashes recorded during major storms (Sept. 5, 2014 and Sept. 4, 2017).

Table 6.15 Statistical summary of inter-stroke time durations of flashes recorded during major storms (Sept. 5, 2014 and Sept. 4, 2017). .88

Table 6.16 Statistical summary of continuing current durations of flashes recorded during major storms (Sept. 5, 2014 and Sept. 4, 2017). 91 


\section{List of Figures}

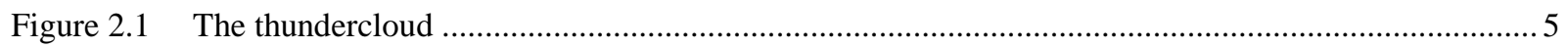

Figure 2.2 A thundercloud, with a fundamental demonstration of electric charge distribution

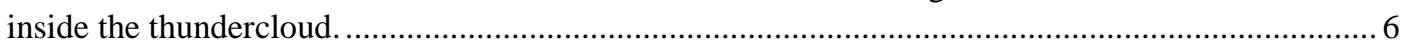

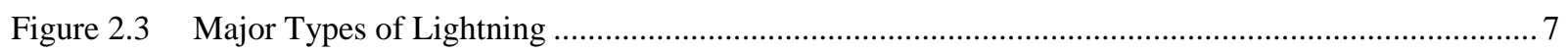

Figure 2.4 Different types of cloud-to-ground lightning ……...........................................................................

Figure 2.5 The sequence of processes involved in a negative downward lightning flash .................................. 10

Figure 2.6 The sequence of processes involved in upward negative lightning ................................................. 12

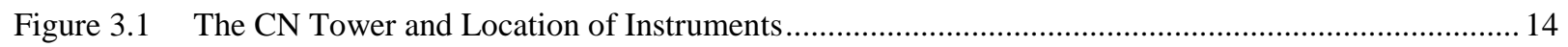

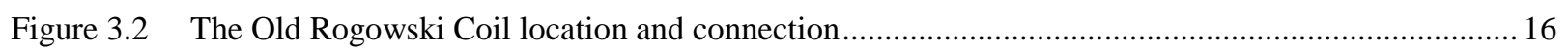

Figure 3.3 The new Rogowski Coil location and connection ........................................................................... 17

Figure 4.1 Phantom v5.0 digital high-speed camera................................................................................. 21

Figure 4.2 Location of Phantom v5.0 HSC and Sony HDR PJ790VB LSC.......................................................22

Figure 4.3 Flow chart describing the methodology of analysis of video records. .............................................. 23

Figure 4.4 Channel trajectory image of the second flash recorded on July 8, 2013 ......................................24

Figure 4.5 Maximum and average channel luminosity time variations along the horizontal pixel line

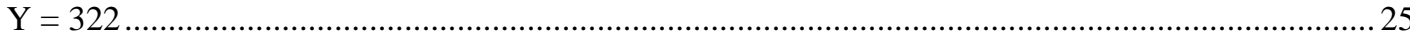

Figure 4.6 Channel trajectory image of the fourth flash recorded on July 14, 2016......................................26

Figure 4.7 Maximum and average channel luminosity time variations along the horizontal pixel line

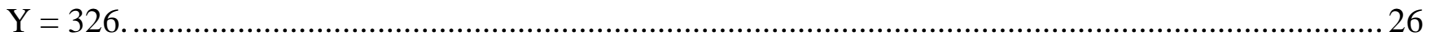

Figure $4.8 \quad$ Flash multiplicity of flashes September 5, 2014 storm ............................................................... 27

Figure 4.9 Channel trajectory image of the third flash recorded on September 5, 2014 ................................28

Figure 4.10 Maximum and average channel luminosity time variations along the horizontal pixel line $\mathrm{Y}=299$.

Figure 4.11 Channel trajectory image of the twelfth flash recorded on September 5, 2014.

Figure 4.12 Maximum and average channel luminosity time variations along the horizontal pixel line $\mathrm{Y}=270$

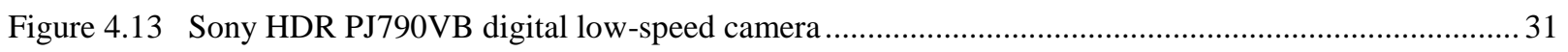

Figure 4.14 Channel trajectory image of the second flash recorded on September 7, 2016 .............................. 32 
Figure 4.15 Maximum and average channel luminosity time variations along the horizontal pixel line $\mathrm{Y}=320$

Figure 4.16 Channel trajectory image of the third flash recorded on July 8, 2013.

Figure 4.17 Maximum and average channel luminosity time variations along the horizontal pixel line $\mathrm{Y}=360$.

Figure 5.1 Channel luminosity variation with time for the Sept. 4, 2017 based on LSC and HSC records ......... 37

Figure 5.2 Channel trajectory images of flash 1 of HSC (left) and its matched LSC flash 7 (right) .................38

Figure 5.3 Channel luminosity variation with time based on flash 1 (HSC) and flash 7 (LSC) .......................... 38

Figure 5.4 Channel trajectory images of flash 2 of HSC (left) and its matched LSC flash 8 (right) .................39

Figure 5.5 Channel luminosity variation with time based on flash 2 (HSC) and flash 8 (LSC) ...................... 40

Figure 5.6 Channel trajectory images of flash 3 of HSC (left) and its matched LSC flash 9 (right) ................41

Figure 5.7 Channel luminosity variation with time based on flash 3 (HSC) and flash 9 (LSC) ......................41

Figure 5.8 Channel trajectory images of flash 4 of HSC (left) and its matched LSC flash 11 (right) ............... 42

Figure 5.9 Channel luminosity variation with time based on flash 4 (HSC) and flash 11 (LSC) .................... 43

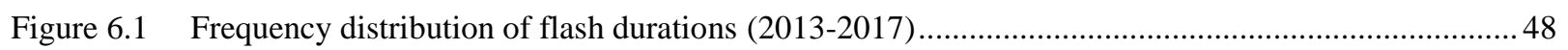

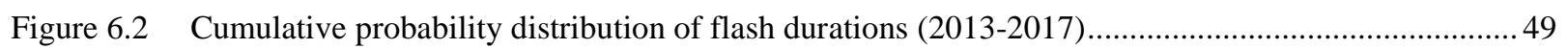

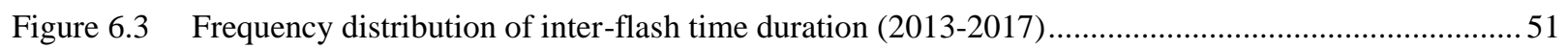

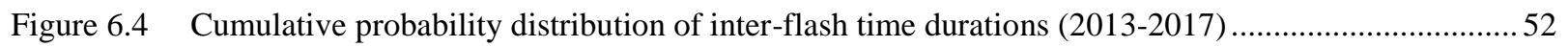

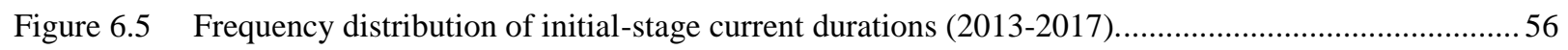

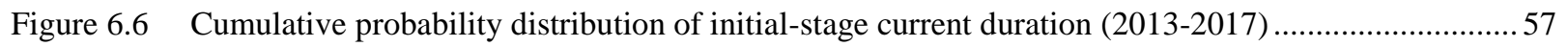

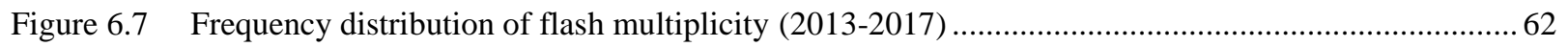

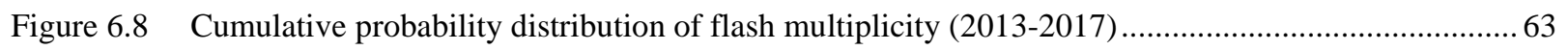

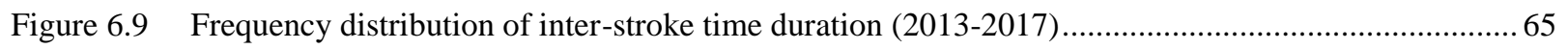

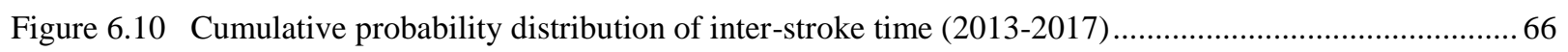

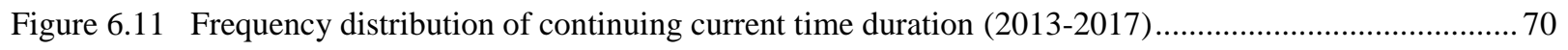

Figure 6.12 Cumulative probability distribution of continuing current time duration $(2013-2017) \ldots \ldots \ldots \ldots \ldots \ldots \ldots . . . . .11$

Figure 6.13 Frequency distribution of flash time duration of flashes recorded during major storms (Sept. 5, 2014 and Sept. 4, 2017) .74

Figure 6.14 Cumulative probability distribution of flash duration of flashes recorded during major storms (Sept. 5, 2014 and Sept. 4, 2017). .75 
Figure 6.15 Frequency distribution of inter-flash time duration of flashes recorded during major storms (Sept. 5, 2014 and Sept. 4, 2017).

Figure 6.16 Cumulative probability distribution of inter-flash time of flashes recorded during major storms

(Sept. 5, 2014 and Sept. 4, 2017).

Figure 6.17 Frequency distribution of initial-stage current duration of flashes recorded during major storms (Sept. 5, 2014 and Sept. 4, 2017).

Figure 6.18 Cumulative probability distribution of initial-stage current duration of flashes recorded during major storms (Sept. 5, 2014 and Sept. 4, 2017).

Figure 6.19 Frequency distribution of flash multiplicity of flashes recorded during major storms (Sept. 5, 2014 and Sept. 4, 2017).

Figure 6.20 Cumulative probability distribution of flash multiplicity of flashes recorded during major storms (Sept. 5, 2014 and Sept. 4, 2017).

Figure 6.21 Frequency distribution of inter-stroke time duration of flashes recorded during major storms (Sept. 5, 2014 and Sept. 4, 2017).

Figure 6.22 Cumulative probability distribution of inter-stroke time duration of flashes recorded during major storms (Sept. 5, 2014 and Sept. 4, 2017).

Figure 6.23 Frequency distribution of continuing current of flashes recorded during major storms (Sept. 5, 2014 and Sept. 4, 2017).

Figure 6.24 Cumulative probability distribution of continuing current duration of flashes recorded during major storms (Sept. 5, 2014 and Sept. 4, 2017). 


\section{Chapter 1}

\section{Introduction}

Lightning is a natural phenomenon; it has likely been present before the emergence of life. Evidence of 250,000-year-old lightning has been found in ancient fulgurites (glassy tubes that lightning forms in sand). Lightning plays a vital role in maintaining the global electric circuit (the fair-weather electric field being about $100 \mathrm{~V} / \mathrm{m}$ pointing downwards, due to negatively charged earth surface and positively charged air aloft). It also produces chemicals in and around its discharge channel including fixed nitrogen, which plants use in the food-making process [1].

Lightning can be defined as a transient high current electric discharge whose path length is generally measured in kilometres, which discharges regions of excess electrical charge developed in thunderclouds [1], [2]. The lightning discharge, in its entirety, whether it strikes the ground or not, is usually termed as a lightning flash [3]. A lightning flash may contain several components referred to as strokes. Every ground flash contains a downward leader and an upward return stroke and may immediately be succeeded by a relatively slow "continuing current." The transient processes prevailing in the lightning channel during the flow of the continuing current are referred to as M-components. The first stroke is initiated by a "stepped leader," while subsequent strokes are initiated by "dart" or "dart-stepped leaders."

A lightning discharge that involves an object on the ground is termed as a lightning strike [3]. Lightning flashes can kill or injure humans and animals by direct strikes. Lightning can trigger electrical shocks in its vicinity. Lightning strikes can also damage aircrafts, 
wind turbines and trees. Lightning strikes are accountable for numerous forest fires [2]. It's observed that lightning flashes that include continuing currents have the ability to set forest fires $[2]$.

Benjamin Franklin showed that a grounded metallic rod placed on the top of a tall structure may protect it from lightning damage. In 1876, James Clerk Maxwell proposed that if lightning were to strike a metal-enclosed building, the current would concentrate on the exterior of the metal enclosure and it would not even be necessary to ground such enclosure.

Since the past few decades, with the escalation of the socio-economic development across the world, a number of tall structures are constructed worldwide. The erection of such tall structures resulted in the obstruction of broadcasting signals. In order to diminish the hindrance to the broadcasting signals, many tall free-standing structures got constructed worldwide to broadcast signals without interruption or the interference caused by ordinary structures in their surrounding vicinities. Important broadcasting tall structures are briefly referred to here. Tokyo Skytree (Japan), the world's tallest tower with a height of $634 \mathrm{~m}$; Canton Tower, located in Guangzhou, China, is 600-m tall; Canadian National (CN) Tower, located at Toronto, with an altitude of 553.3 $\mathrm{m}$. Several broadcasting towers of moderate heights are located on mountain tops. Their effective elevations are higher than their physical heights [3]. Some of these towers are constructed in Europe, namely, Gaisberg Tower (100-m tall), located in Austria, placed on the top of a 1287-m mountain; Peissenberg Tower (150-m tall) in Germany, located on a 988-m; and the 55-m tall tower Mount San Salvatore in Switzerland erected at the top of 640-m mountain.

The probability of a structure being struck by lightning increases with its height and the flash density it its vicinity. Most lightning flashes to a very tall structure are initiated by the structure itself [3]. Therefore, tall broadcasting towers are often struck by lightning. Hence, it's vital to protect these tall broadcasting structures against the destructive effects of lightning strikes. The prescribed tall structures are well equipped with lightning measurement systems to facilitate lightning studies, which can further assist in the formation of more advanced lightning protection systems. It also helps in understanding the risk posed to electronic and communication systems located in the vicinity of tall structures due to electromagnetic interference (EMI), resulting from the lightning-generated electromagnetic pulse (LEMP). 
The lightning phenomenon is discussed in Chapter 2, which is followed by a discussion about cloud electrification and different types of lightning.

Chapter 3 contributes to a discussion about CN Tower lightning measurement systems since 1991.

Chapter 4 discusses the presently operational imaging systems (Phantom v5.0 high-speed digital camera and the continuously-recording Sony HDR VJ790VB digital camera) used to record CN Tower lightning flashes. Followed by demonstrating luminosity versus time based on video records obtained from the two imaging systems, to further characterize flash components.

Chapter 5 emphasizes the analysis of a major storm that took place during the night of September 4, 2017, based on the records of high-speed and low-speed digital imaging systems. In this chapter, the comparison between the data sets recorded by the two cameras is conducted. Furthermore, this chapter provides insight on storm's macroscopic characteristics, including the number of flashes, inter-flash time and flash duration.

Chapter 6 focuses on the primary objective of this work, namely the statistical analysis of CN Tower lightning flash components based on the video data, recorded during the past five years (2013-2017). A yearly statistical comparison regarding CN Tower lightning macroscopic (number of flashes, inter-flash times and flash durations) and microscopic (initial-stage current durations, number return strokes and M-components and inter-stroke times) characteristics is conducted. In addition, a vital comparison between two major storms, which took place September 5, 2014 and on September 4, 2017, is performed based on various flash components.

Chapter 7 presents the conclusions that are based on the results of previous chapters. It also includes suggestions for future research based on the contributions of this thesis. 


\section{Chapter 2}

\section{Lightning Phenomenon}

\subsection{Physics of Lightning}

Lightning is an electrostatic discharge of an excess electric charge developed in a thunderstorm cloud. The primary source of lightning is a cloud type termed cumulonimbus, commonly referred to as thundercloud [3]. Thunderclouds are formed in an atmosphere containing cold dense air aloft and warm moist air at low levels [4]. The parcels of warm moist air at low levels rise in strong updrafts to form clouds. When a parcel rises above the temperature colder than $0{ }^{\circ} \mathrm{C}$, some water particles starts to freeze, but others remain in a liquid state (they are termed supercooled water droplets) [3]. At temperatures colder than $-40^{\circ} \mathrm{C}$, all water droplets are frozen. In the temperature range of $0{ }^{\circ} \mathrm{C}$ to $-40{ }^{\circ} \mathrm{C}$ supercooled water droplets and ice crystals coexist, forming a mixed phase region where most electrifications occur [3], as shown in Figure 2.1.

The precipitation model of the thundercloud suggests that gravity pulls heavy raindrops, hail, and graupel particles; the small water droplets and ice crystals remains suspended [6]. The microphysics of charge transfer explains that the collisions between falling graupel particles and suspended ice crystals, provided that the temperature is below a critical value called a charge reversal temperature $T_{R}$, the falling graupel particles acquire negative charges and the ice crystals attain positive charges. At a temperature above $T_{R}$, graupel particles attain positive charges and ice crystals acquire negative charges. $T_{R}$ is thought to be about $-15^{\circ} \mathrm{C}[6]$. 

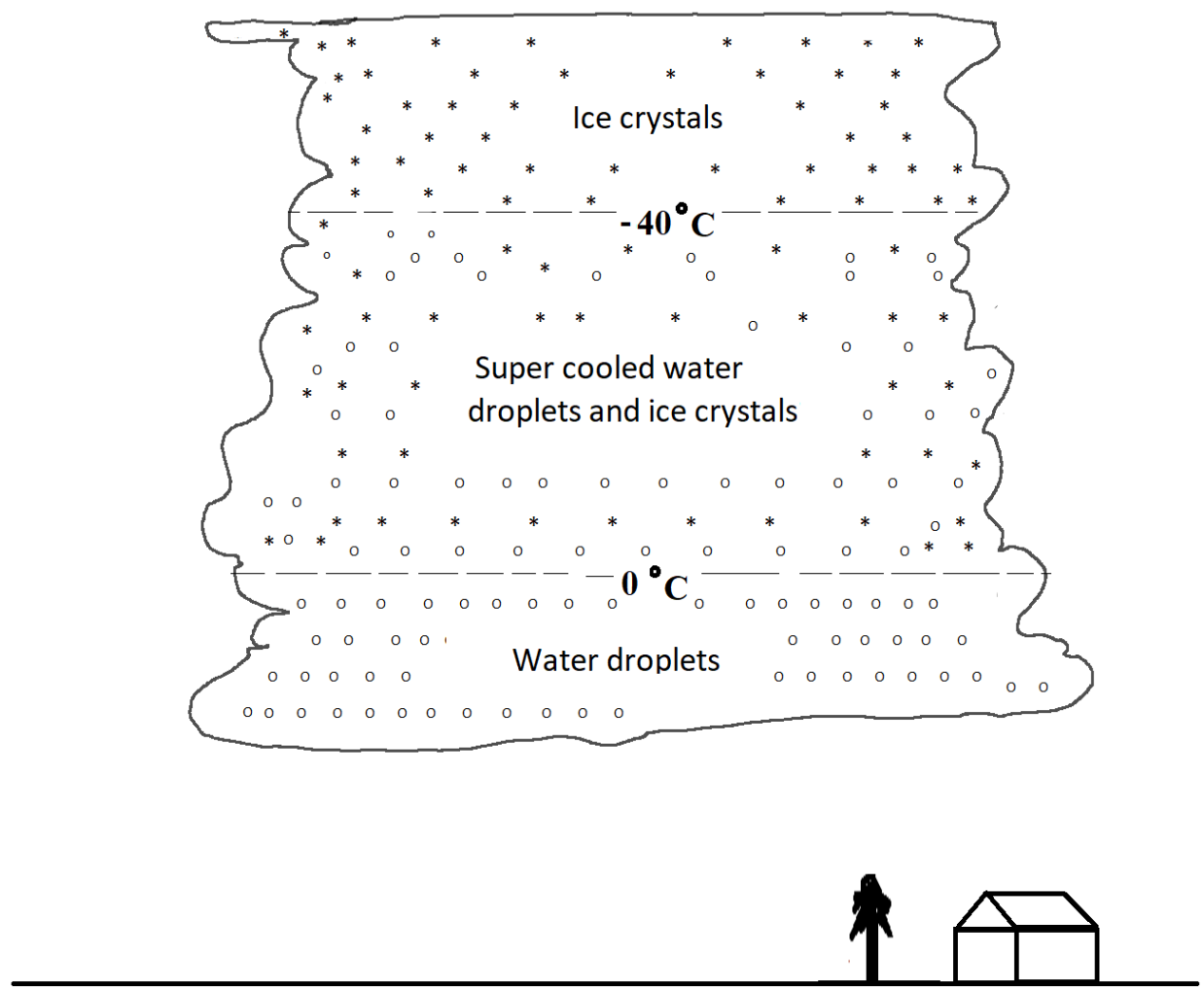

Figure 2.1 - The thundercloud.

It has been observed that a thundercloud comprises a tripolar structure [2], as illustrated in Figure 2.2; with an upper positive charge region (the presence of suspended ice crystals forms the top region), central layer of negative charge (created due to graupel particles that pick negative charges below $\mathrm{T}_{\mathrm{R}}$ ), and a lower positive charge (created due to graupel particles that pick up positive charges when falling below temperatures higher than $T_{R}$ ). The primary negative charge layer at the center of the thundercloud is always found to be at temperatures between $-10{ }^{\circ} \mathrm{C}$ to $30{ }^{\circ} \mathrm{C}[5]$. The top two charge regions ( $\mathrm{P}$ and $\left.\mathrm{N}\right)$, are usually called main charges, which are often specified to be equal in magnitude. At the bottom of the cloud the small pocket of positive charge exists (p). The two main charge regions ( $\mathrm{P}$ and $\mathrm{N}$ ) form a positive dipole. Screening layers are found at the top and sides of the cloud; its origin may be due to cosmic rays, which ionize air molecules [5]. 


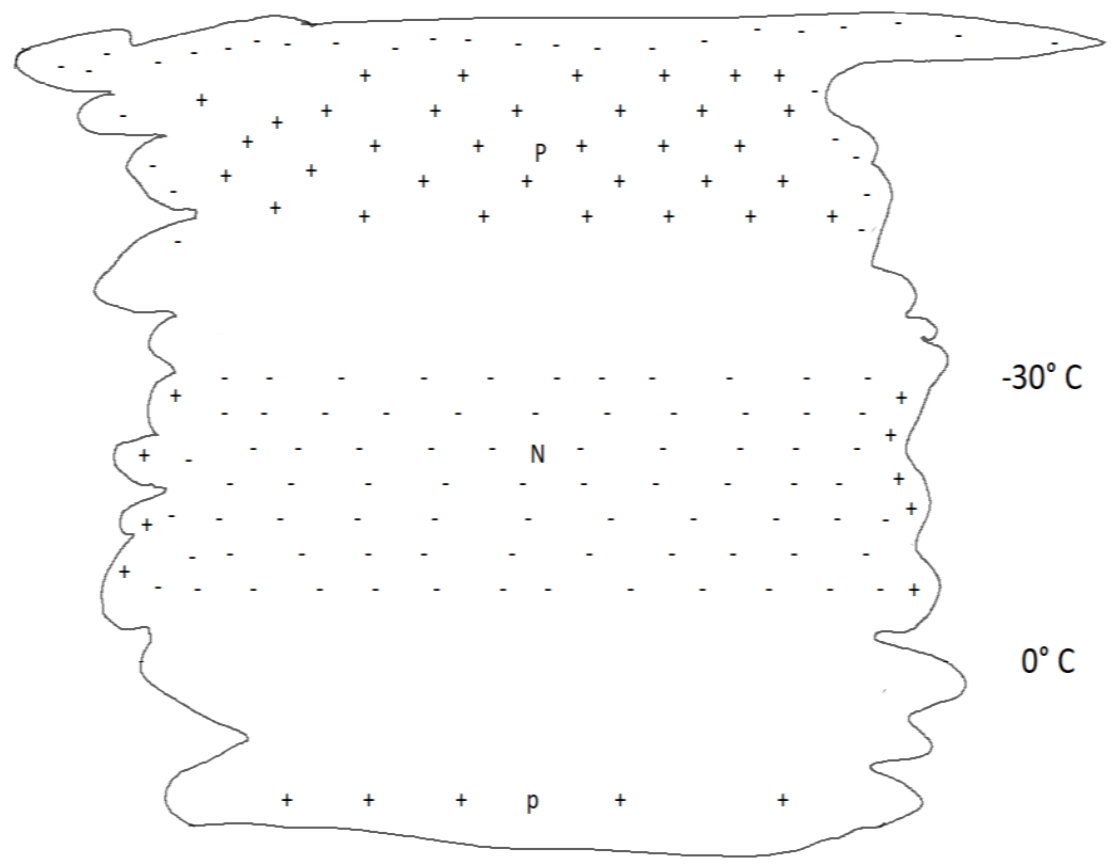

Figure 2.2 - A thundercloud with a fundamental demonstration of electric charge distribution inside the thundercloud.

The electric field intensity at the ground level, under a thunderstorm is typically $1000 \mathrm{~V} / \mathrm{m}$ (100 to $300 \mathrm{~V} / \mathrm{m}$ during fair weather conditions). Enhancements of the electric field at the sharp objects on the ground lead to corona discharge and spray positive charge into the air near ground. The ground under the main part of the thunderstorm is also positively charged (which is negative during fair weather conditions) [5].

Lightning can occur between two different charged regions within a single cloud (intracloud), between adjacent clouds (intercloud), between cloud and the air above (cloud-to-air) or between cloud and ground (cloud-to-ground), as illustrated in Figure 2.4 [4]. The cloud-toground lightning has been of great interest than other forms of lightning, as it causes numerous injuries to humans and animals, forest fires and disturbance in power transmission and distribution systems [1]. Lightning discharges between a cloud and the ground can be categorized in accordance with the polarity of charge lowered to a ground and the direction of motion of initial leader [3], as illustrated in Figure 2.4. 


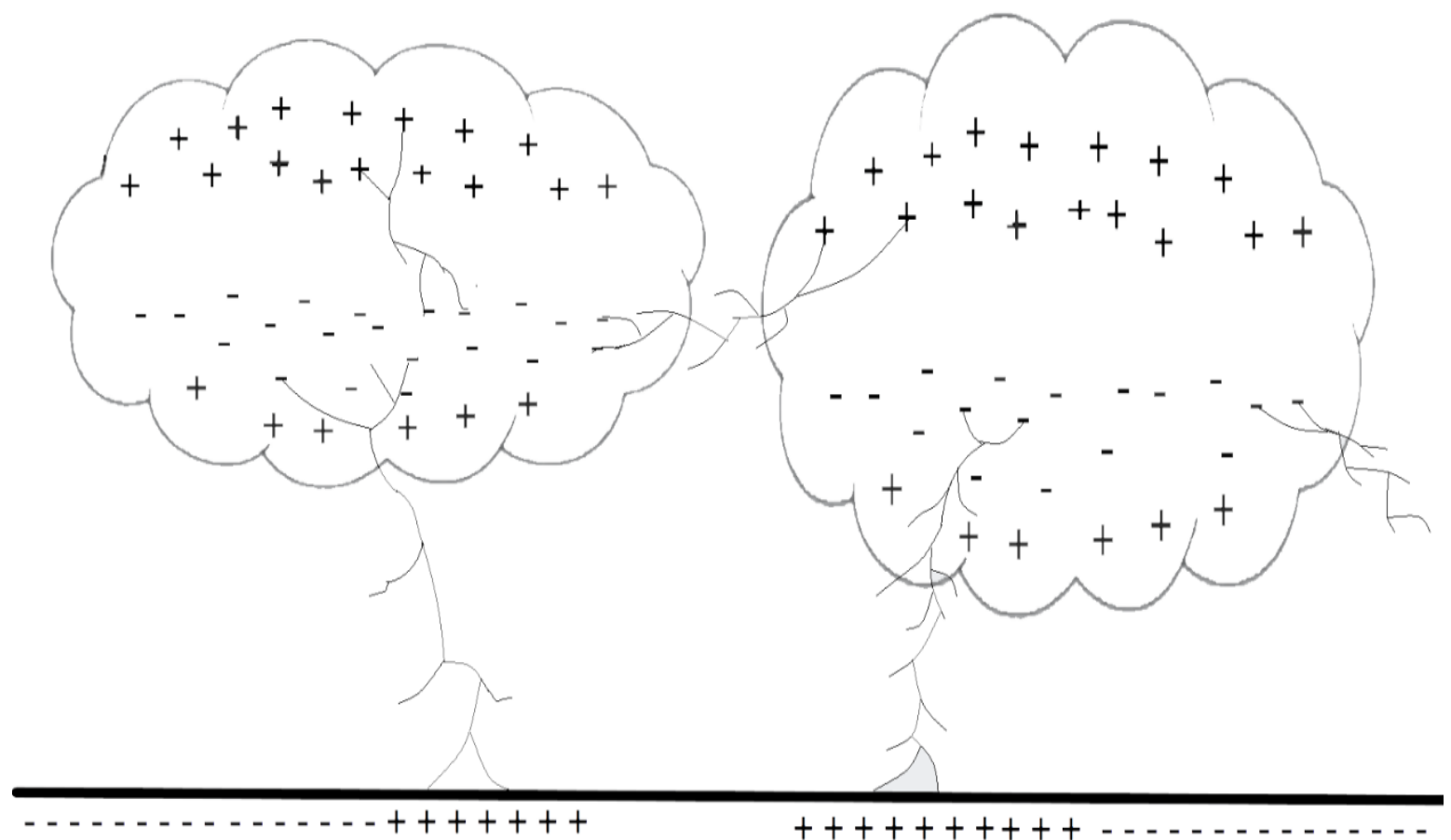

Figure 2.3 - Major Types of Lightning.
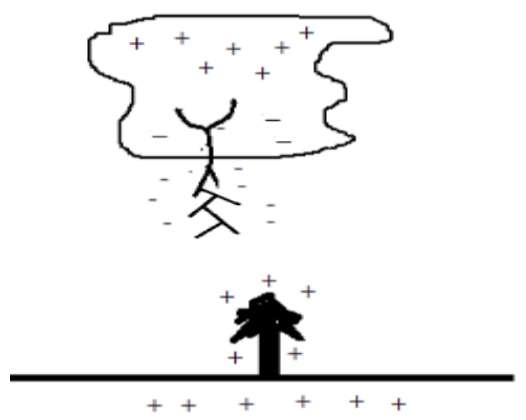

(a) Downward

Negative Lightning
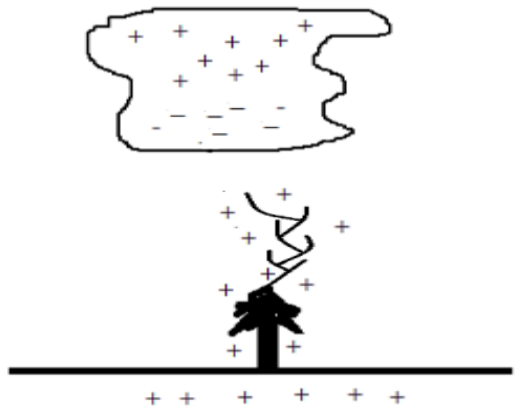

(b) Upward Negative

Lightming
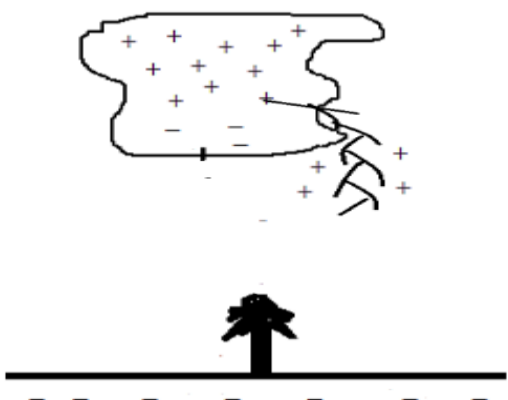

(c) Downward Positive Lightming
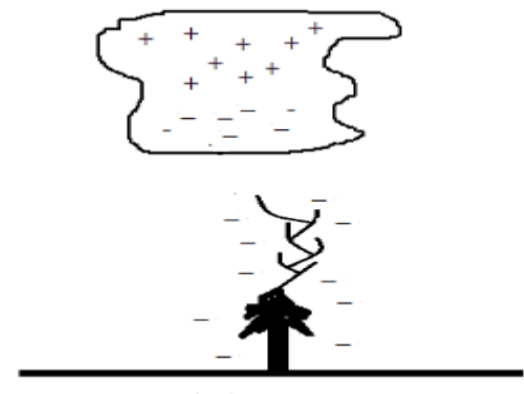

(d) Upward Positive Lightming

Figure 2.4 - Different types of cloud-to-ground lightning. 
It has been observed that about $90 \%$ of cloud-to-ground (CG) discharges are negative and about $10 \%$ or less are downward positive. The upward negative and positive discharges initiated from tall structures higher than 100-m or objects of reasonable height situated on top of the mountains [3].

\subsection{Downward Negative Lightning}

Downward negative lightning discharges are initiated in the cloud and propagates in a downward direction, transporting negative charge to ground. The overall cloud-to-ground discharge is referred to as a flash. Each cloud-to-ground flash is composed of a number of strokes. The minimum number of strokes is one [1].

Figure 2.5 illustrates the sequence of processes comprising a negative downward lightning flash. Downward negative lightning discharges are initiated as a result of in-cloud preliminary discharge involving the main negative charge center and the lower positive charge center [3]. The stepped leader (SL) is initiated by preliminary breakdown. In negative downward lightning, the stepped leader is a negatively charged plasma channel propagating towards the ground in a series of discrete steps, each is about 50-m in length. As the stepped leader approaches the ground the electric field intensity at the grounded objects is enhanced, and when a specific critical value is exceeded, the upward connecting leader from grounded objects are initiated. This indicates the beginning of the attachment process [3]. This process is completed when the upward and downward leaders attain contact, probably some tens of meters above ground. The completion of the attachment process is succeeded by the flow of a return stroke (RS) from the ground object to the cloud, which neutralizes the leader charge and effectively lowers several coulombs of the charge deposited on the stepped leader channel, to the ground. The return stroke can often be followed by a continuing current phase, of some hundreds of amperes, lasting for some milliseconds. The perturbations often occur during the steady flow of the continuing current with an associated channel luminosity; such surges are called M-components [3]. The M-component mode of charge transfer to the ground requires the existence of a grounded channel carrying a continuing current that acts as a waveguiding structure. It's possible that, as the conductivity of the path to ground decreases, the downward M-component wave can transform into a dart leader. 
When the first return stroke and an in-cloud charge activity terminate, the flash may end, and such case is referred to as a single-stroke flash. However, often the residual of the first stroke channel is transversed by a continuous leader known as dart leader [3].

During the time interval between the return strokes and the initiation of the subsequent leader, $J$ and $K$ processes occur in the cloud. The J-process amounts to a redistribution of charge in the cloud, in response to the preceding return stroke. The K-processes can be viewed as transients occurring during the slow J-processes. The J-process is often regarded as a relatively slow positive leader extending from the top of the previous channel into the higher areas of the negative charge region, the K-process than being a relatively fast recoil streamer that begins at the tip of the positive leader and propagates to the flash origin. Both the $\mathrm{J}$ and $\mathrm{K}$ processes, in cloudto-ground lightning discharges serve to transport additional negative charge into the existing channel, although not all the way to the ground [3]. From a photographic point of view, the Kprocesses are accompanied by detectable luminosity and are observed to be attempted leaders towards the ground [2], [3]. When this additional charge is available, a continuous leader, known as the dart leader (DL), moves through the defunct return stroke channel and deposits a negative charge along the channel length. Some dart leaders exhibit stepping upon approaching the ground, which are referred to as dart-stepped leaders. The apparent difference between the two types of leaders is related to the fact that the stepped leader develops in the virgin air while the dart leader follows the pre-conditioned path of preceding strokes [3]. When dart or dart-stepped leaders approach the ground, the attachment process takes place, after the downward dart leader makes contact with the upward leader initiated from the ground. Once the attachment process is accomplished, the subsequent return stroke wave is initiated and moves upward to neutralizes the leader charge [1], [3]. 


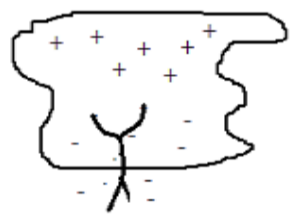

Stepped Leader

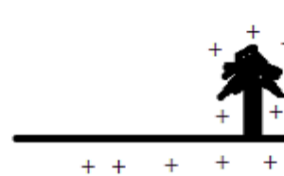

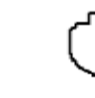
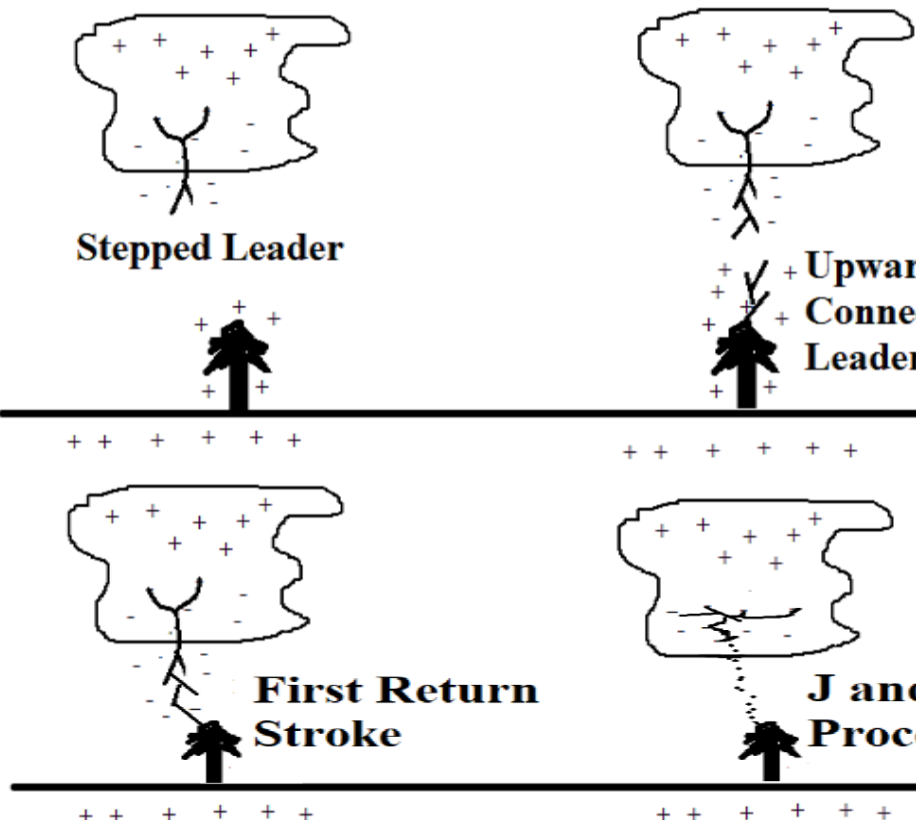

$+\gamma+$ Upward

+ Connecting
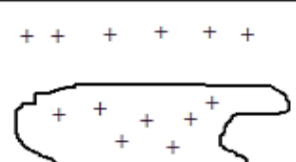

(-

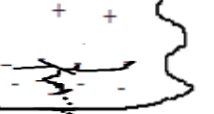

J and $\mathbf{K}$ 2 Processes

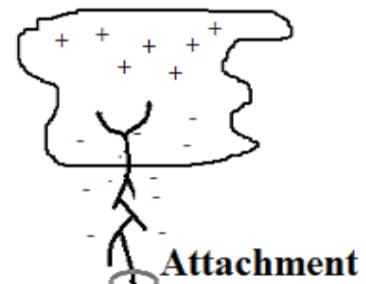

Process

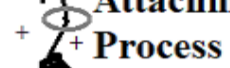

个
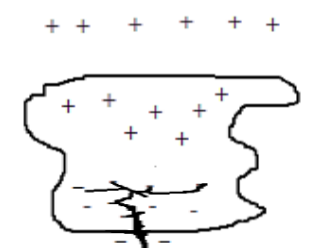

\section{Dart} Leader

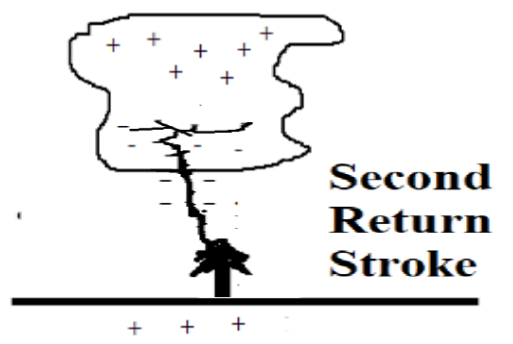

Figure 2.5 - The sequence of processes involved in negative downward lightning flash.

\subsection{Downward Positive Lightning}

The downward positive lightning transports positive charge from cloud to ground (CG). The positive lightning is of significant practical interest because of its higher current peak and a more substantial amount of charge transferred to the ground as compared to downward negative lightning flash. Positive flashes are generally composed of a single return stroke succeeded by a phase of a continuing current, preceded by significant in-cloud activity. Photographic observations show that positive lightning discharges usually exhibit up to tens of kilometers of horizontal channels. The positive cloud-to-ground lightning is relatively frequent during the dissipating stage of a thunderstorm or winter thunderstorms [1], [3]. 


\subsection{Upward Initiated Lightning}

The discovery of upward-initiated-lightning is generally attributed to McEachron (1939) who made photographic and current measurements at the Empire State Building (a steel frame building 443.2-m in height) in New York. Upward lightning discharges are usually initiated by leaders that originate from grounded objects, generally tall towers or moderate height structures located on the top of a mountain and propagate upwards towards the charged clouds aloft. Structures with elevation less than 100-m usually experience downward lightning, objects within the altitude of 100-500 m experience both upward and downward lightning flashes, and structures with height above 500-m experience upward-inititated lightning. Upward negative discharges are initiated by upward positive leader initiated from tall grounded objects, Figure 2.4(b), and upward positive discharges are initiated by upward negative leaders initiated from ground objects, Figure 2.4(d). It has been observed that upward-initiated lightning usually lowers negative charge to ground than positive charge [3].

Upward leaders are initiated from the tops of the tall grounded structure when the electric field intensity due to in-cloud discharge occurring in the charged cloud built overhead of tall structure, exceeds the breakdown value over some critical distance from the tip of the tall object. As the upward leader from the top of a tall structure links the gap between the tall grounded structure and the thundercloud aloft, the initial continuous current flows from the cloud toward the tall grounded object. The lightning flash may terminate after the flow of the initial continuous current or can be followed, after a phase of a no current interval, by a sequence of the subsequent downward leader and upward return stroke [3], as illustrated in Figure 2.6.

Upward lightning can also be initiated artificially by launching a rocket that extends a thin wire into the gap between the charged cloud and the ground that later gets replaced by the plasma channel of an upward leader. Like tall object-initiated lightning discharges, rocket-triggered flashes are composed of initial stage current (ISC) followed by downward-leader-upward-returnstroke sequences [3]. The initial stage current in tall object-initiated lightning is similar to the initial stage current in rocket-triggered lightning, except for ISC pulses, which in object-initiated lightning exhibit larger peaks, shorter risetimes and shorter half-peak widths than those for ISC pulses in rocket-triggered lightning. The observed differences are assumed to be a result of the 
more profound branching of tower-initiated lightning discharges in comparison with rockettriggered lightning [7], [8].

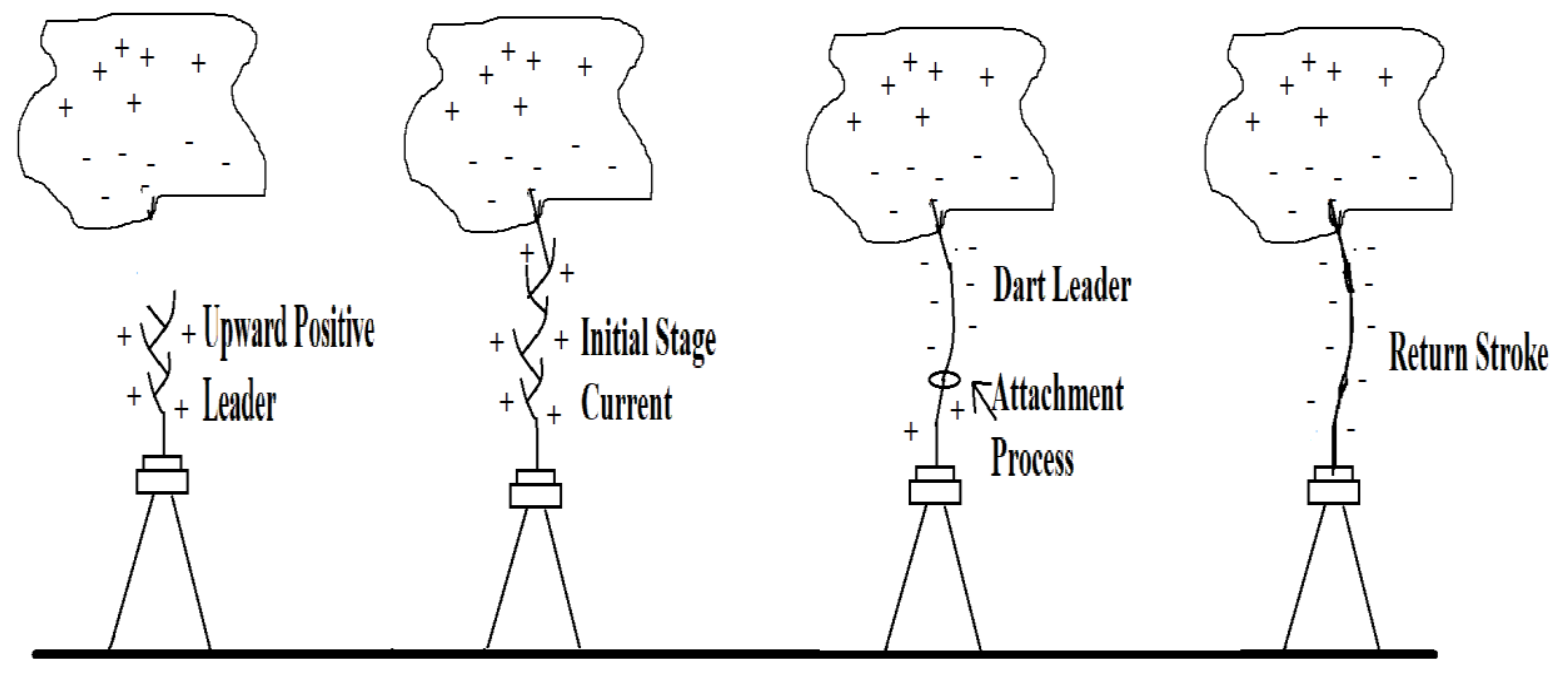

Figure 2.6 - The sequence of processes involved in an upward negative lightning. 


\section{Chapter 3}

\section{CN Tower Lightning Measurement Systems}

\subsection{Overview of the Measurement Systems}

The Canadian National (CN) Tower is 553-m high, one of the tallest free-standing structure in the world located at $43.64^{\circ} \mathrm{N}$ and $79.38^{\circ} \mathrm{W}$, in downtown Toronto, Ontario, Canada. CN Tower usually receives several dozens of lightning flashes yearly [9], due to its high altitude. Although, the lightning ground flash density is about two [10]. Therefore, CN Tower presents one of the best sites in the world to observe lightning to study the physics of lightning phenomenon and to collect the characteristics of optical parameters [11], [12]. The lightning strikes to the CN Tower were first observed in 1978. Since 1991, five measurement systems commenced to operate to simultaneously capture the return stroke current derivative (using Rogowski coil and Tektronix RTD 710A digitizer), the vertical component of electric field; the azimuthal and radial component of magnetic field (using broadband active sensors and Tektronix RTD 710A digitizers), the 2-D images of flash trajectories (using the VHS cameras) and the return stroke velocity (using photodiode system). Since 1996, the proliferation of measurement systems has been occurring. In 1996, a high-speed camera with a frame rate of 1000 frames/second (vision research phantom v2.0). In 1997, an optical fiber link and a new Rogowski coil with a noise protected current sensing system was installed. 
Tip of the Tower 553-m

New Coil 509-m

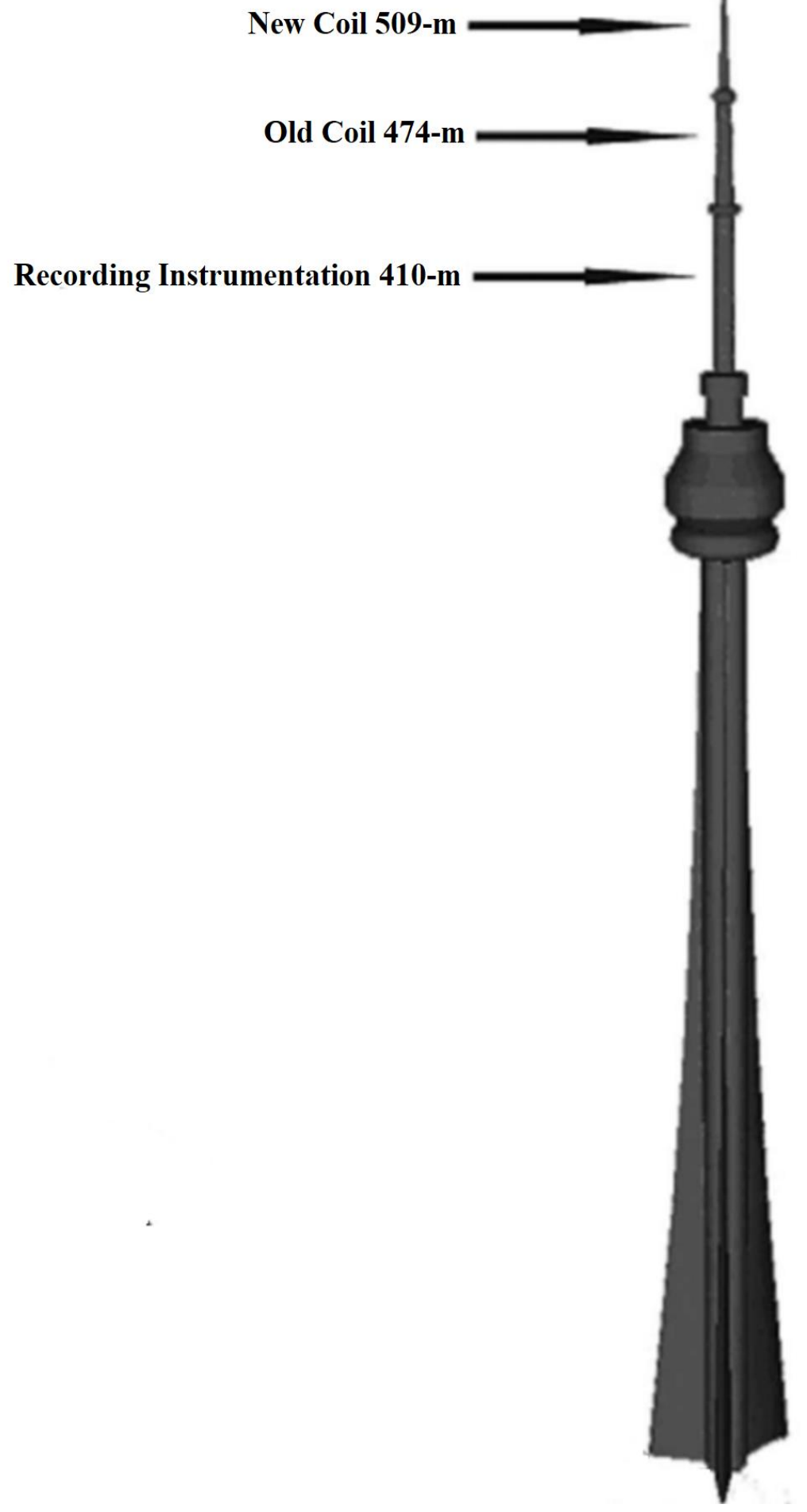

Figure 3.1 - The CN Tower and Location of Instruments. 
In 2001, two double-channel digitizers (LeCroy LT362), with 2 ns time resolution were acquired to record the current derivative and its radiated electromagnetic fields for lightning return strokes. The four units of a Global Positioning System (GPS) were also acquired for time synchronization of $\mathrm{CN}$ Tower lightning recording instruments [13]. In order to avoid the contamination of the initially-injected lightning current by reflections from the tower's structural discontinuities, the Rogowski coils were placed as far as possible from main structural discontinuities, namely the tip of the tower, the top and bottom of the Space Deck, the top and bottom of the Sky Pod, and ground [14]. The locations of the CN Tower lightning measurement systems are illustrated in Figure 3.1 [15].

\subsection{Old Rogowski Coil}

In order to measure the lightning current derivative a $40 \mathrm{MHz}$ bandwidth, a Rogowski coil was installed in 1990 at the 474-m above ground level (AGL). The coil has a sensitivity of 0.359 $\mathrm{V} /(\mathrm{A} / \mathrm{ns})$ and it encircles one-fifth of the CN Tower's pentagonal structure, as illustrated in Figure 3.2 [16]. Due to the cross-sectional symmetry of the structure, the measured signal corresponds to $20 \%$ of the total lightning current. The 3-m long coil consists of two $1.5 \mathrm{~m}$ pieces, which are connected to a matching impedance at one end and resistors at another end, to absorb any reflections and damp oscillations in the coil. The impedance box is connected via $165 \mathrm{~m}, 50 \Omega$ triaxial cable (Belden RG-8/U) to one channel of LeCroy LT342L digitizer. 

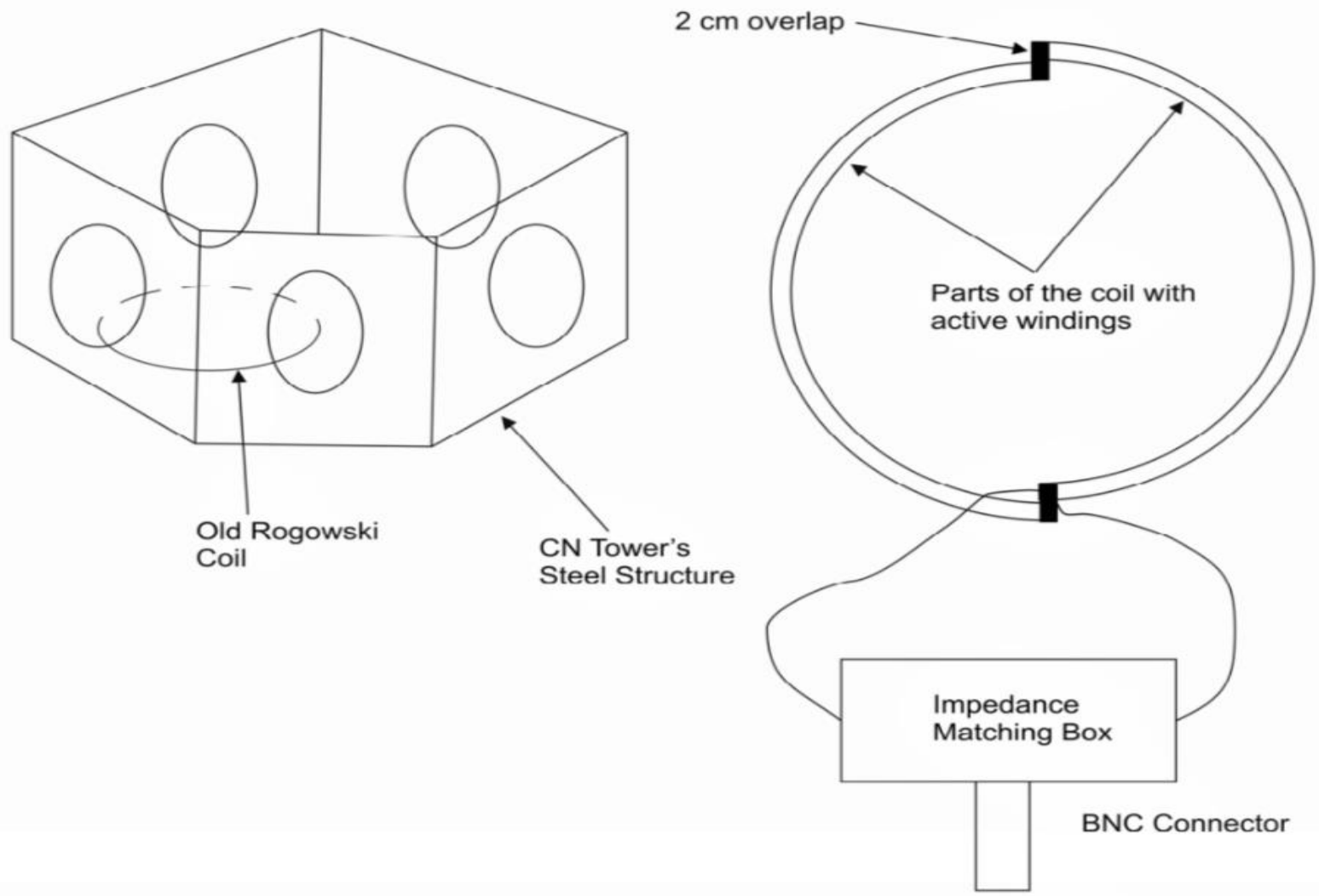

50 ohm output

Figure 3.2 - The Old Rogowski Coil location and connection.

The lightning current measured by the old Rogowski coil, contains a significant amount of noise and the apparent reasons for that are:

- The coil encircling one-fifth of the CN Tower's pentagonal steel structure, and thus leading to the measurement of only $20 \%$ of the total amount of current.

- The use of $50 \Omega, 165$-m triaxial cable, to connect the old Rogowski coil to the digitizer.

- The old Rogowski coil is susceptible to noise from communication antennas as well as the LORAN-C signals used for radio navigation by the ships [24]. 


\subsection{New Rogowski Coil}

In 1997, a new Rogowski coil with 20-MHz bandwidth was installed at 509 m AGL. Its first measurement current derivative signal was recorded in 1999. The new 6-m long Rogowski coil comprises four $1.5 \mathrm{~m}$ long segments, and it encircles the whole CN Tower's steel structure. Hence it measures the total lightning current derivative signal. The sensitivity of the new coil is 1.264 $\mathrm{V} /(\mathrm{A} / \mathrm{ns})$. The coil is connected to the recording station placed at $403 \mathrm{~m}$ AGL, via an optical fiber link, as illustrated in Figure 3.3 [16]. The two segments of the coil are connected to a matching box 1 , and another two sections are connected to matching box 3. Matching boxes 1 and 3 are then connected to matching box 2 so that a $50 \Omega$ impedance is obtained at the output of matching box 2. Furthermore, a 30-dB attenuator was used between matching box 2 and an optical transmitter, to avoid the saturation of the optical fiber link.

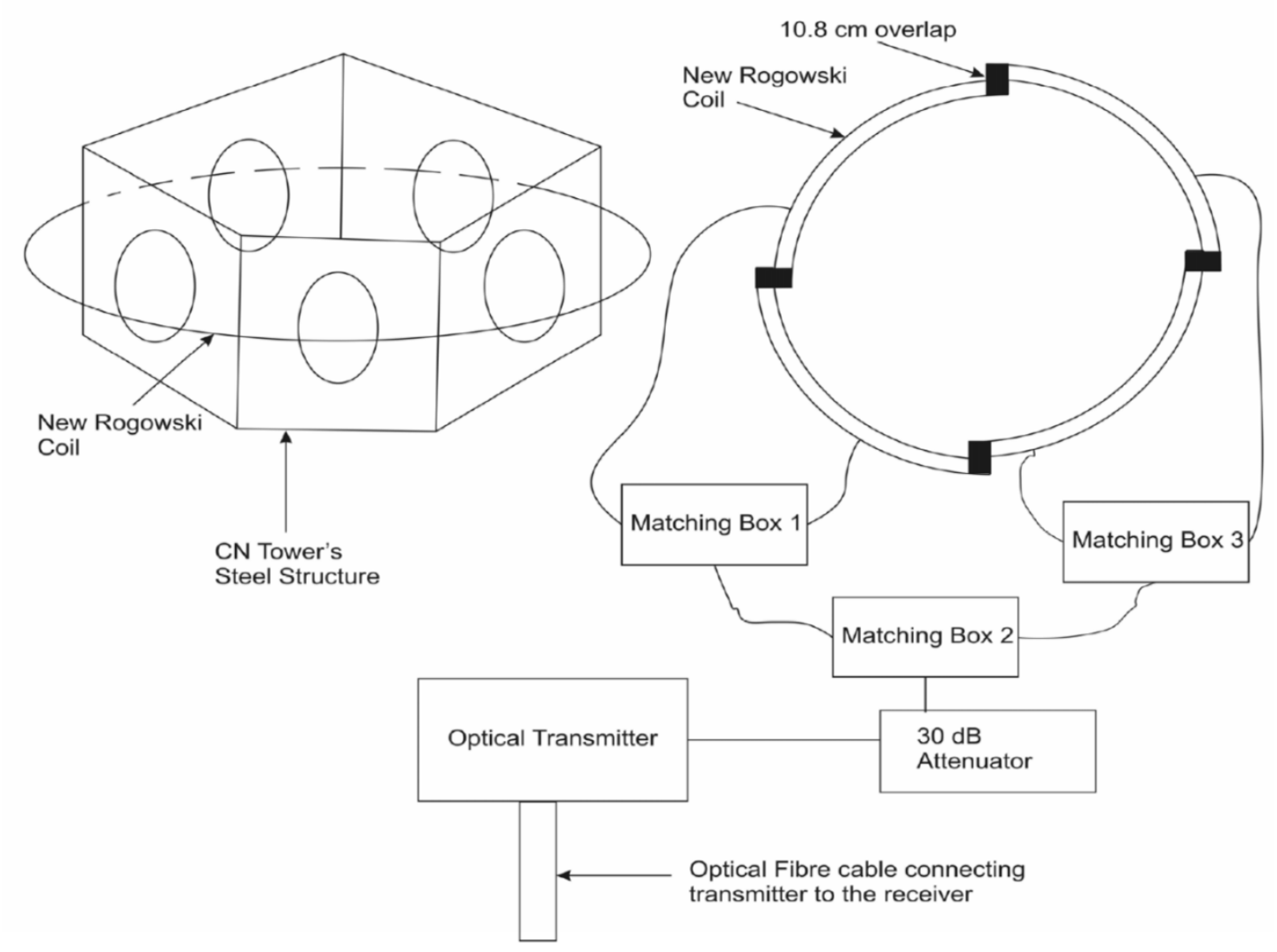

Figure 3.3 - The new Rogowski Coil location and connection. 
The current derivative signals recorded by the new Rogowski coil has better signal-to-noise ratio in comparison with the current derivative signal recorded by the old Rogowski coil due to the following facts:

- The new Rogowski coil measures $100 \%$ of the total lightning current derivative signal.

- The coil is connected to the recording station via an optical fiber link.

- The advanced design of the new Rogowski coil makes it less susceptible to noise.

\subsection{Real-Time Digitizers}

The real-time digitizers are used to obtain the lightning current derivative signals. Since 2011, two independent measurement systems have been recording CN Tower lightning current derivative signals and each system had its digitizer. The old Rogowski coil is connected via a triaxial cable to a new double-channel 8-bit National Instrument (NI) PCI 5114 digitizer. The new Rogowski coil is connected via NanoFast optical fiber link to the LeCroy LT342L digitizer. In 2014, a more advanced NI PXIe 5160 digitizer was acquired. The NI PXIe 5160 digitizer along with a timing module and the embedded controller is placed in NI PXIe-1082 chassis [17].

Technical Specifications of NI PCI 5114 digitizer

- Number of channels: 2

- Memory per channel: 64 MB

- Bandwidth: $12 \mathrm{~Hz}$ to $125 \mathrm{MHz}$

- Resolution: 8 bits

- Sampling: up to $250 \mathrm{MS} / \mathrm{s}$ 
Technical Specifications of LeCroy LT342L

- Number of channels: 2

- Memory per channel: $2 \mathrm{MB}$

- Bandwidth: $25 \mathrm{~Hz}$ to $500 \mathrm{MHz}$

- Resolution: 8 bits

- Sampling: up to $500 \mathrm{MS} / \mathrm{s}$

Technical Specifications of NI PXIe 5160

- Number of channels: 2

- Memory per channel: $2 \mathrm{MB}$

- Bandwidth: $500 \mathrm{MHz}$

- Resolution: 10 bits

- Sampling: up to $50 \mathrm{GS} / \mathrm{s}$

\subsection{Flash Trajectory Imaging Systems}

Although the lightning current derivative has been measured at the tower since 1991, the characterization of $\mathrm{CN}$ Tower lightning flash components has been a significant challenge because the current derivative measurement systems have been configured to trigger on the high rate of rise of the current [18], [19]. It was impossible to record currents with low rates of rise, such as the initial-stage current (ISC), the M-components and the continuing current (CC), with such measurement configuration of the current derivative measurement systems. The acquisition of the digital imaging systems provides the detailed information of flash components including the ISC, M-components, return strokes, continuing current duration and flash duration. The video records also provide the details regarding flash direction (upwards or downwards). 


\section{Chapter 4}

\section{CN Tower Lightning Imaging Systems}

CN Tower lightning trajectories are recorded by a continuously recording Sony HDR PJ790VB digital camera (CRC), operating at $60 \mathrm{fps}$ and a Vision Research Phantom v5.0 digital high-speed camera (HSC), operating at 1000 fps.

The analysis of $\mathrm{CN}$ Tower lightning flashes captured by the two cameras is carried out by studying the maximum and average lightning channel luminosity variation along successive frames, across a certain pixel level, within each flash [13], [25]. The luminosity variation with time is analyzed with the help of RGB values recorded for the pixels, in successive frames of a video, captured by the two digital cameras. The records of both HSC and LSC are used to characterize the various $\mathrm{CN}$ Tower lightning flash components, within each flash.

It's important to mention that, in many cases, when the low-speed camera records were perfectly time matched with the lightning currents measured at the tower, a linear correlation between channel luminosity peak and the current peak has been established [13].

\subsection{High-Speed Digital Camera}

In 2006, a phantom v5.0 HSC (Fig. 4.1) operating at $1 \mathrm{~ms}$ resolution (capturing 1000 frames per second), representing each frame is captured in $1 \mathrm{~ms}$ was acquired and it is placed at $4.31 \mathrm{~km}$, $36.54^{\circ}$ north-north-east (NNE) of the tower at Broadview Ave., as illustrated in Figure 4.2. The pixel resolution of HSC is $1024 \times 1024$. However, it has been set to operate at $512 \times 512$ pixel 
resolution, to provide a longer recording time of $1300 \mathrm{~ms}$, out of which $300 \mathrm{~ms}$ is used as a pretriggering time to ensure the recording of the initial stage current. The remaining time (1000 ms) is set to record the return strokes, continuing currents (CC) and M-components. Phantom v5.0 HSC has internal image storage memory of 1024 images per second, at $1000 \mathrm{fps}$ [21], [25].

The exposure time of HSC is $10 \mu s$, and it's triggered by external Miops Nero trigger. The Phantom v5.0 has SR-CMOS anti-blooming sensors, which allows continuously variable shutter speeds down to $10 \mu s$. [20], [21].

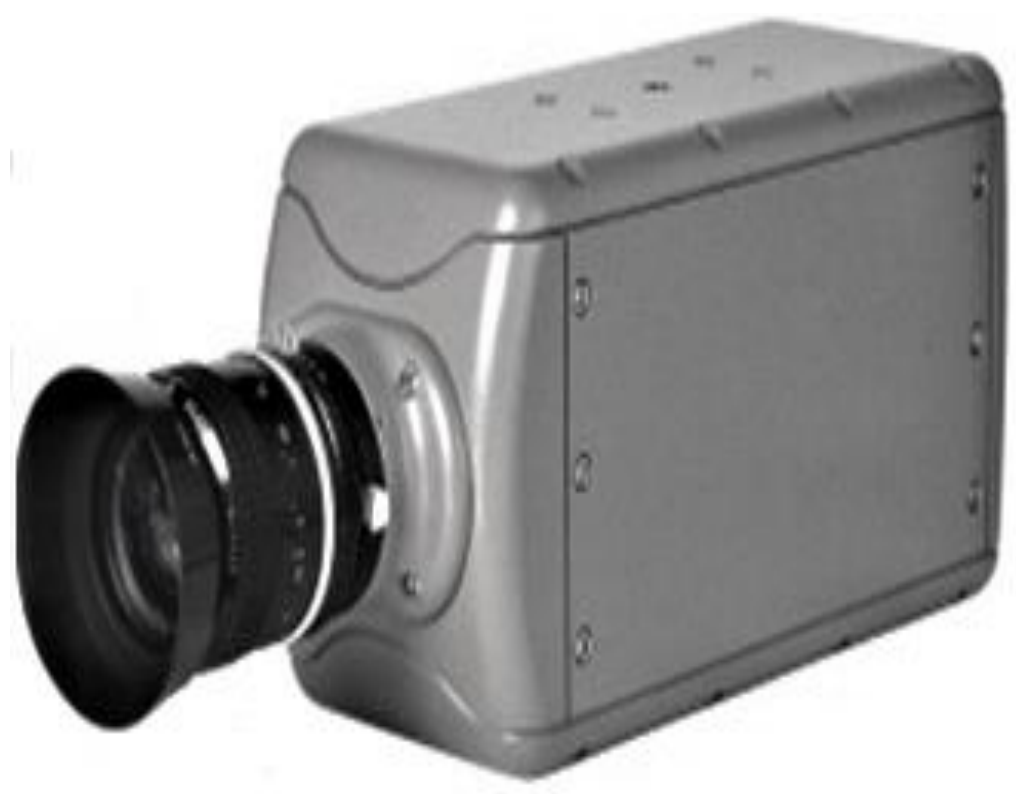

Figure 4.1 - Phantom v5.0 digital high-speed camera. 


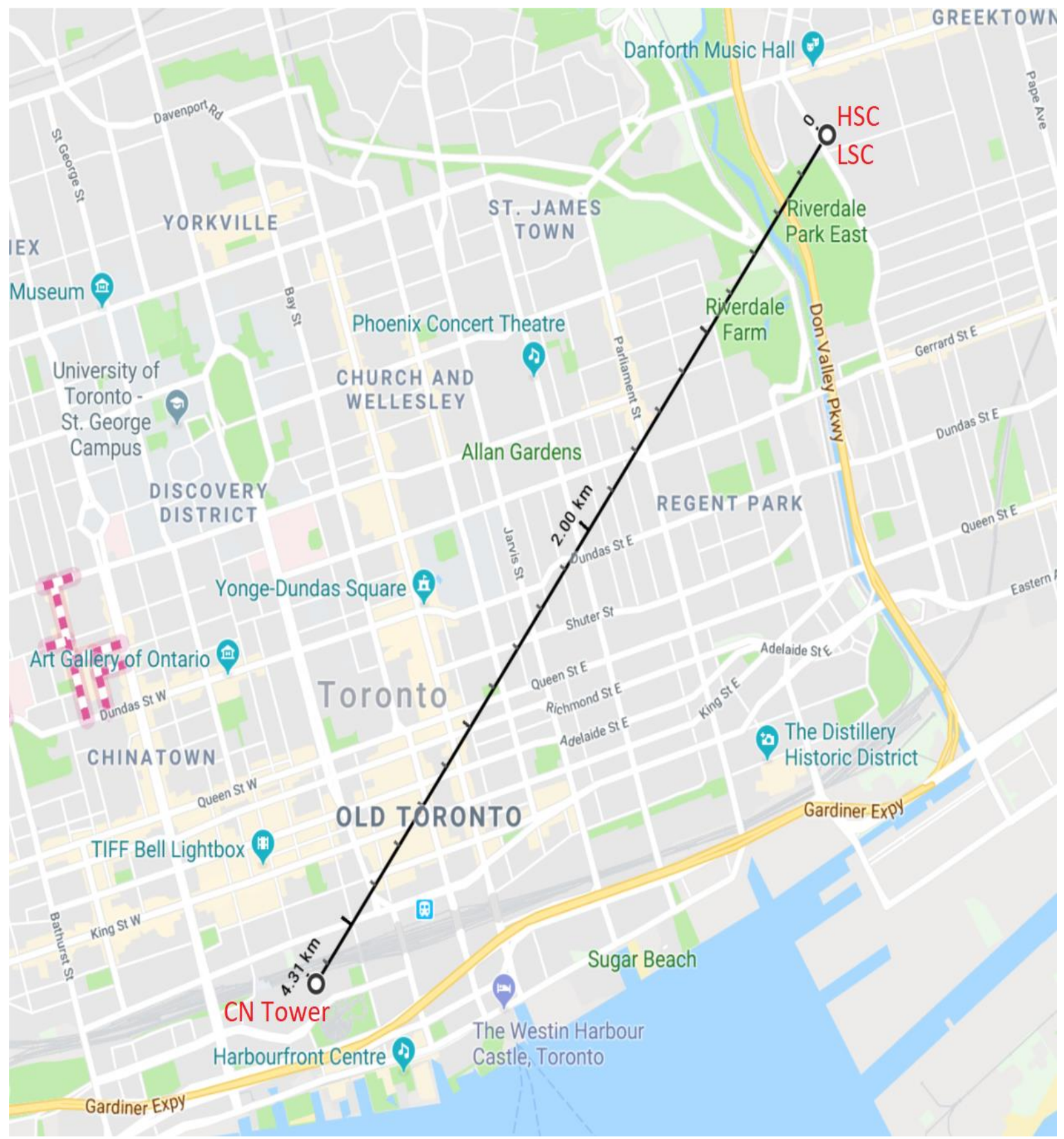

Figure 4.2 - Location of Phantom v5.0 HSC and Sony HDR PJ790VB LSC. 


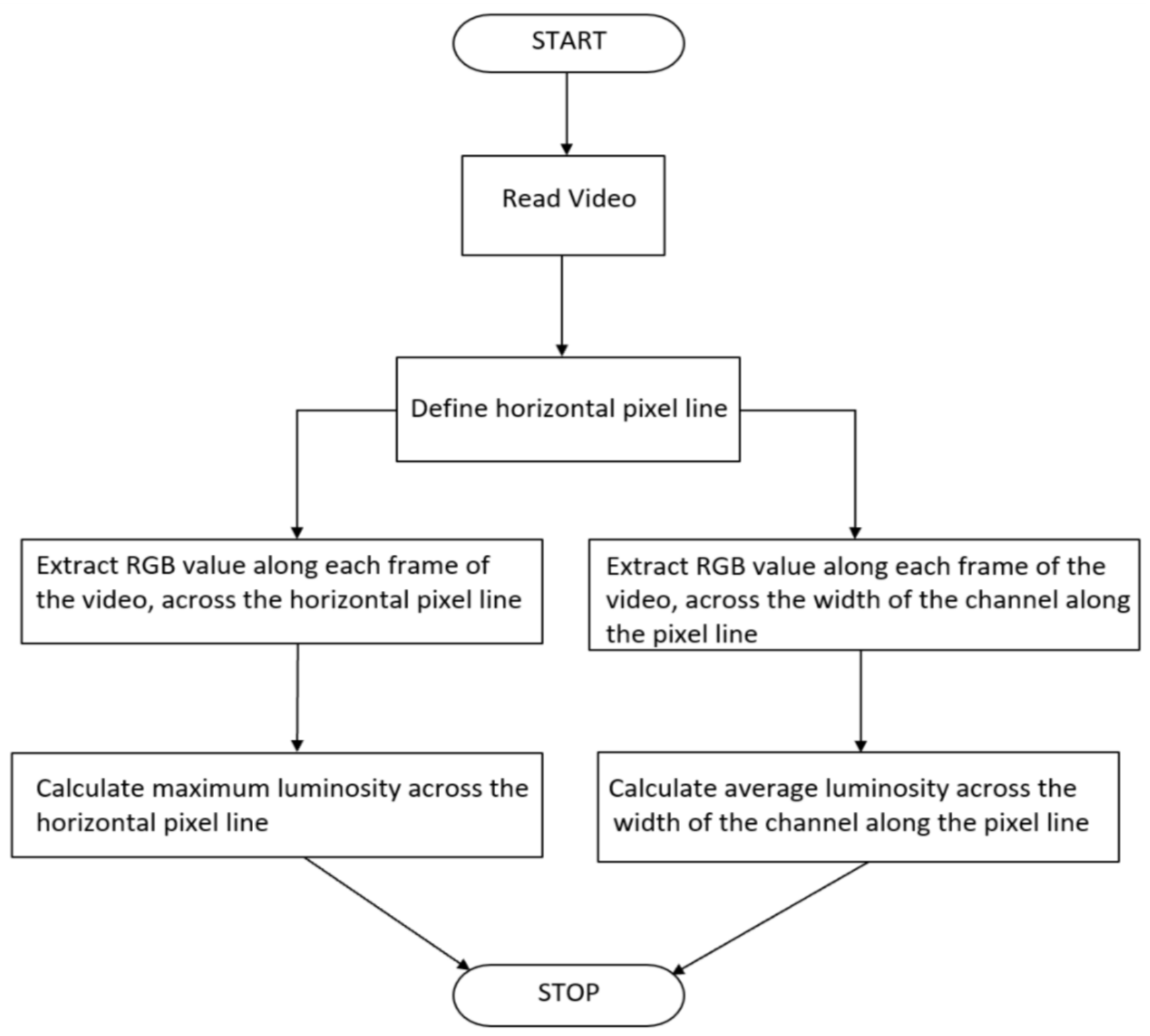

Figure 4.3 - Flow chart describing the methodology of analysis of video records.

The HSC comprises 24 bits-per-pixel (bpp), which indicates that the red, green and blue subpixels, for each pixel, use 8 bits each, which have integer value from 0 to 255 . Due to the saturation level at 255 , the luminosity variation beyond that level is not recorded. To resolve this problem, the average luminosity variation with time across the width of the channel is determined.

The images recorded for each flash captured by Phantom v5.0 are saved in separate files with extension .cine. The raw .cine files can be converted to the desired format using Phantom Camera Control (PCC) software, which can be further processed in MATLAB to obtain luminosity variation with time, for each flash recorded [25]. The analysis of luminosity time variation is 
performed along the successive frames of the video records, along the horizontal pixel line carrying the brightest pixels. The maximum and average luminosity variation with time for various flashes, captured by Phantom v5.0 HSC are presented in the following figures. Flash trajectory images presented in this thesis represents the brightest frames of flashes and are used to represent the horizontal pixel line level, across which the luminosity time variations for each flash is calculated. The horizontal level of the pixel line is different for every flash because every flash have different lightning channel trajectory with different brightest levels that shows the appropriate luminosity variations that could help to determine various flash components

Figure 4.4 illustrates the channel trajectory image of the second flash recorded on July 8, 2013. The figure demonstrates that the flash struck the tower $17 \mathrm{~m}$ below its tip. At the horizontal pixel line $\mathrm{Y}=322$, the maximum luminosity variation with time across the whole pixel line is evaluated over 1300 frames and presented in Figure 4.5 (blue). The average luminosity variation across the 10-pixel wide channel is also demonstrated in Figure 4.5 (red).

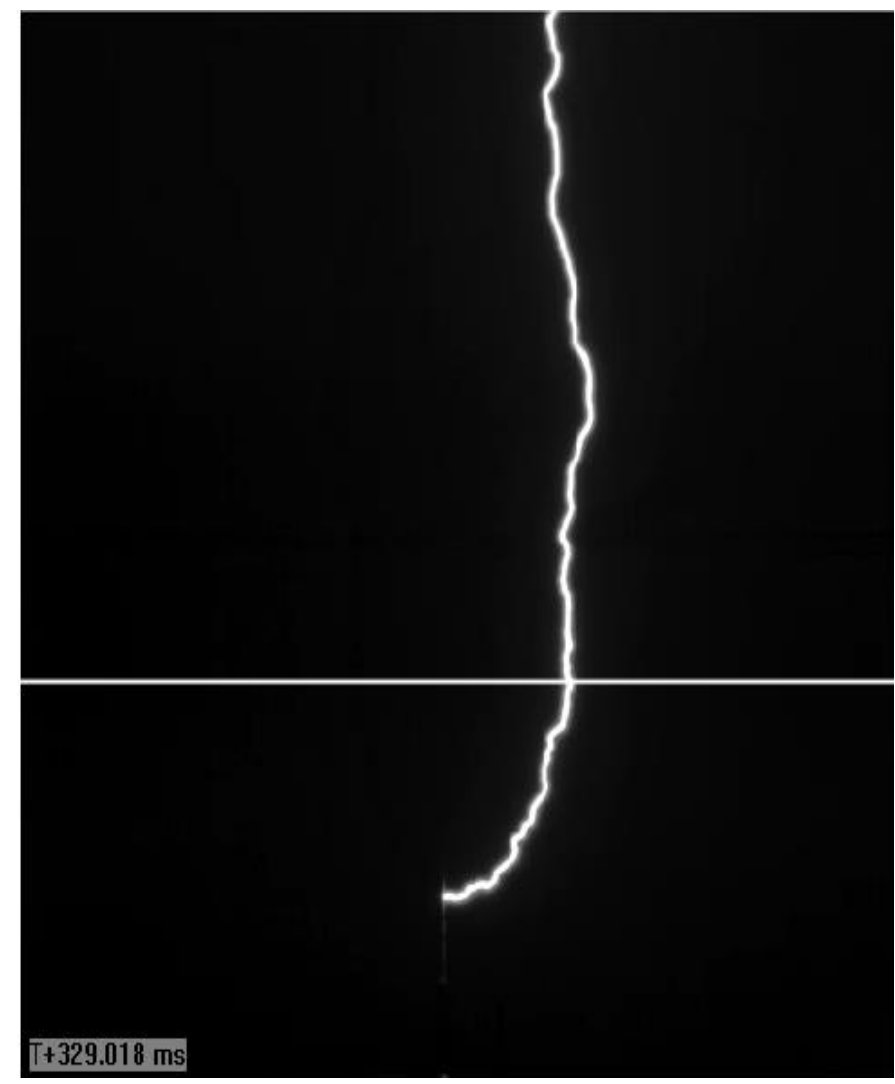

Figure 4.4 - Channel trajectory image of the second flash recorded on July 8, 2013. 


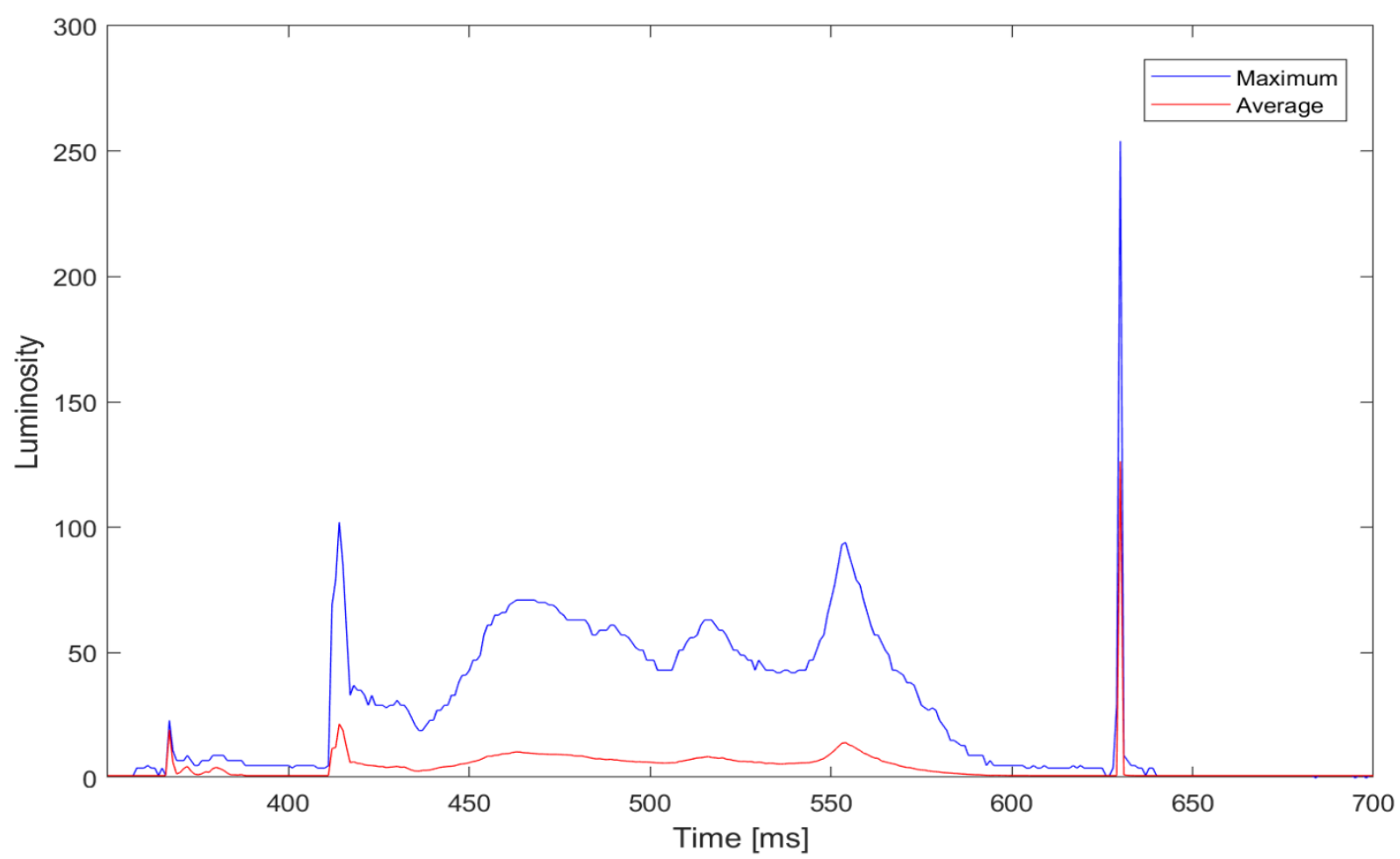

Figure 4.5 - Maximum and average channel luminosity time variations along the horizontal pixel line $\mathrm{Y}=322$.

The channel luminosity variation with time, as illustrated in Figure 4.5 presents the existence of an initial stage current (ISC) that lasted for $267 \mathrm{~ms}$, followed by a single return stroke.

Figure 4.6 presents the channel trajectory image of the fourth flash recorded on July 14, 2016. At the horizontal pixel line of 326 , the maximum luminosity variation with time is evaluated across the whole pixel line (blue) and the average luminosity variation with time is calculated across a 12-pixel wide channel (red), is illustrated in Figure 4.7. 


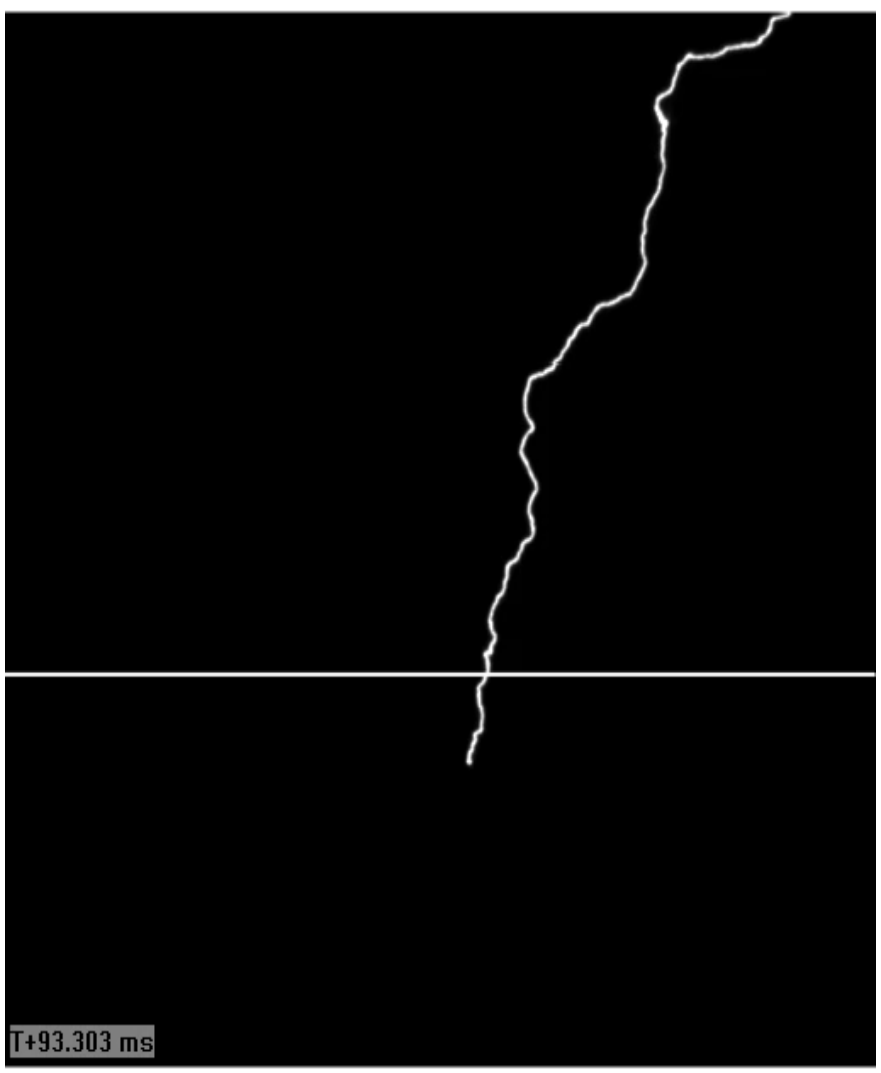

Figure 4.6 - Channel trajectory image of the fourth flash recorded on July 14, 2016.

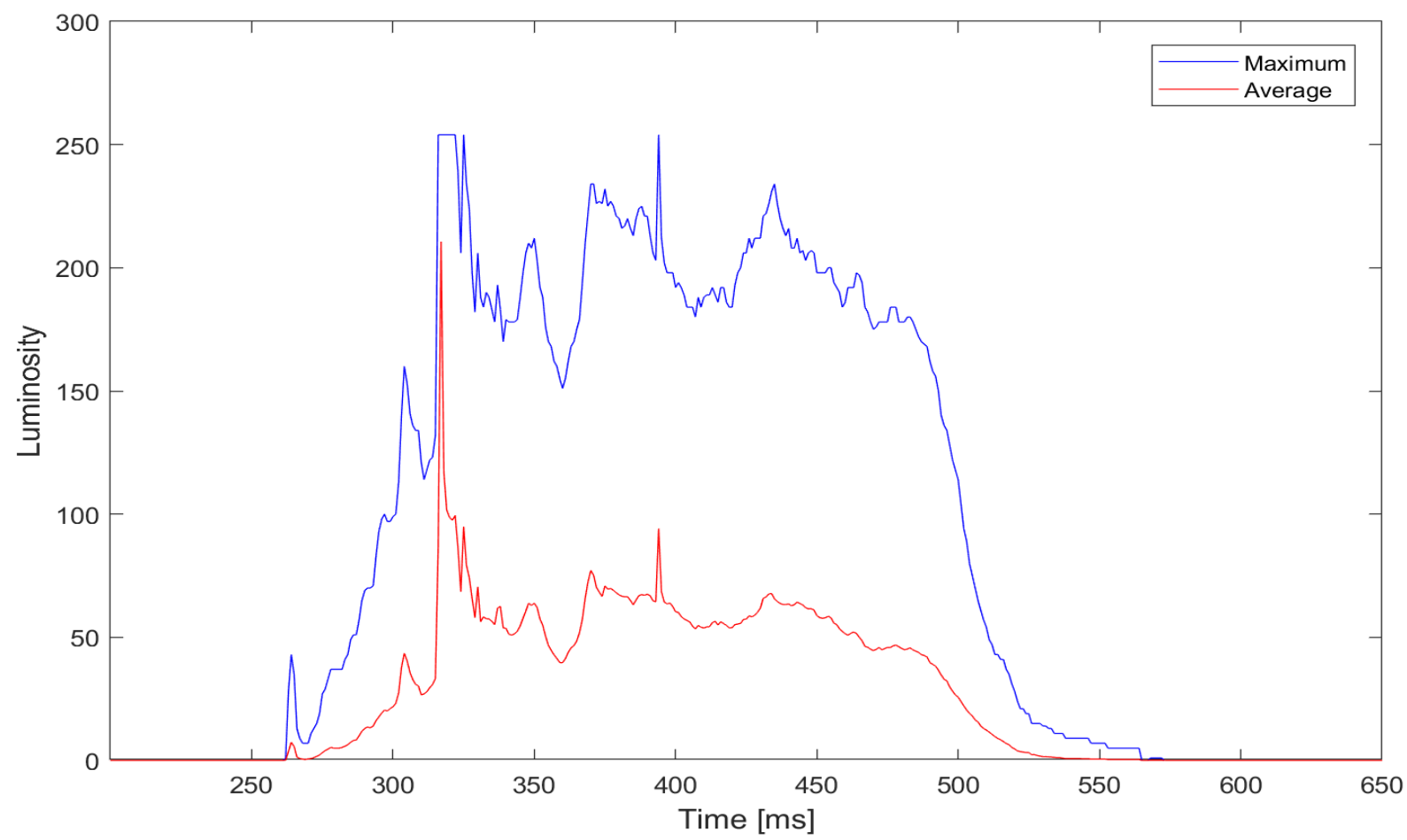

Figure 4.7 - Maximum and average channel luminosity time variations along the horizontal pixel line $\mathrm{Y}=326$. 
The luminosity variation with time as demonstrated in Figure 4.7, reveals the existence of an ISC of duration $310 \mathrm{~ms}$, containing several M-components.

\subsection{September 5, 2014 Storm Captured by HSC}

It was observed that on September 05, 2014, the HSC recorded a total of thirteen CN Tower flashes. The storm lasted for 111.4 mins, resulting in, on an average, a flash to the tower every nine mins. The storm led to 13 flashes containing a total of 10 return strokes and the flash multiplicity varied between 1 to 3 . Figure 4.8 presents the flash multiplicity of flashes with respect to time of occurrence. The figure demonstrates the flash multiplicity of the six flashes (blue lines) and the red squares represents the flashes that contained only the initial-stage current (ISC).

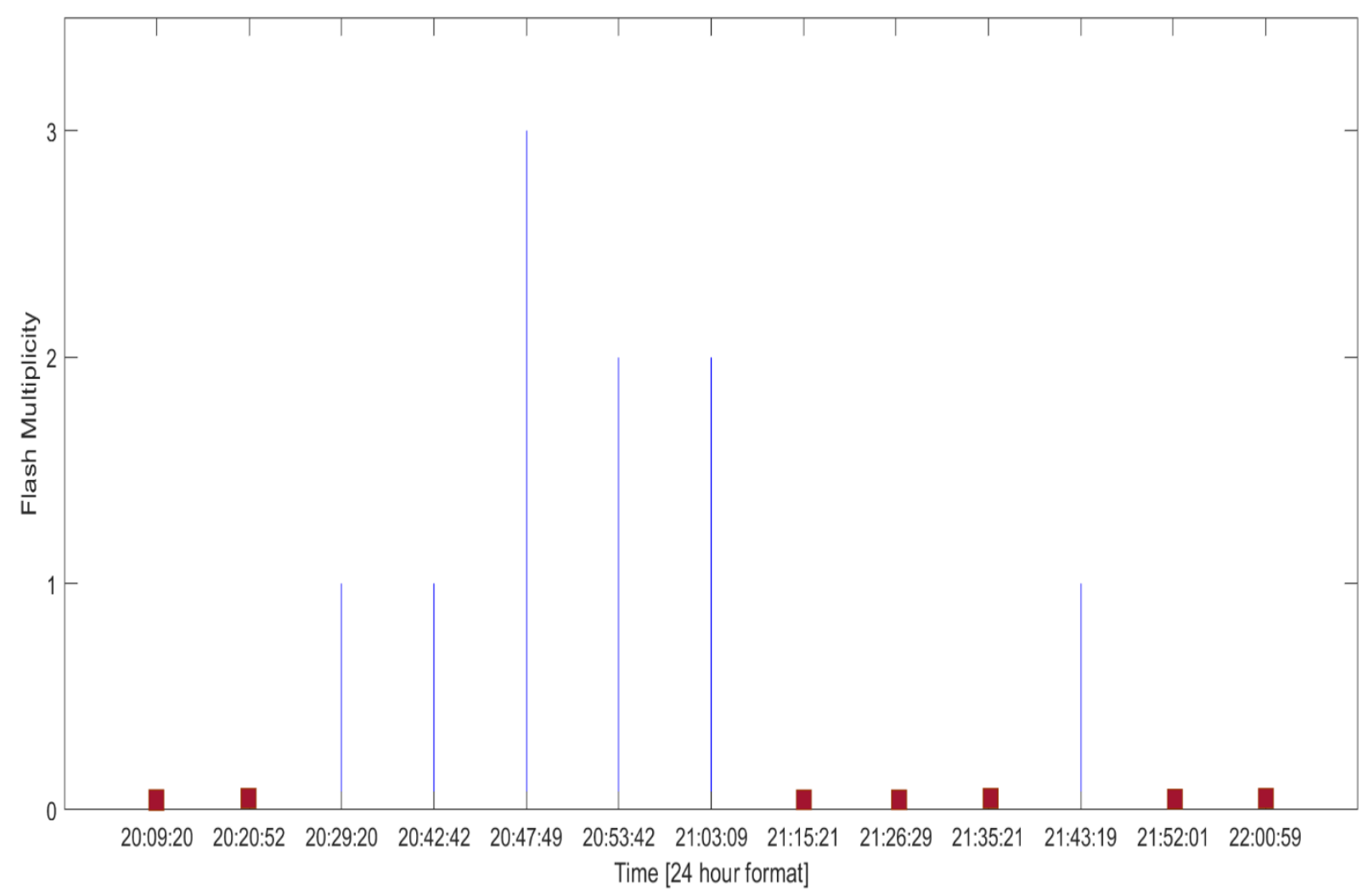

Figure 4.8 - Flash multiplicity of September 5, 2014 storm. 
The following figures present the maximum and average luminosity variation with time for the two flashes that struck the tower during 2014 storm.

Figure 4.9 illustrates the channel trajectory image of the third flash that struck the tower during the storm. At the horizontal pixel line $\mathrm{Y}=299$, the maximum and average luminosity variation across the whole pixel line and across the 15-pixel wide channel is evaluated respectively, as shown in Figure 4.10.

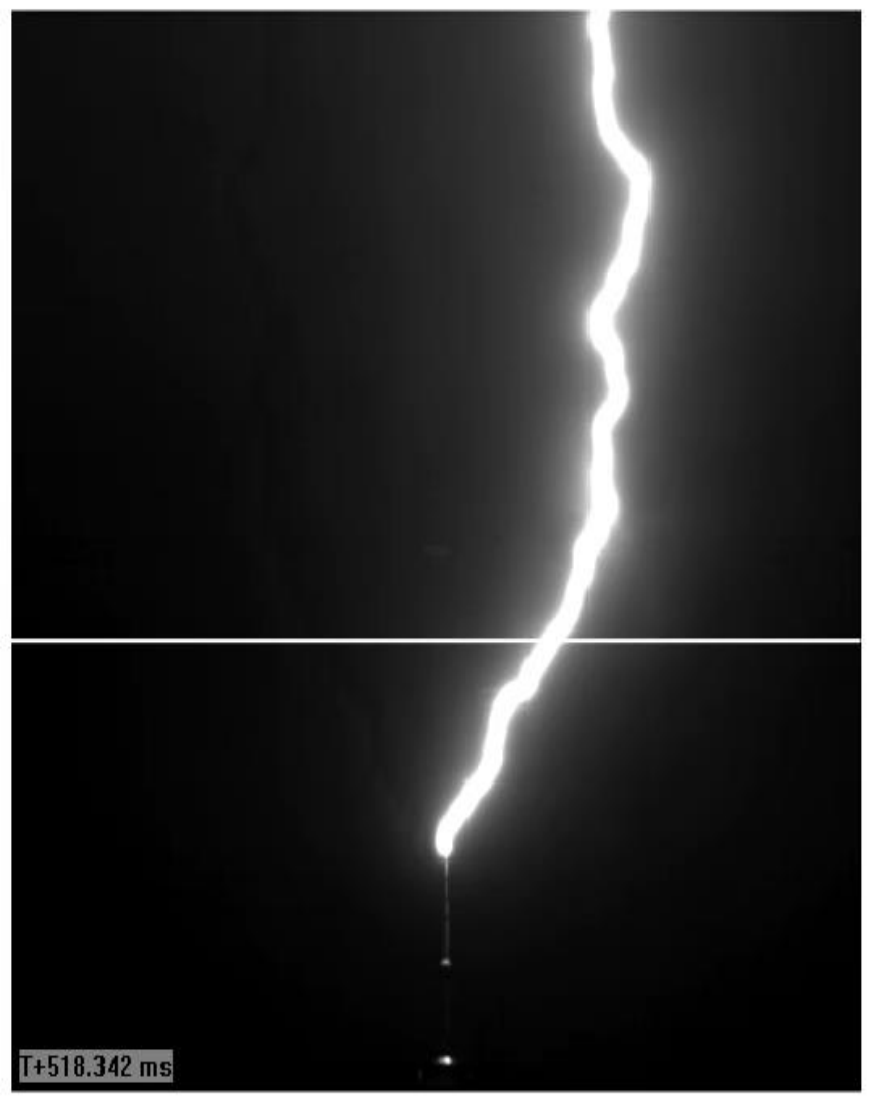

Figure 4.9 - Channel trajectory image of the third flash recorded on September 5, 2014. 


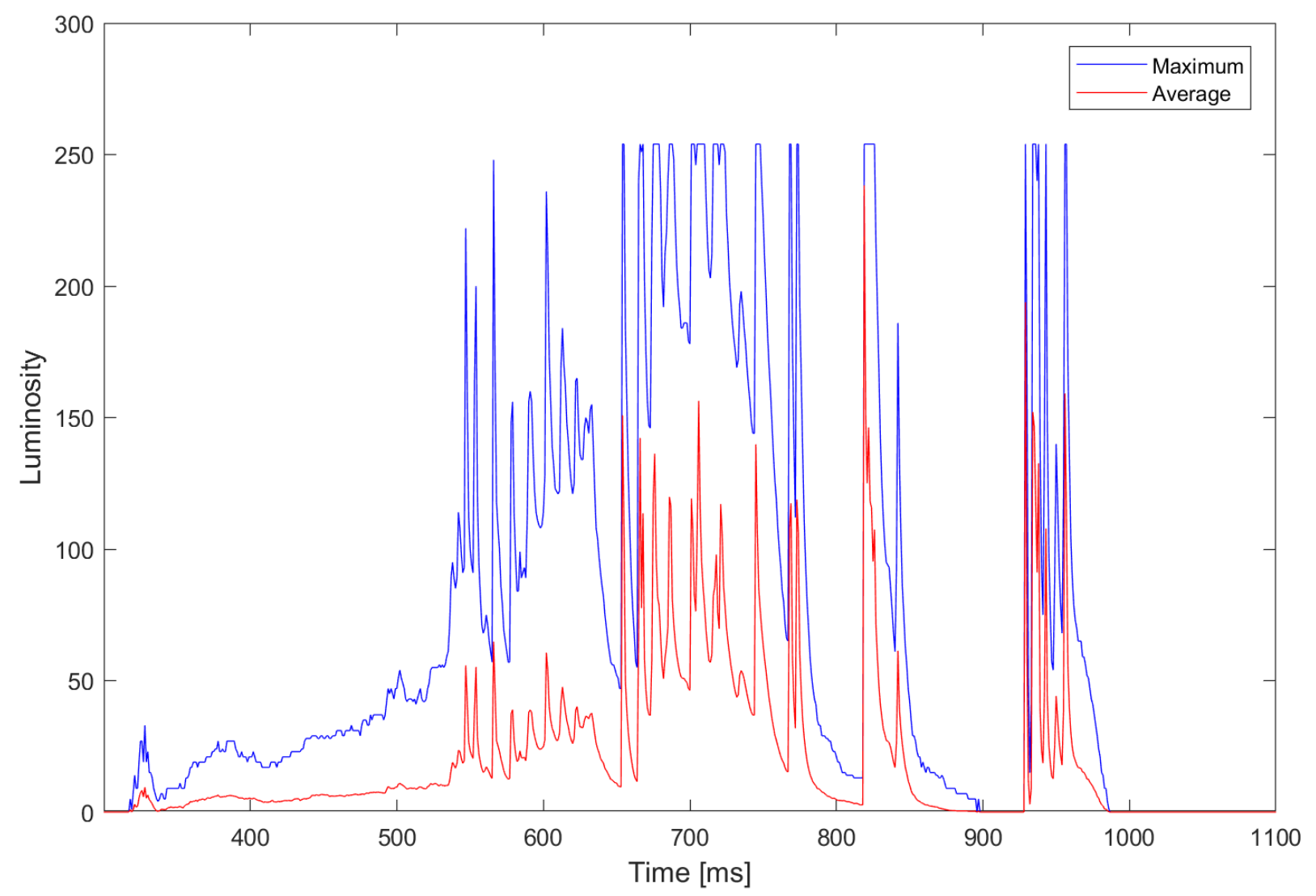

Figure 4.10 - Maximum and average channel luminosity time variations along the horizontal pixel line $\mathrm{Y}=299$.

The luminosity variation with time as illustrated in Figure 4.10 reveals the existence of ISC of duration $591 \mathrm{~ms}$, containing several M-components, followed by one return stroke and a continuing current, containing several M-components.

Figure 4.11 presents the channel trajectory image of the twelfth flash that CN Tower received. At the horizontal pixel line $\mathrm{Y}=270$, the maximum and average luminosity variation across the whole pixel line and across the 10-pixel wide channel is evaluated respectively, as presented in Figure 4.12. 


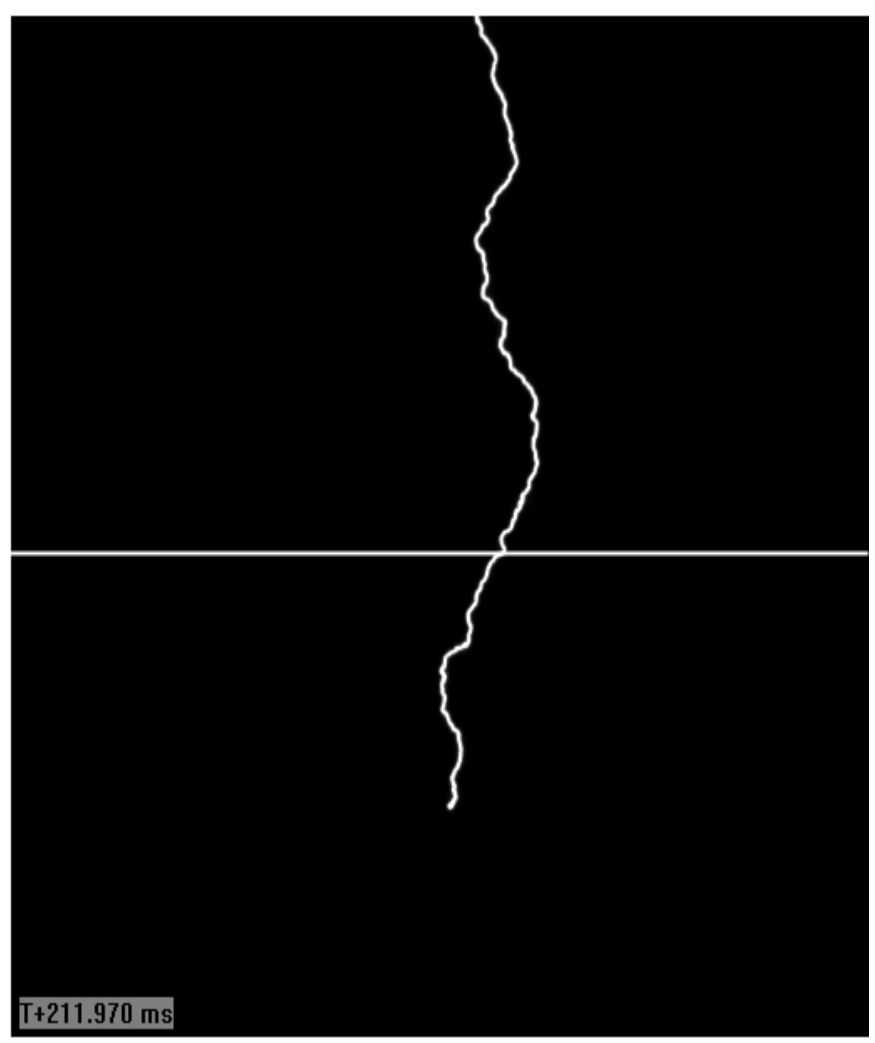

Figure 4.11 - Channel trajectory image of the twelfth flash recorded on September 5, 2014.

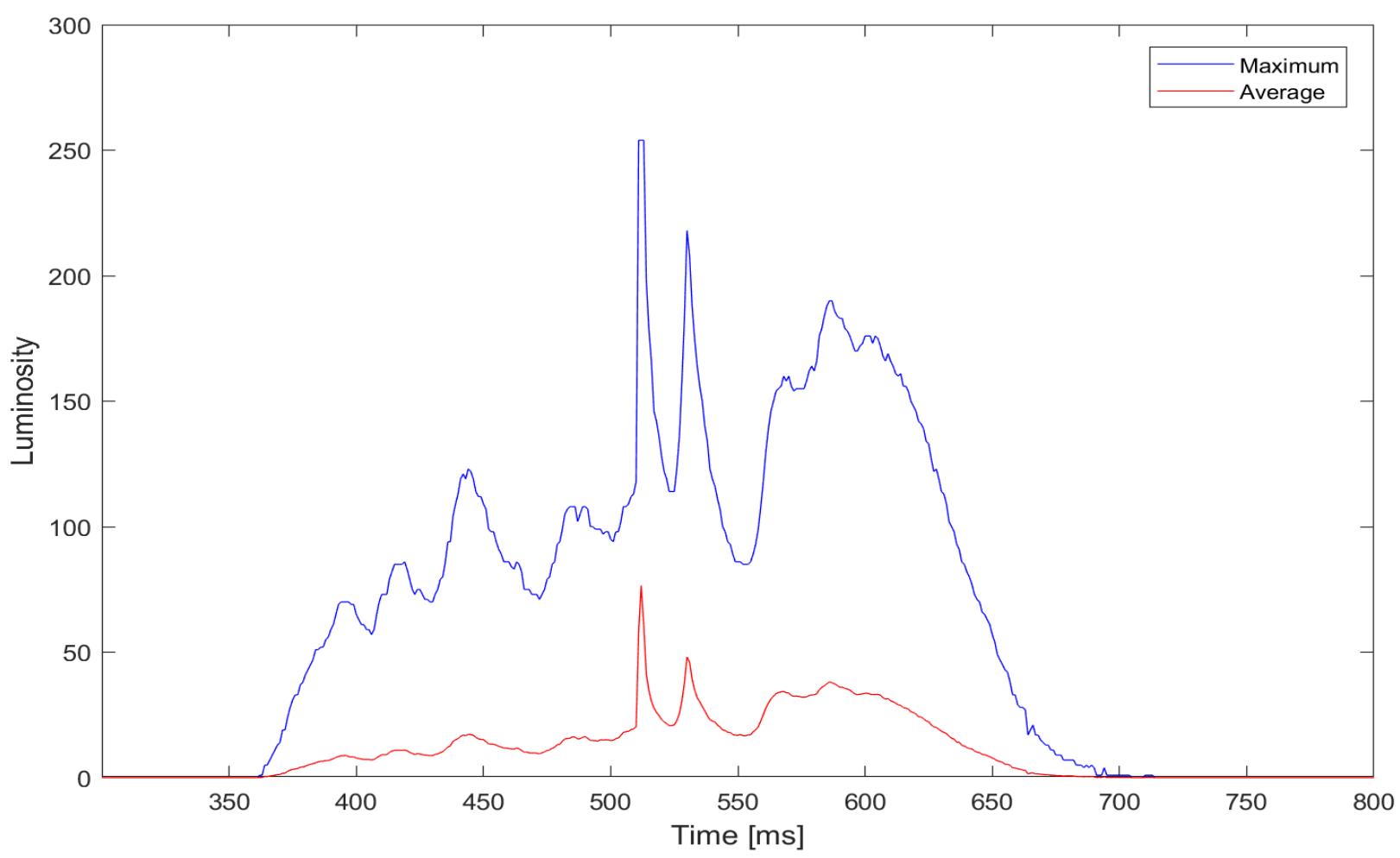

Figure 4.12 - Maximum and average channel luminosity time variations along the horizontal pixel line $\mathrm{Y}=270$. 
The luminosity variation with time as demonstrated in figure 4.12 , reveals the existence of only ISC of duration $360 \mathrm{~ms}$, containing several M-components.

\subsection{Continuously Recording Digital Camera}

The Sony HDR PJ790VB digital low-speed camera (LSC) is placed beside the HSC (Figure 4.13). It operates at 60 frames/sec (time resolution of $16.67 \mathrm{~ms}$ ), representing that every single frame of video is captured in $16.67 \mathrm{~ms}$ and it has 1090x 1080 pixel resolution. It has an embedded flash memory of $96 \mathrm{~GB}$, which allows the continuous recording up to 37 hours and 50 mins. It has back-illuminated Exmor CMOS sensor which performs on-chip analog to digital signal conversion and noise reduction. It comprises 24 bits per pixel, which indicates that the red, green and blue subpixels, for each pixel uses 8 bits each. The Sony HDR PJ790VB store the recorded files in .$m 2 t s$ format. The raw .m2ts format can be converted to the desired format using Sony PlayMemories software, that can be further processed in MATLAB to obtain luminosity time variation plots for the recorded flashes. The following figures demonstrate the maximum and average luminosity time variation of several flashes captured by LSC.

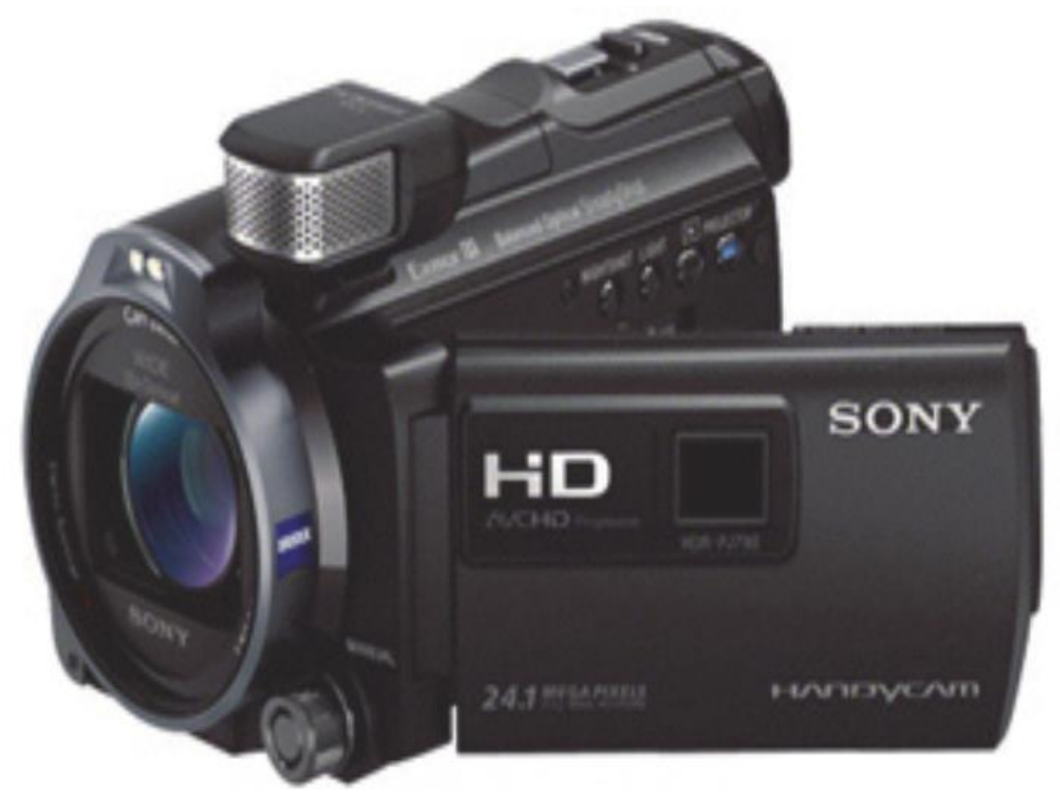

Figure 4.13 - Sony HDR PJ790VB digital low-speed camera. 
Figure 4.14 illustrates the channel trajectory image of the second flash recorded by LSC on September 7, 2016. At a horizontal pixel level of $\mathrm{Y}=320$, the maximum and average luminosity variation with time is evaluated, across the whole pixel line and the 12-pixel wide channel respectively, as shown in Figure 4.15.

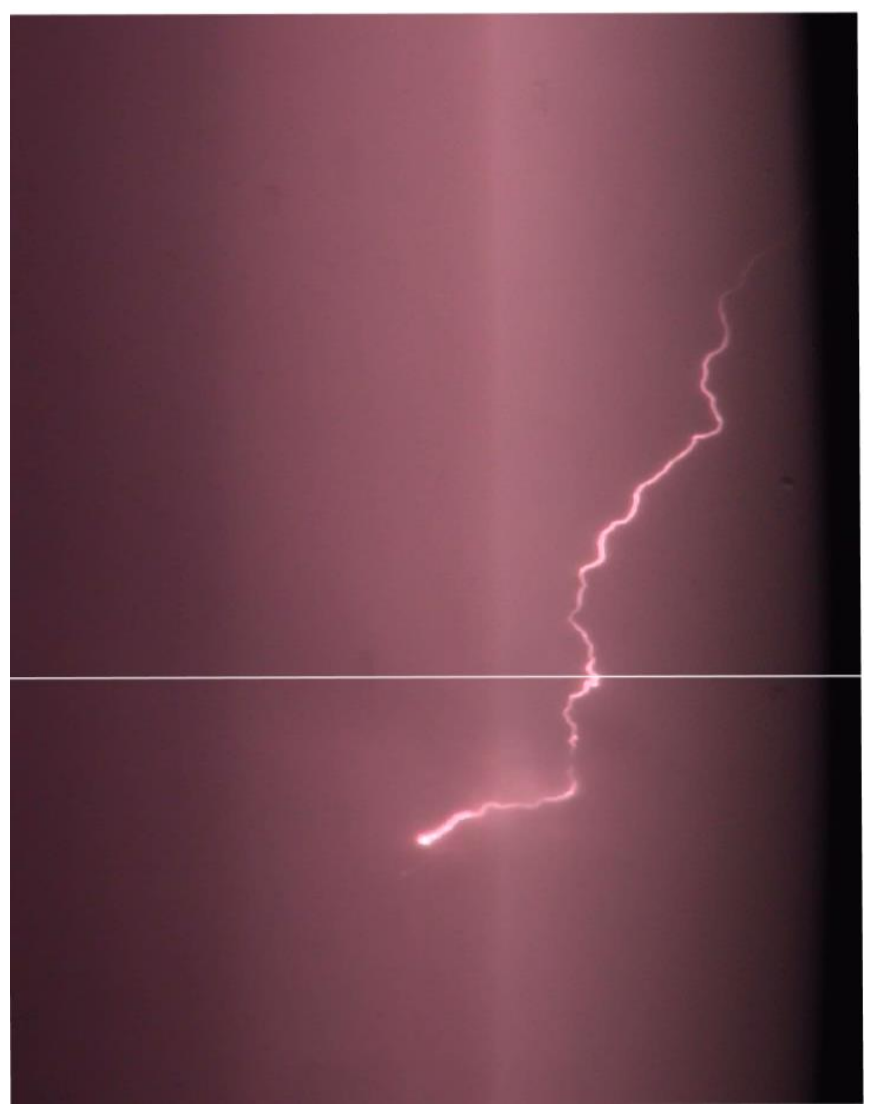

Figure 4.14 - Channel trajectory image of the second flash recorded on September 7, 2016. 


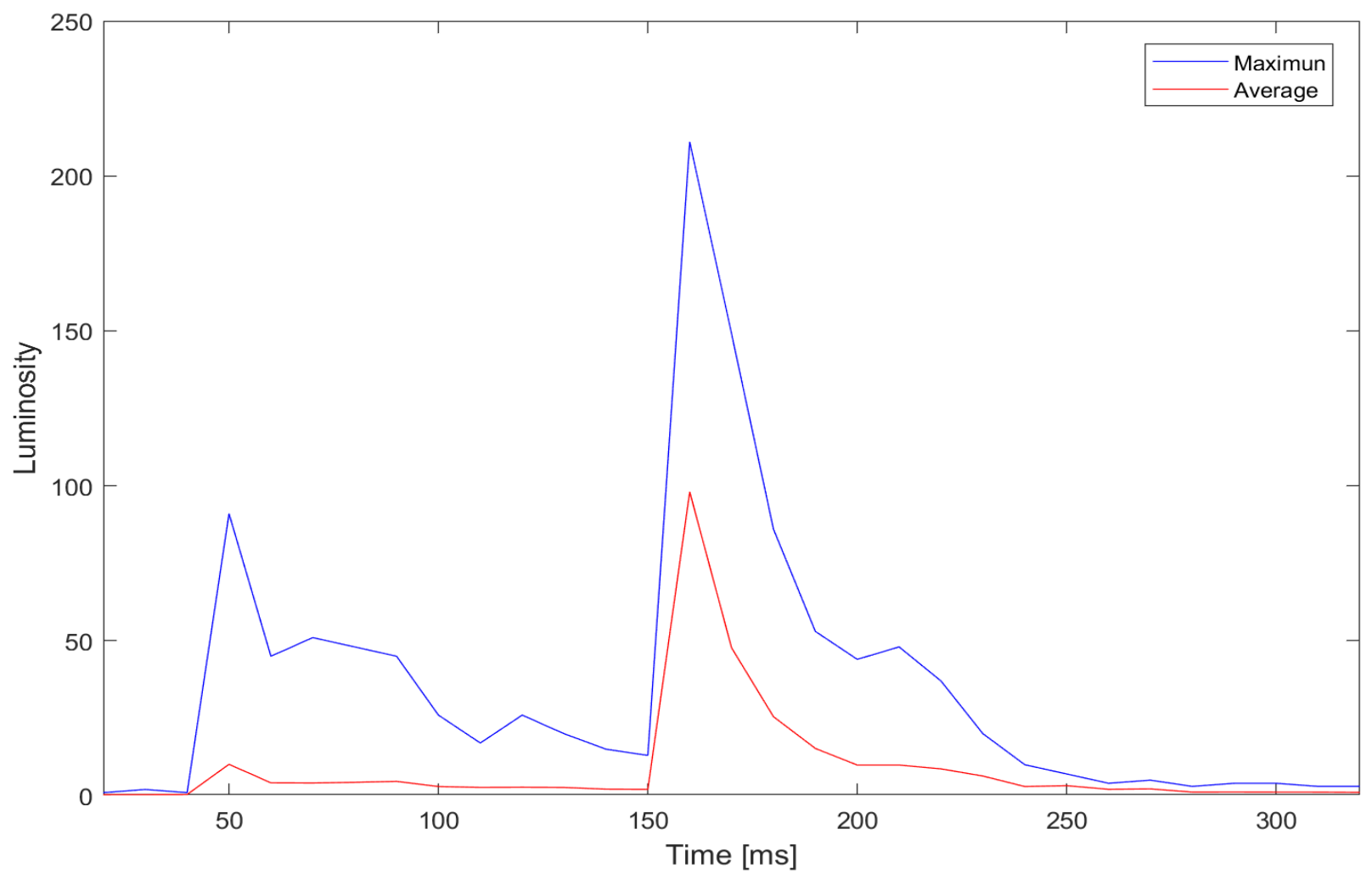

Figure 4.15 - Maximum and average channel luminosity time variations along the horizontal pixel line $\mathrm{Y}=320$.

The luminosity variation with time as presented in Figure 4.15 reveals the existence of only ISC, with a duration of $198 \mathrm{~ms}$, containing several M-components.

Figure 4.16 demonstrates the channel trajectory image of the third flash recorded on July 8 , 2013. The maximum and average luminosity variation with time is evaluated at a horizontal pixel line level of $Y=360$, across a whole pixel line and a 15-pixel wide channel respectively, as shown in Figure 4.17. 


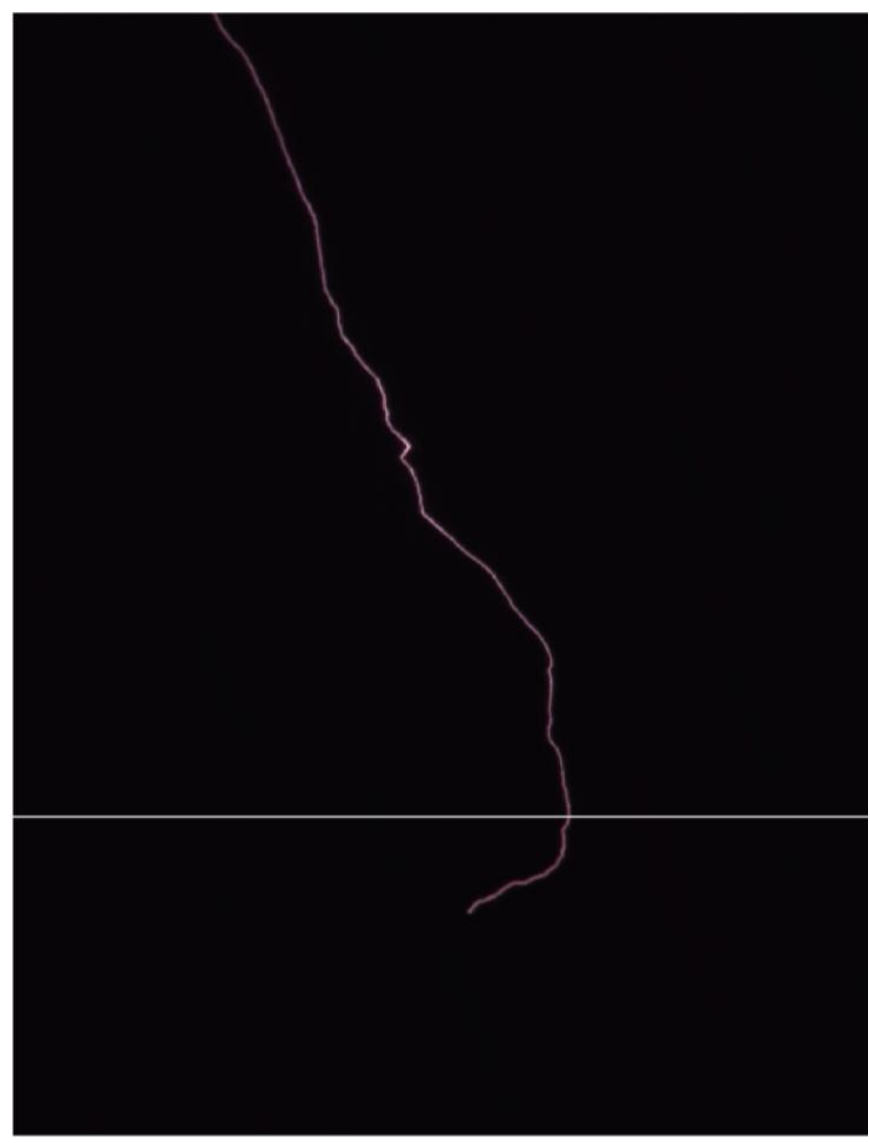

Figure 4.16 - Channel trajectory image of the third flash recorded on July 8, 2013.

The luminosity variation with time as illustrated in Figure 4.17, reveals the existence of an ISC, with a duration of $158 \mathrm{~ms}$, containing several M-components. 


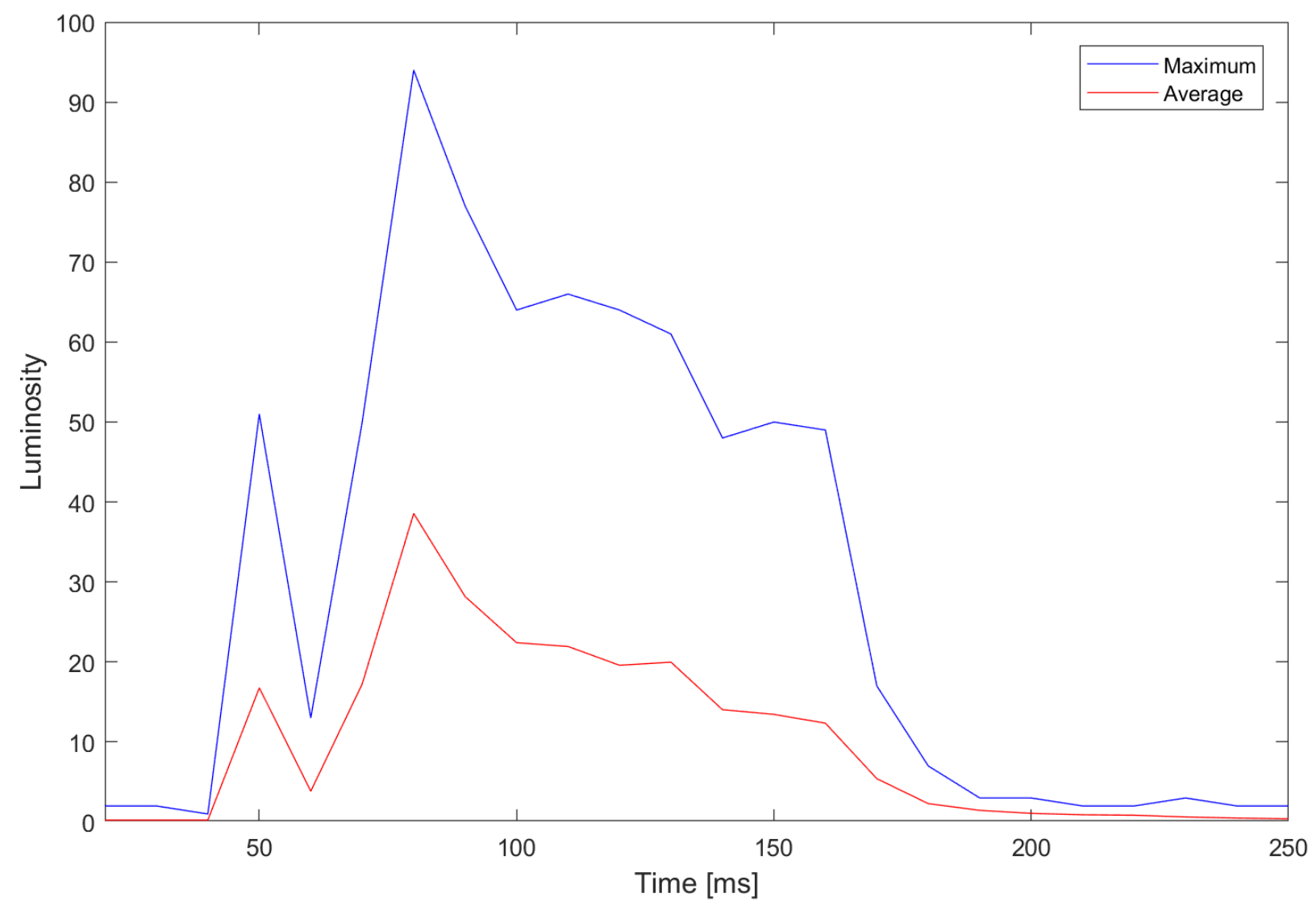

Figure 4.17 - Maximum and average channel luminosity time variations along the horizontal pixel line $\mathrm{Y}=360$. 


\section{Chapter 5}

\section{Lightning Storm Observed at CN Tower on September 4, 2017}

The Sony HDRPJ790VB digital low-speed camera (LSC) proved to be pivotal for continuously recording all lighting events at the tower, and its records are later analyzed to confirm the operation and failure of other CN Tower lightning measurement systems. The September 4, 2017 storm, which lasted for $2961 \mathrm{~s}$ (49.35 minutes), produced eleven flashes to the tower with an average inter-flash time of $291.9 \mathrm{~s}$. Figure 5.1 presents the channel luminosity variation with time for the entire storm based on LSC trajectory records. The figure indicates the existence of eleven flashes during the storm [22].

Although it was observed that LSC recorded eleven CN Tower flashes, the HSC records were found to only contain four flashes. It's worth mentioning that the absence of GPS timing in LSC records required extensive analysis of the inter-flash timing of the two data sets to match the four HSC records, with the corresponding LSC flashes. This comprehensive analysis produced exact matching. It was found out that the four HSC flashes matched the LSC flashes HSC1, HSC2, HSC3, and HSC4, as illustrated in Figure 5.1. The inter-flash times for the two data sets were found to be $282 \mathrm{~s}, 192 \mathrm{~s}, 695 \mathrm{~s}$ respectively [22]. 


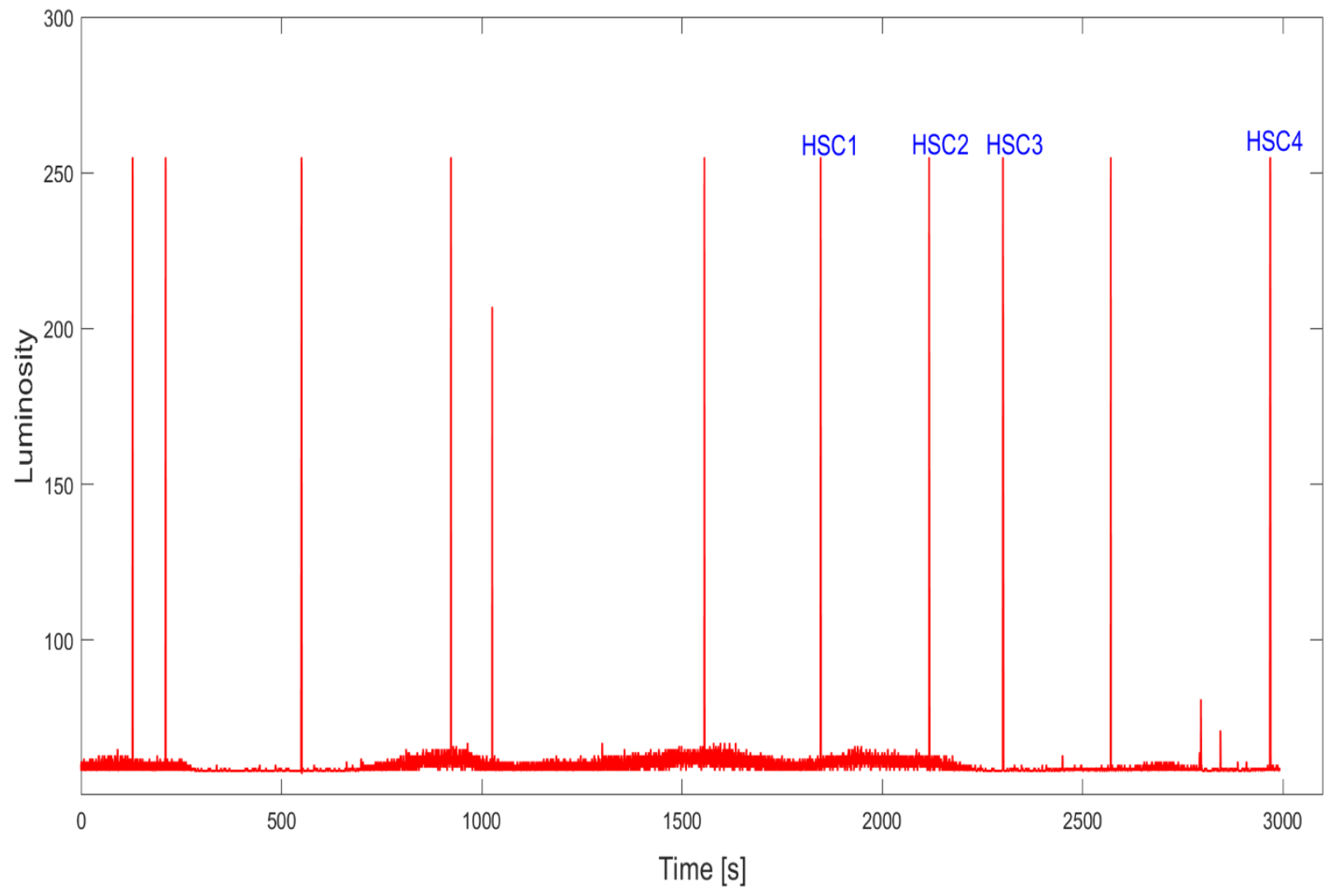

Figure 5.1 - Channel luminosity variation with time for the Sept. 4, 2017, based on LSC and HSC records.

The comparison between the lightning data recorded by HSC and LSC illustrated that the economical LSC turns out to be an extremely valuable imaging system. As the significantly valuable continuously recording imaging system (LSC) confirmed the operation or the failure of the HSC. However, LSC does not have an adequate frame rate (60 fps) to capture every subtle detail of a flash, including the M-components. Figure 5.2 presents the channel trajectories of the first flash recorded by HSC (left) and its matched seventh flash recorded by LSC (right). The variation of the maximum luminosity, as a function of time, is evaluated along horizontal pixel line of $\mathrm{Y}=288$ over 1300 frames (HSC) and another one $\mathrm{Y}=350$ over 60 frames (LSC) and is plotted in Figure 5.3 [22]. 


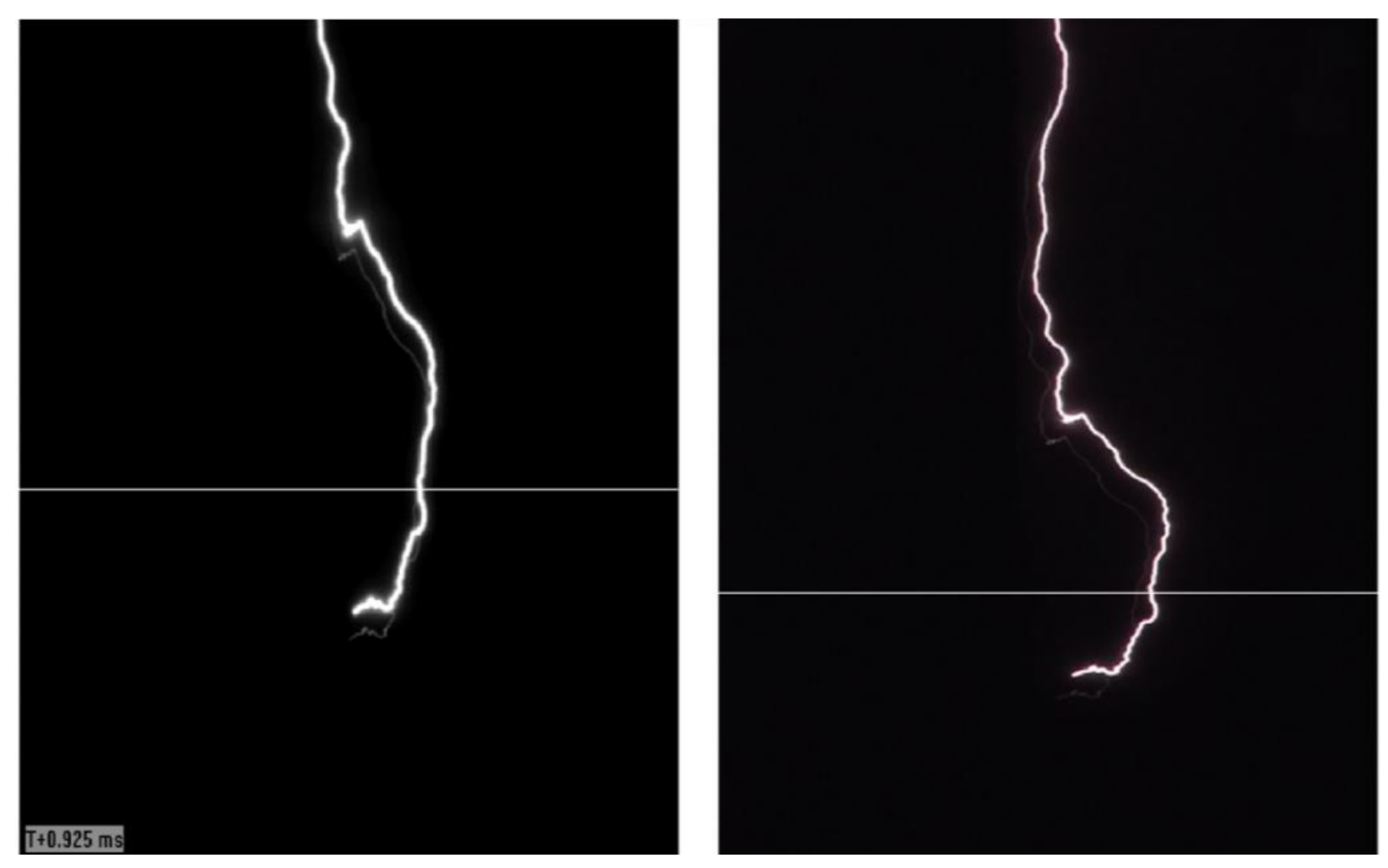

Figure 5.2 - Channel trajectory images of flash 1 of HSC (left) and its matched LSC flash 7 (right).

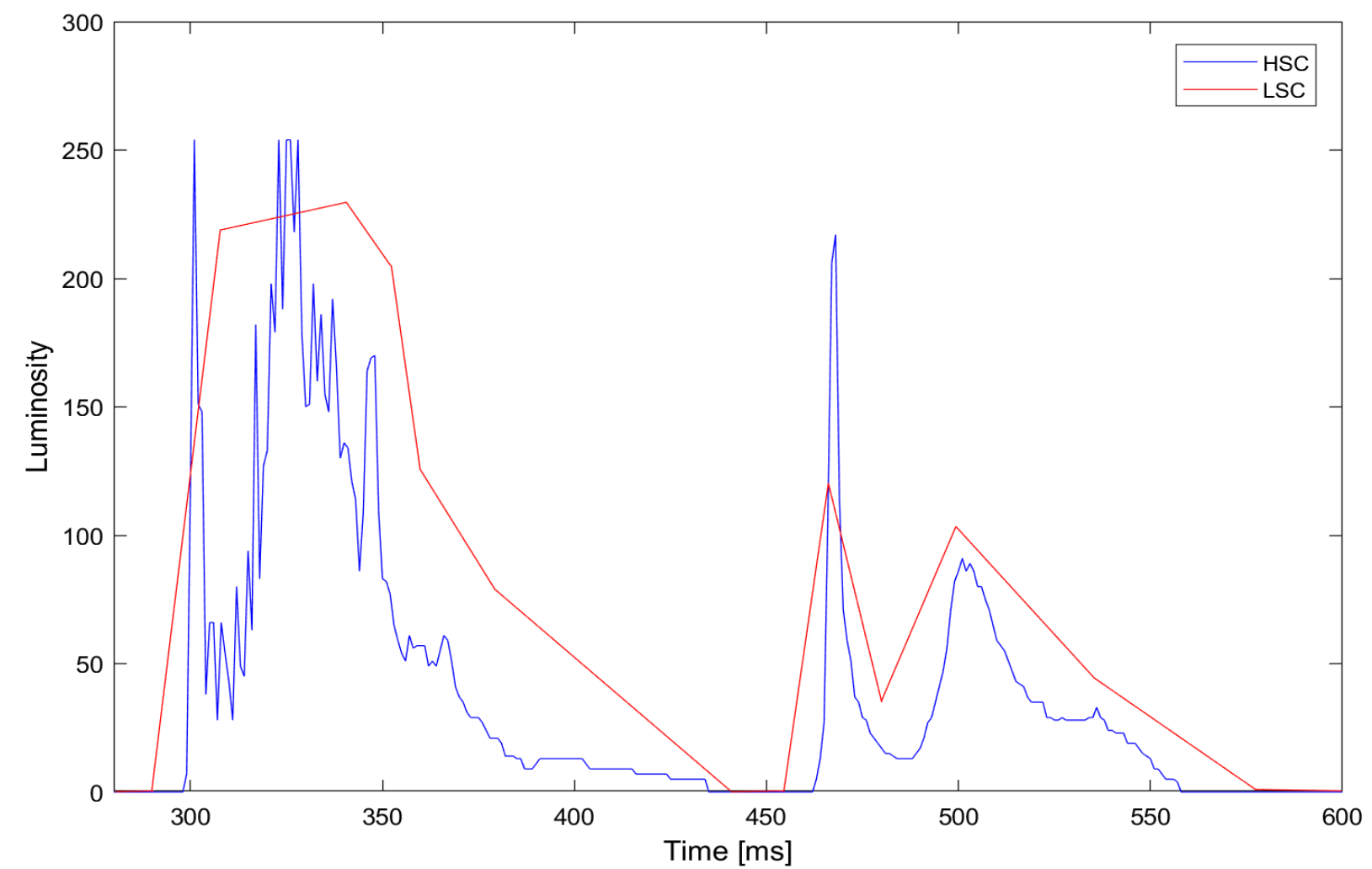

Figure 5.3 - Channel luminosity variations with time based on flash 1 (HSC) and flash 7 (LSC). 
Figure 5.3 displays a flash that begins with an initial stage current (ISC), with a duration of $167 \mathrm{~ms}$ and includes several M-components, which is followed by a single return stroke. The return stroke is followed by a continuing current, with at least one M-component superimposed on it. Based on Figure 5.3, it's evident that the detailed characteristics of flash components require at least $1 \mathrm{~ms}$ resolution imaging system. The imaging systems with a higher frame rate than $1000 \mathrm{fps}$ would be of much interest to use [22].

Figure 5.4 illustrates the channel trajectories of the second flash recorded by HSC (left) and its matched eighth flash recorded by LSC (right). The time variation of the maximum channel luminosities is analyzed along the horizontal pixel lines $\mathrm{Y}=261$, and $\mathrm{Y}=322$ for HSC and LSC, respectively, and are demonstrated in Figure 5.5.
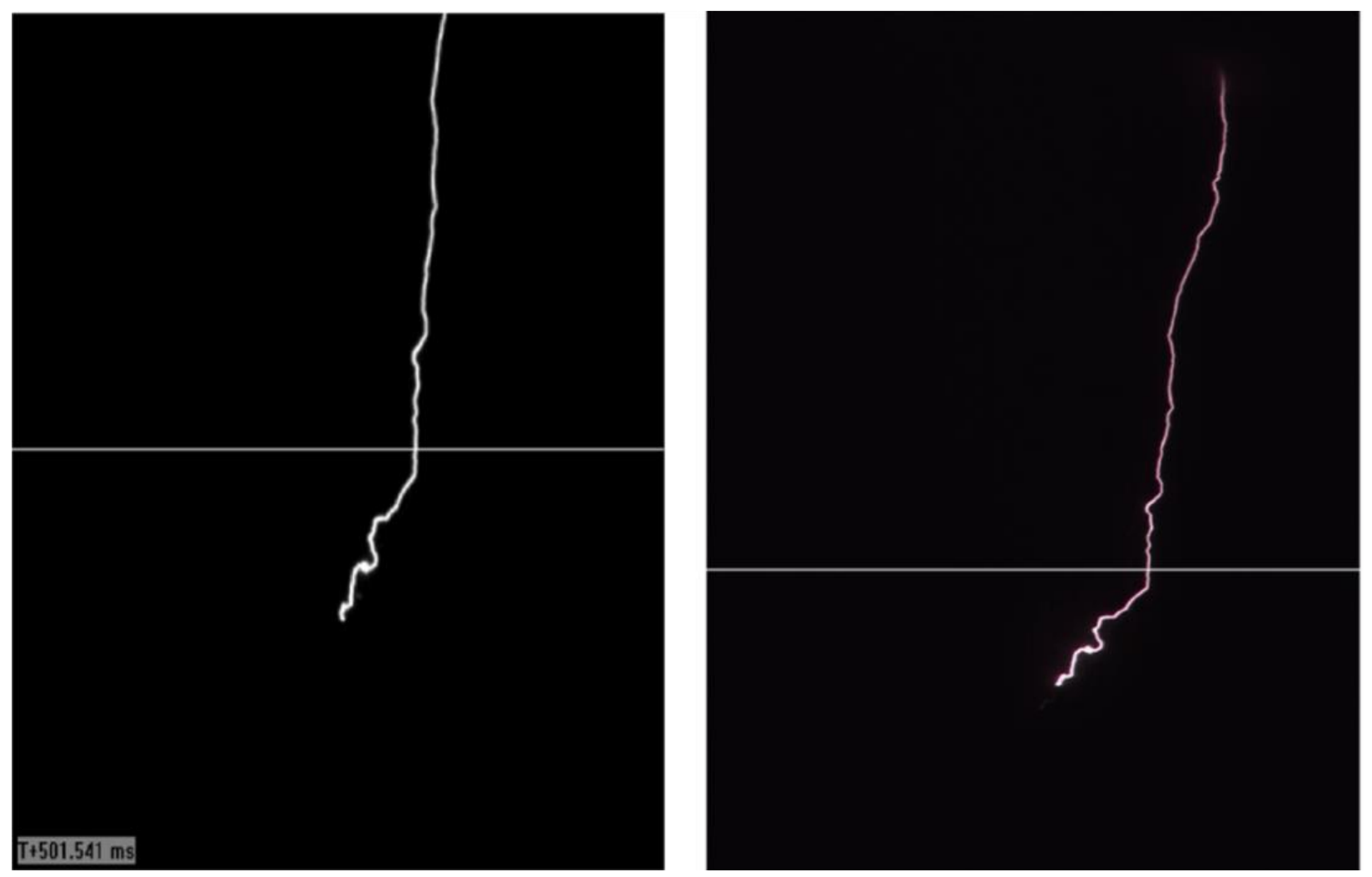

Figure 5.4 - Channel trajectory images of flash 2 of HSC (left) and its matched LSC flash 8 (right). 


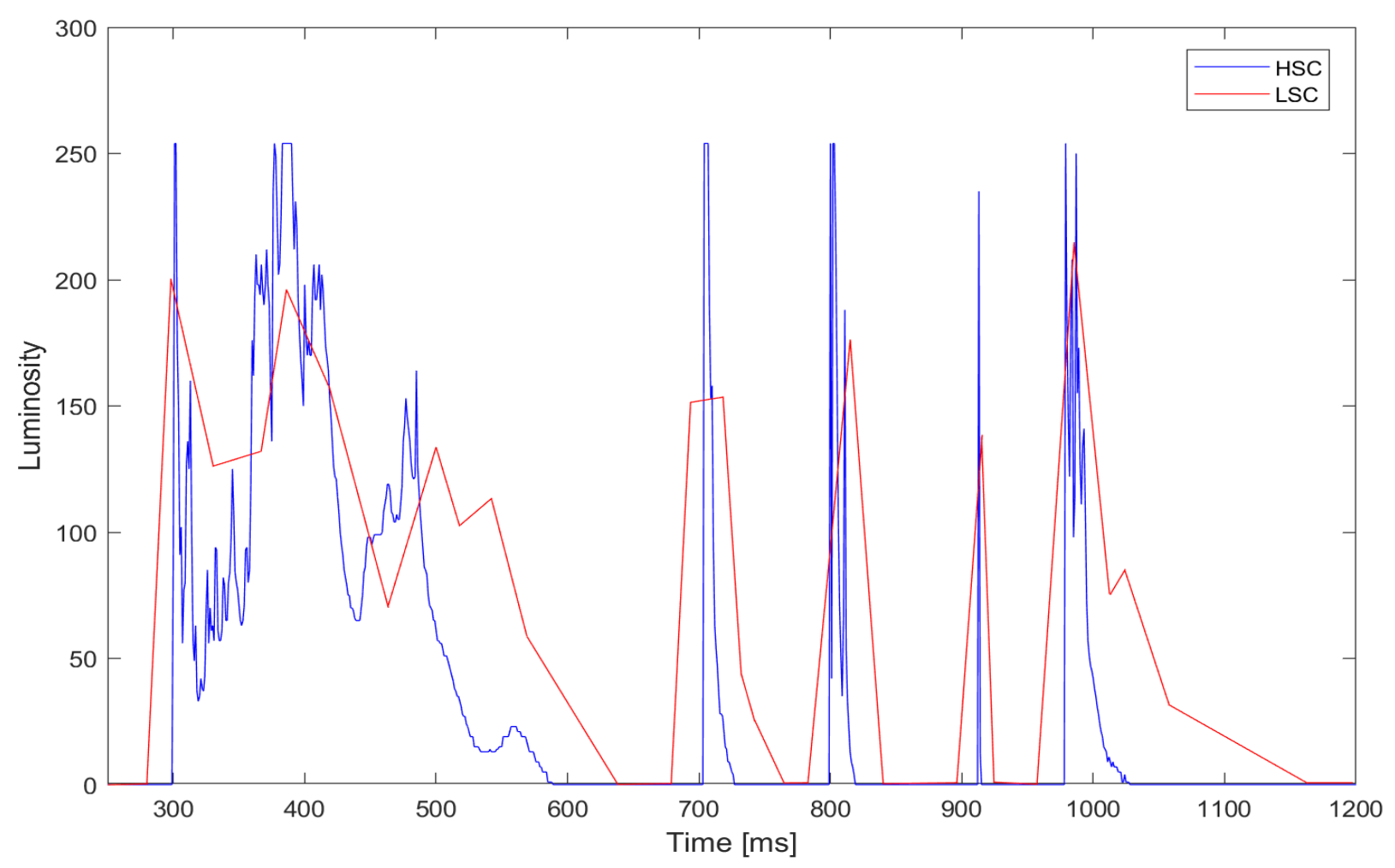

Figure 5.5 - Channel luminosity variations with time based on flash 2 (HSC) and flash 8 (LSC).

The luminosity variation with time, along with successive frames, as illustrated in Figure 5.5, displays a flash starting with ISC of $293 \mathrm{~ms}$ duration, containing several M-components, and followed by four return strokes. The second and fourth return strokes are followed by containing current, with several M-components superimposed on it.

Figure 5.6 presents the channel trajectory of the third flash, recorded by the HSC (left), and its matched ninth flash recorded by LSC (right). The time variation of the maximum channel luminosity is analyzed along the horizontal pixel lines $\mathrm{Y}=283$ and $\mathrm{Y}=345$ for HSC and LSC, respectively, and are demonstrated in Figure 5.7. 

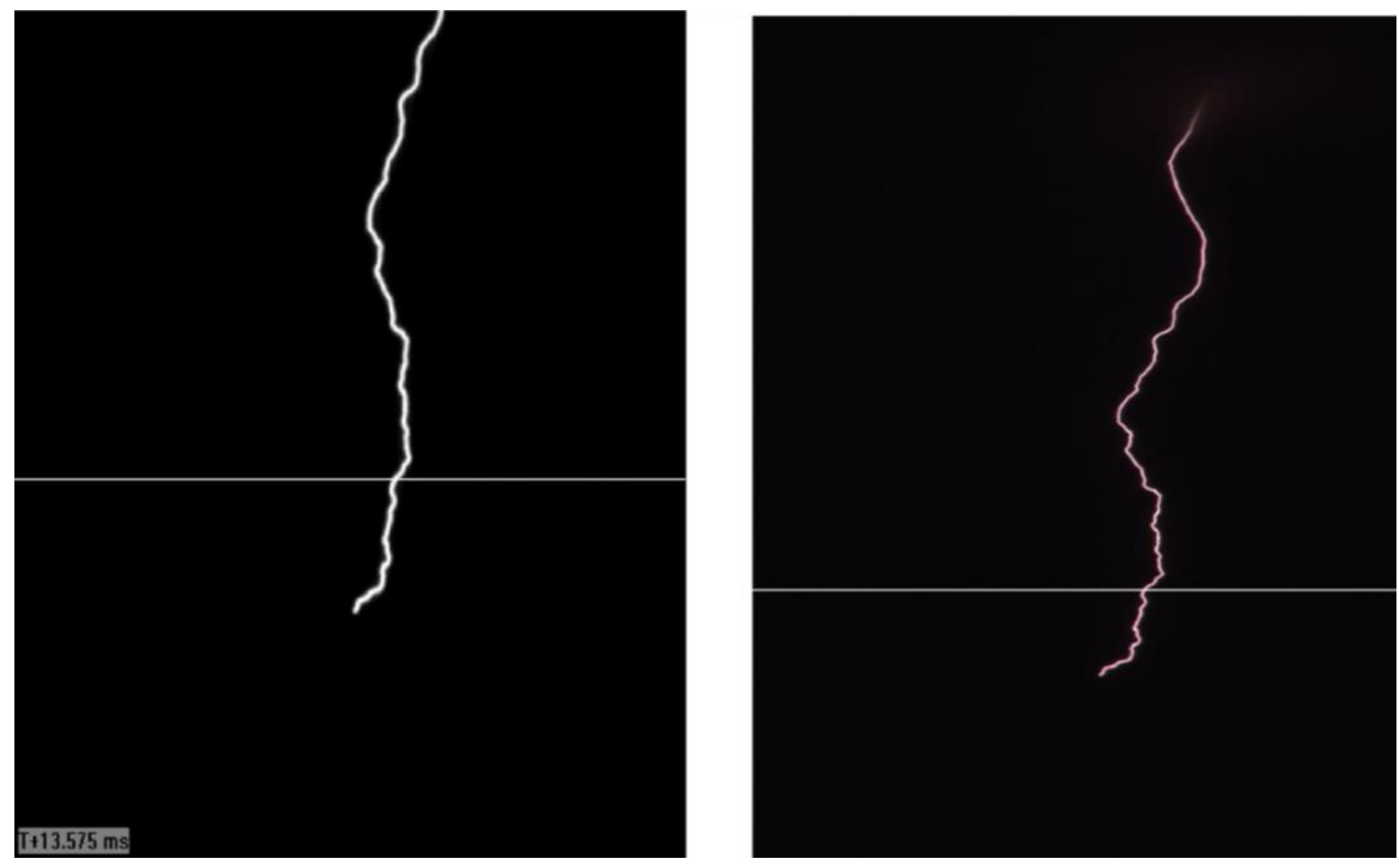

Figure 5.6 - Channel trajectory images of flash 3 of HSC (left) and its matched LSC flash 9 (right).

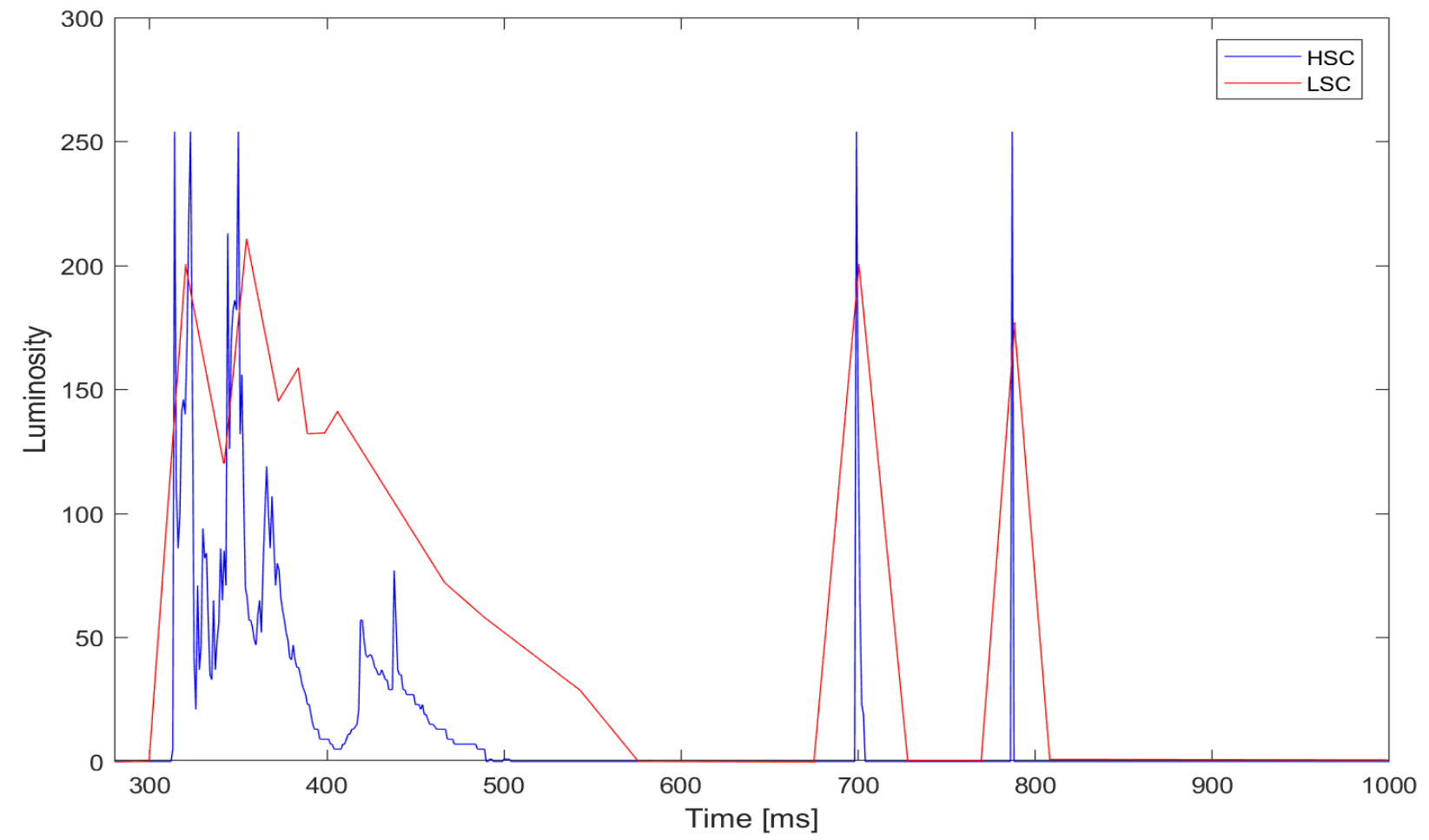

Figure 5.7 - Channel luminosity variations with time based on flash 3 (HSC) and flash 9 (LSC). 
Figure 5.7 presents a flash that begins with ISC of $170 \mathrm{~ms}$ duration, containing several Mcomponents, and followed by two return strokes.

Figure 5.8 illustrates the channel trajectory image of the fourth flash, recorded by HSC (left), and its matched eleventh flash, recorded by LSC (right). The time variation of maximum channel luminosity is analyzed along horizontal pixel lines $\mathrm{Y}=292$ for $\mathrm{HSC}$ and $\mathrm{Y}=354$ for LSC, respectively, are demonstrated in Figure 5.9.
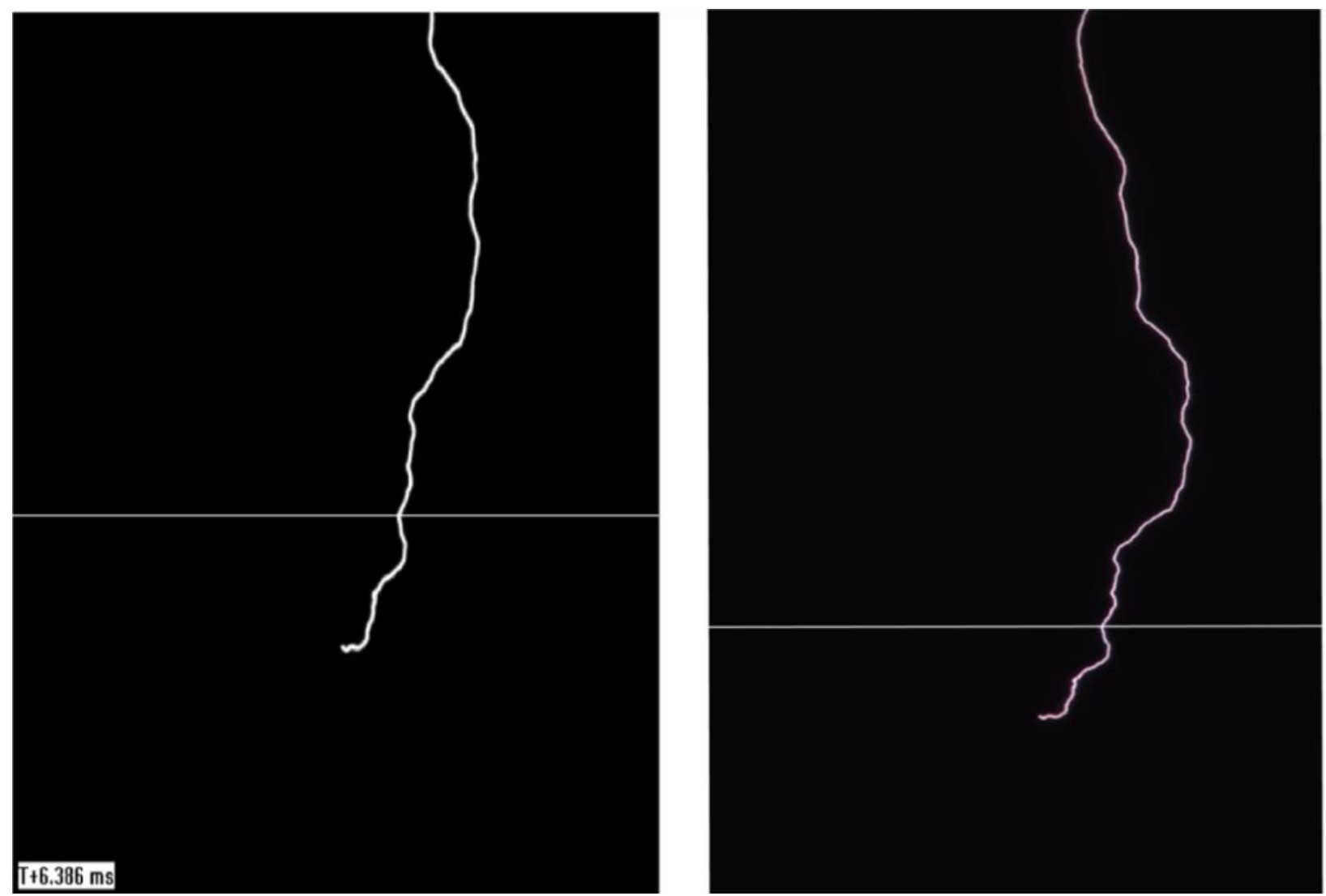

Figure 5.8 - Channel trajectory images of flash 4 of HSC (left) and its matched LSC flash 11 (right). 


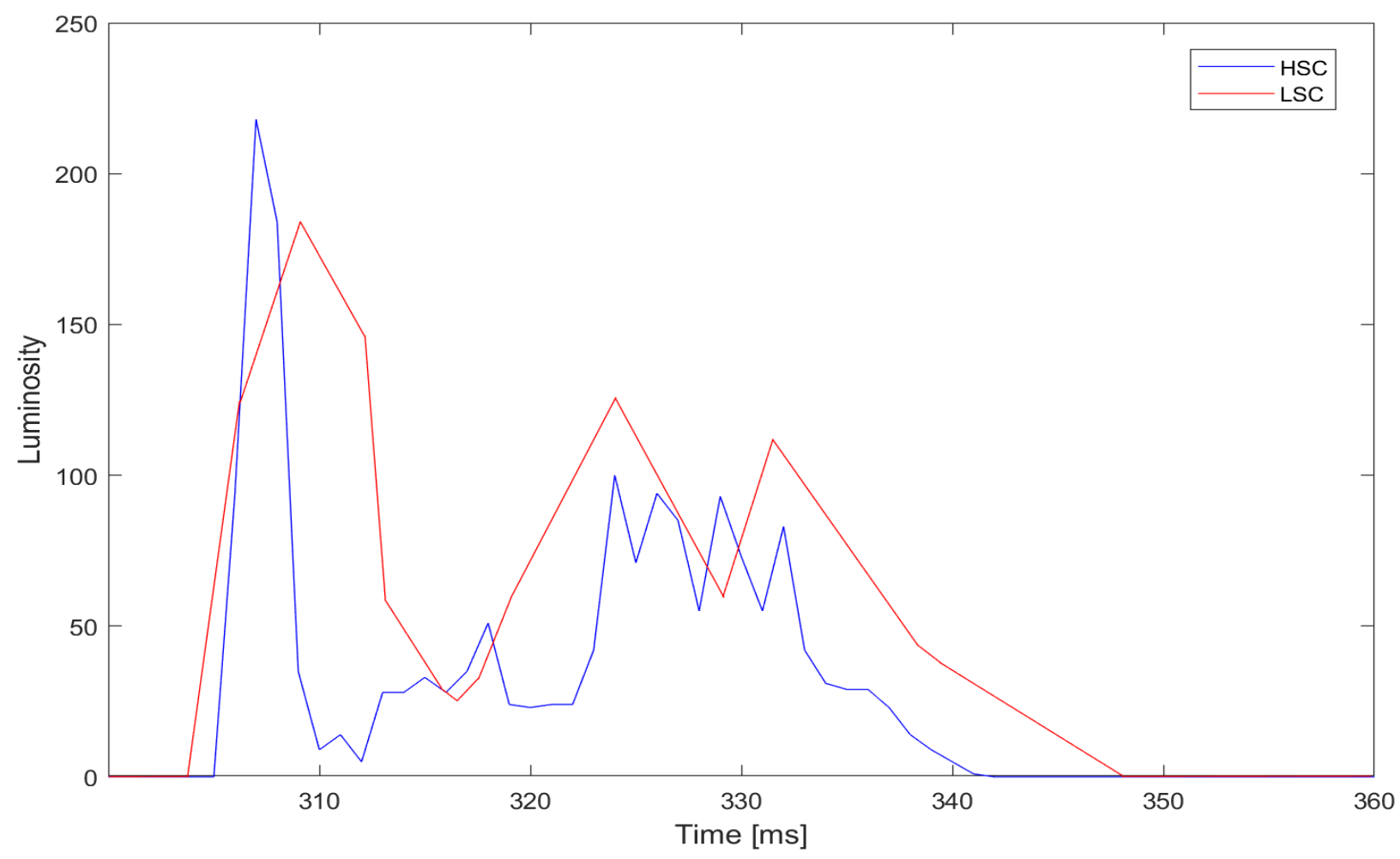

Figure 5.9 - Channel luminosity variations with time based on flash 4 (HSC) and flash 11 (LSC).

Figure 5.9 illustrates a flash containing only ISC with time duration of $37 \mathrm{~ms}$, comprising several M-components.

The comparison between the lightning data recorded by HSC and LSC illustrated that the economical continuously recording LSC turns out to be an extremely valuable imaging system, without which the storm would not have materialized. Also, such continuously recording imaging system (LSC) would confirm the operation or the failure of other CN Tower lightning measurement systems, including the current recording system at the tower [22]. 


\section{Chapter 6}

\section{Flash Characteristics}

The acquisition of the data from Sony HDRPJ790VB low-speed camera (LSC) and Phantom v5.0 high-speed camera (HSC) provides necessary details, by analysing luminosity variation with time, regarding different flash components namely initial-stage current (ISC) duration, flash multiplicity, inter-stroke time (IST), flash duration, inter-flash time and continuing current time duration.

This section focuses on analyzing fifty-eight CN Tower lightning flashes captured by LSC and HSC, in the period of last five years (2013-2017), which can be classified as 2013 received seven flashes, 2014 received eighteen flashes, 2015 received eight flashes, 2016 received fourteen flashes and 2017 received eleven flashes. Also, the comparison has been conducted between the two storms received on September 5, 2014, and September 4, 2017, which contained thirteen and eleven flashes respectively.

The statistical results presented in this thesis will further help in the establishment of a more advanced approach in designing the protective measures against the lightning hazards to the tall structures. 


\subsection{Flash Duration (2013-2017)}

The flash duration is defined total discharge time. The flash duration of each CN Tower flash (usually upward initiated), begins with an initial-stage current (ISC), which contains several Mcomponents superimposed on it. In many cases the ISC is followed by downward-leader-upwardreturn-stroke sequences. Flashes with long flash durations represents severe threat to electrical power installations and tall structures [23]. Table 6.1 demonstrates the flash duration and the interflash time duration of all 58 flashes, based on HSC and LSC video records.

Table 6.1 Flash durations and inter-flash time durations of all 58 flashes based on video records (2013-2017).

\begin{tabular}{|c|c|c|c|c|}
\hline \multicolumn{5}{|c|}{ Flash Duration and Inter-Flash Time [2013-2017] } \\
\hline Year & Flash number & Date & Flash Duration [ms] & Inter-Flash Time [s] \\
\hline \multirow[t]{13}{*}{2013} & 1 & July 8 & 85 & \\
\hline & & & & 462 \\
\hline & 2 & July 8 & 287 & \\
\hline & & & & 267 \\
\hline & 3 & July 8 & 158 & \\
\hline & & & & \\
\hline & 4 & July 19 & 262 & \\
\hline & & & & 382 \\
\hline & 5 & July 19 & 476 & \\
\hline & & & & \\
\hline & 6 & September 11 & 240 & \\
\hline & & & & 101 \\
\hline & 7 & September 11 & 267 & \\
\hline & & & & \\
\hline \multirow{11}{*}{2014} & 8 & Julv 7 & 240 & \\
\hline & & & & 347 \\
\hline & 9 & July 7 & 219 & \\
\hline & & & & 168 \\
\hline & 10 & July 7 & 111 & \\
\hline & & & & \\
\hline & 11 & September 1 & 161 & \\
\hline & & & & 343 \\
\hline & 12 & September 1 & 125 & \\
\hline & 13 & Sentemher 5 & 240 & \\
\hline & 13 & september 5 & 240 & \\
\hline
\end{tabular}




\begin{tabular}{|c|c|c|c|c|}
\hline & & & & 692 \\
\hline & 14 & September 5 & 191 & \\
\hline & & & & 508 \\
\hline & 15 & September 5 & 767 & \\
\hline & & & & 792 \\
\hline & 16 & September 5 & 370 & \\
\hline & & & & 307 \\
\hline & 17 & September 5 & 702 & \\
\hline & & & & 353 \\
\hline & 18 & September 5 & 510 & \\
\hline & & & & 567 \\
\hline & 19 & September 5 & 708 & \\
\hline & & & & 722 \\
\hline & 20 & September 5 & 390 & \\
\hline & & & & 668 \\
\hline & 21 & September 5 & 210 & \\
\hline & & & & 532 \\
\hline & 22 & September 5 & 293 & \\
\hline & & & & 478 \\
\hline & 23 & September 5 & 364 & \\
\hline & & & & 522 \\
\hline & 24 & September 5 & 360 & \\
\hline & & & & 538 \\
\hline & 25 & September 5 & 99 & \\
\hline \multirow[t]{15}{*}{2015} & 26 & July 17 & 167 & \\
\hline & & & & 228 \\
\hline & 27 & July 17 & 225 & \\
\hline & & & & 327 \\
\hline & 28 & July 17 & 382 & \\
\hline & & & & \\
\hline & 29 & September 8 & 132 & \\
\hline & & & & 192 \\
\hline & 30 & September 8 & 185 & \\
\hline & & & & \\
\hline & 31 & September 12 & 576 & \\
\hline & & & & 187 \\
\hline & 32 & September 12 & 32 & \\
\hline & & & & 292 \\
\hline & 33 & September 12 & 264 & \\
\hline \multirow[t]{8}{*}{2016} & 34 & July 14 & 397 & \\
\hline & & & & 231 \\
\hline & 35 & July 14 & 350 & \\
\hline & & & & 324 \\
\hline & 36 & July 14 & 602 & \\
\hline & & & & 248 \\
\hline & 37 & July 14 & 310 & \\
\hline & & & & \\
\hline
\end{tabular}




\begin{tabular}{|c|c|c|c|c|}
\hline & 38 & July 25 & 307 & \\
\hline & & & & 432 \\
\hline & 39 & July 25 & 482 & \\
\hline & & & & 264 \\
\hline & 40 & July 25 & 472 & \\
\hline & & & & \\
\hline & 41 & September 7 & 220 & \\
\hline & & & & 242 \\
\hline & 42 & September 7 & 198 & \\
\hline & & & & 344 \\
\hline & 43 & September 7 & 142 & \\
\hline & & & & \\
\hline & 44 & September 9 & 282 & \\
\hline & & & & 149 \\
\hline & 45 & September 9 & 392 & \\
\hline & & & & 167 \\
\hline & 46 & September 9 & 46 & \\
\hline & & & & 372 \\
\hline & 47 & September 9 & 432 & \\
\hline 2017 & 48 & September 4 & 175 & \\
\hline & & & & 80 \\
\hline & 49 & September 4 & 160 & \\
\hline & & & & 340 \\
\hline & 50 & September 4 & 150 & \\
\hline & & & & 370 \\
\hline & 51 & September 4 & 210 & \\
\hline & & & & 120 \\
\hline & 52 & September 4 & 148 & \\
\hline & & & & 540 \\
\hline & 53 & September 4 & 660 & \\
\hline & & & & 300 \\
\hline & 54 & September 4 & 290 & \\
\hline & & & & 282 \\
\hline & 55 & September 4 & 720 & \\
\hline & & & & 192 \\
\hline & 56 & September 4 & 480 & \\
\hline & & & & 180 \\
\hline & 57 & September 4 & 510 & \\
\hline & & & & 515 \\
\hline & 58 & September 4 & 37 & \\
\hline
\end{tabular}

Figure 6.1 illustrates the frequency distribution of the flash duration of all 58 flashes recorded over the last five years (Table 6.1). The figure shows that $76 \%$ of flashes have flash 
durations within $400 \mathrm{~ms}$ and $24 \%$ of flashes have flash durations within the range $400 \mathrm{~ms}-800$ ms. It's worth mentioning that the flash durations within $400 \mathrm{~ms}$ were found to be $85 \%$ in 2013, $77.8 \%$ in $2014,87.5 \%$ in $2015,71 \%$ in 2016 , and $63.6 \%$ in 2017 . The longest flash duration of $767 \mathrm{~ms}$, was received in 2014. However, the flashes with flash duration beyond $400 \mathrm{~ms}$ were $14.2 \%$ in $2013,22 \%$ in $2014,12.5 \%$ in $2015,28.5 \%$ in 2016 , and $36.4 \%$ in 2017.

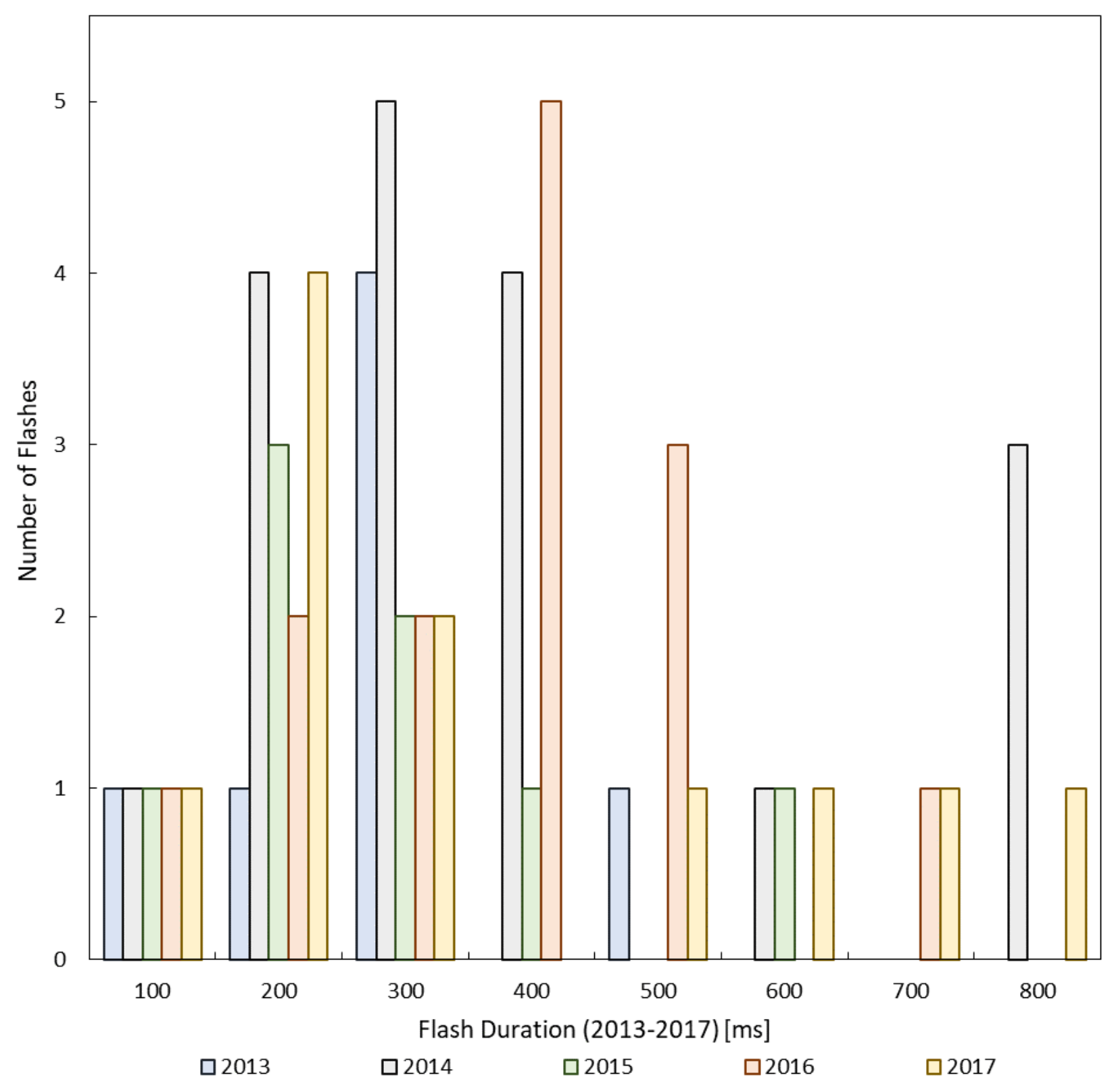

Figure 6.1 - Frequency distribution of flash durations (2013-2017). 
Figure 6.2 presents the cumulative probability of flash duration comprised by CN Tower flashes in each year, for comparison purpose. The cumulative probability distribution (CPD) of any flash parameter indicates the percentage of flashes having the parameter value equal to or higher than the specified value.

The longest flash duration of $767 \mathrm{~ms}$, was received in 2014, followed by 2017, which received the longest flash duration of $720 \mathrm{~ms}, 6.1 \%$ smaller flash duration as compared to 2014. Whereas, Figure 6.2 and Table 6.2 demonstrates that 50\% CPD of flashes received in 2017 had $28 \%$ longer flash duration as compared to 2014. Though, the average flash duration of 2014 is the largest out of all years, due to the highest number of flashes received.

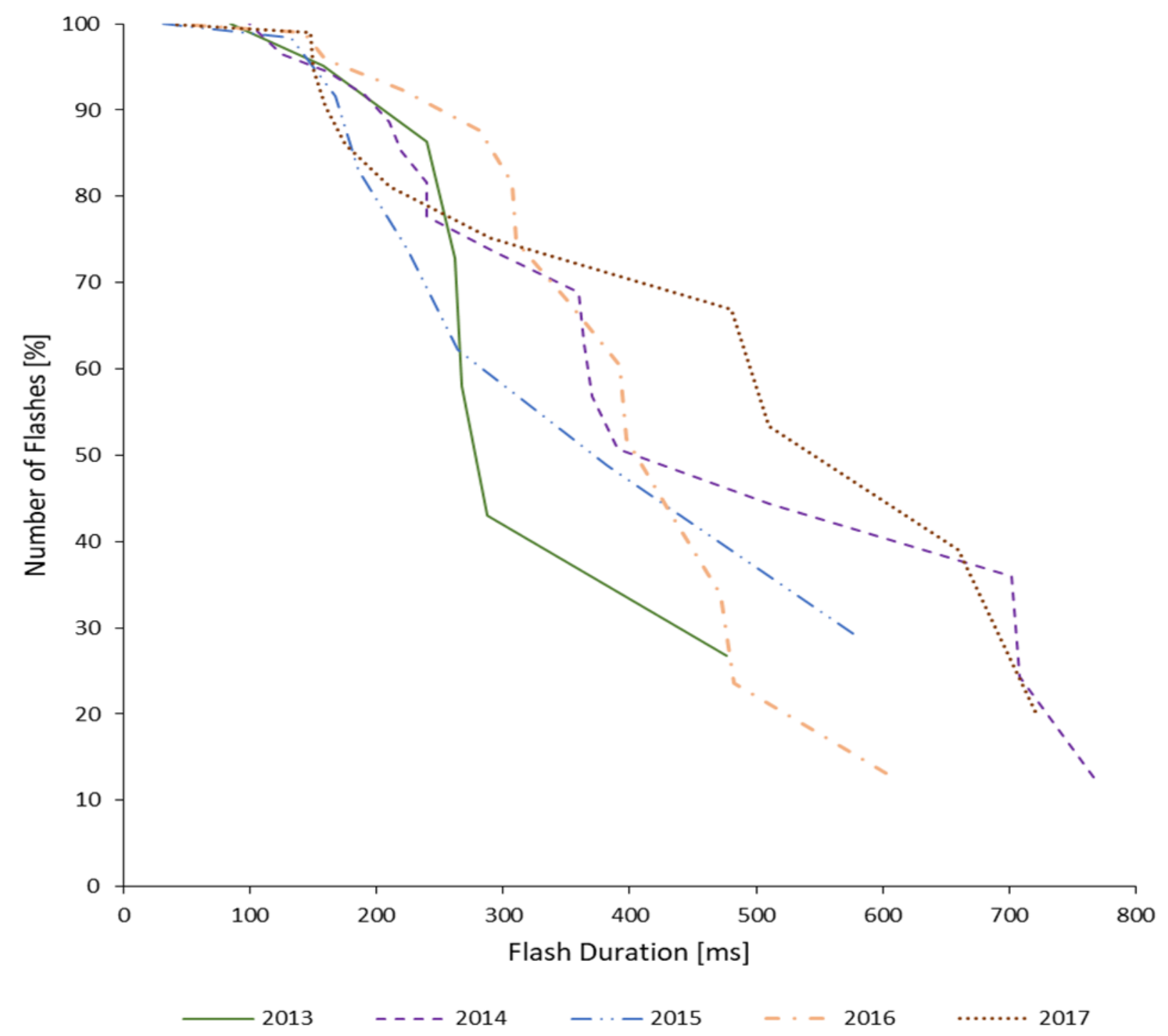

Figure 6.2 - Cumulative probability distribution of flash durations (2013-2017). 
Table 6.2 Statistics of flash durations based on video records (2013-2017).

\begin{tabular}{|c|c|c|c|c|c|}
\hline \multicolumn{6}{|c|}{ Flash Duration [ms] } \\
\hline & 2013 & 2014 & 2015 & 2016 & 2017 \\
\hline Minimum & 85 & 99 & 32 & 46 & 37 \\
\hline Maximum & 476 & 767 & 576 & 602 & 720 \\
\hline Mean & 253.57 & 336 & 245.37 & 328 & 321.82 \\
\hline $50 \%$ Probability & 252 & 355 & 250 & 390 & 495 \\
\hline Standard Deviation & 121.5 & 208 & 167.7 & 151 & 231 \\
\hline
\end{tabular}

It has also been noted that 2015 received the lowest number of flashes as compared to other years and interestingly also accounts for the lowest flash duration of $32 \mathrm{~ms}$, with lowest average flash duration and lowest 50\% CPD, respective to all other years.

Although, the 50\% probability based on the CPD of 2014 (355 ms) is 9\% shorter as compared to 2016 (390 ms), which is a slight difference. Also, the same pattern can be seen between the year 2013 and 2015, with almost 2013 ( $252 \mathrm{~ms}$ ) being on higher side with only $0.7 \%$ of the difference, with respect to 2015 (250 ms), which is making these years significantly having closer 50\% CPD.

\subsection{Inter-flash Time Duration (2013-2017)}

Inter-flash time duration is defined as the time difference between two subsequent flashes. The subsequent flashes with shorter inter-flash time durations pose a severe threat to tall structures. 
The data comprised of 44 inter-flash time intervals that proved to have the frequency distribution within the range of $80 \mathrm{~s}$ and $792 \mathrm{~s}$.

Figure 6.3 displays the frequency distribution of inter-flash time durations for flashes received in the last five years (Table 6.1). The figure demonstrates that $68 \%$ of inter-flash time intervals are within $400 \mathrm{~s}$ and $32 \%$ of inter flash time intervals are within the range of $400 \mathrm{~s}$ to 640 s, which can be further elaborated as, the inter-flash time intervals within $400 \mathrm{~s}$ were $75 \%$ in 2013, $33.3 \%$ in $2014,100 \%$ in $2015,60 \%$ in 2016 , and $80 \%$ in 2017 . Also, the inter-flash time intervals beyond 400 s were $25 \%$ in 2013, 66.6\% in 2014, 40\% in 2016, and $20 \%$ in 2017.

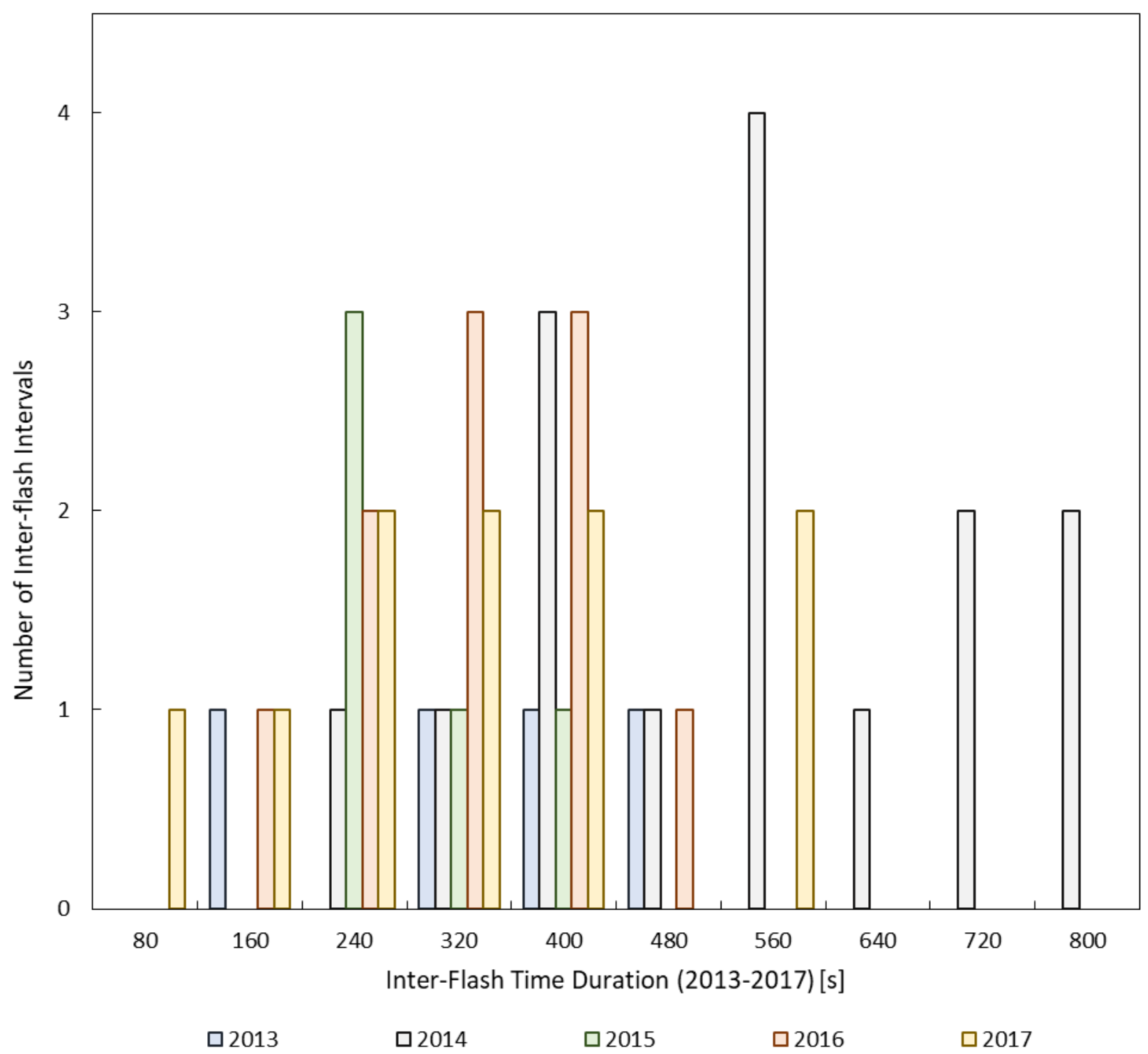

Figure 6.3 - Frequency distribution of inter-flash time duration (2013-2017). 
Figure 6.4 presents the CPD of inter-flash time duration comprised by CN Tower flashes in each year, for comparison purpose. The figure and Table 6.3 reveal that 2014 had the highest interflash time of $792 \mathrm{~s}$, and the largest average (502.5 s) and 50\% CPD (540 s) in contrast to other years.

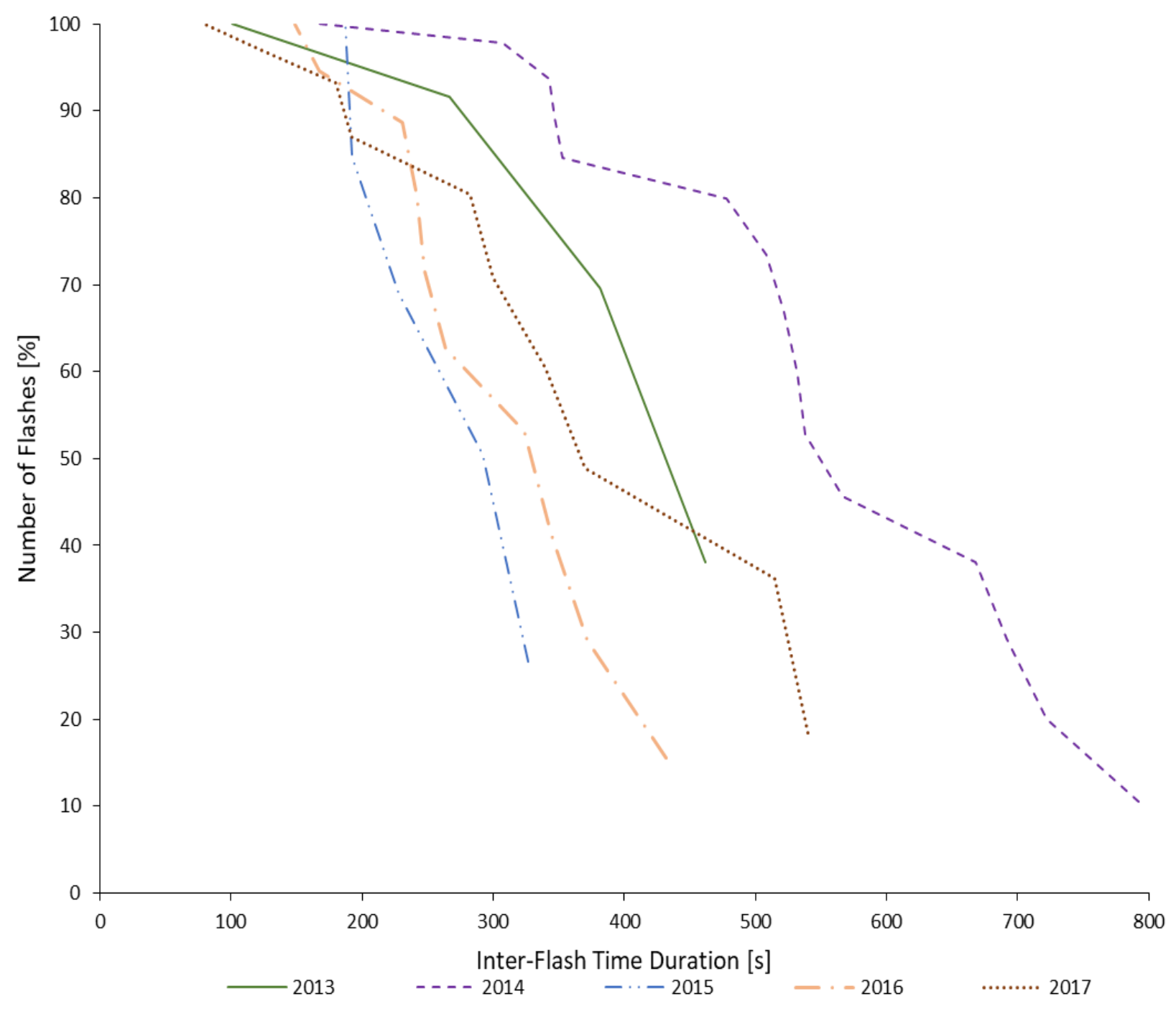

Figure 6.4 - Cumulative probability distribution of inter-flash time durations (2013-2017). 
Table 6.3 Statistics of inter-flash time duration based on video records (2013-2017).

\begin{tabular}{|c|c|c|c|c|c|}
\hline \multicolumn{7}{|c|}{ Inter-Flash Time [s] } \\
\hline & 2013 & 2014 & 2015 & 2016 & 2017 \\
\hline Minimum & 101 & 168 & 187 & 149 & 80 \\
\hline Maximum & 462 & 792 & 327 & 432 & 540 \\
\hline Mean & 303 & 502.5 & 245.2 & 277.3 & 291.9 \\
\hline 50\% Probability & 384 & 540 & 243 & 306 & 345 \\
\hline Standard Deviation & 156.7 & 174.6 & 62 & 89.8 & 155 \\
\hline
\end{tabular}

For comparison, it's also noted that the minimum inter-flash time duration of 2014 (168 s), 2015 (187 s) and 2016 (149 s) was above 150 s. Whereas, 2013 (101 s) and 2017 (80 s) had minimum inter-flash time duration within $100 \mathrm{~s}$. The table also depicts that 2015 had lowest maximum inter-flash time, shortest overall average and lowest 50\% CPD, as compared to other years.

\subsection{Initial-Stage Current Duration (2013-2017)}

In case of the grounded tall objects, upward negative discharge is initiated by upward positive leaders from the top of the tall object. The initial-stage current (ISC) is established, as the upward positive leaders bridge the gap between the object and the negative charge source in the cloud and the ISC usually lasts for some hundreds of milliseconds. The upward leader and the initial stage current constitute the initial stage of an upward flash [3]. The flashes which contain 
long initial-stage current durations accounts for charge transfer for long time durations, which poses significant threat to the tall structures.

Table 6.4 Initial-stage current durations based on video records (2013-2017).

\begin{tabular}{|c|c|c|c|}
\hline \multicolumn{4}{|c|}{ Initial-Stage Current Duration [ms] } \\
\hline Year & Flash number & Date & Initial-Stage Current Duration [ms] \\
\hline \multirow[t]{7}{*}{2013} & 1 & July 8 & 85 \\
\hline & 2 & July 8 & 267 \\
\hline & 3 & July 8 & 158 \\
\hline & 4 & July 19 & 246 \\
\hline & 5 & July 19 & 228 \\
\hline & 6 & September 11 & 240 \\
\hline & 7 & September 11 & 182 \\
\hline \multirow[t]{18}{*}{2014} & 8 & July 7 & 240 \\
\hline & 9 & July 7 & 219 \\
\hline & 10 & July 7 & 111 \\
\hline & 11 & September 1 & 161 \\
\hline & 12 & September 1 & 125 \\
\hline & 13 & September 5 & 240 \\
\hline & 14 & September 5 & 191 \\
\hline & 15 & September 5 & 591 \\
\hline & 16 & September 5 & 291 \\
\hline & 17 & September 5 & 442 \\
\hline & 18 & September 5 & 260 \\
\hline & 19 & September 5 & 620 \\
\hline & 20 & September 5 & 390 \\
\hline & 21 & September 5 & 210 \\
\hline & 22 & September 5 & 293 \\
\hline & 23 & September 5 & 335 \\
\hline & 24 & September 5 & 360 \\
\hline & 25 & September 5 & 99 \\
\hline \multirow[t]{7}{*}{2015} & 26 & July 17 & 167 \\
\hline & 27 & July 17 & 225 \\
\hline & 28 & July 17 & 207 \\
\hline & 29 & September 8 & 132 \\
\hline & 30 & September 8 & 185 \\
\hline & 31 & September 12 & 198 \\
\hline & 32 & September 12 & 32 \\
\hline
\end{tabular}




\begin{tabular}{|c|c|c|c|}
\hline & 33 & September 12 & 218 \\
\hline \multirow[t]{14}{*}{2016} & 34 & July 14 & 316 \\
\hline & 35 & July 14 & 350 \\
\hline & 36 & July 14 & 324 \\
\hline & 37 & July 14 & 310 \\
\hline & 38 & July 25 & 189 \\
\hline & 39 & July 25 & 207 \\
\hline & 40 & July 25 & 178 \\
\hline & 41 & September 7 & 178 \\
\hline & 42 & September 7 & 198 \\
\hline & 43 & September 7 & 142 \\
\hline & 44 & September 9 & 198 \\
\hline & 45 & September 9 & 242 \\
\hline & 46 & September 9 & 46 \\
\hline & 47 & September 9 & 298 \\
\hline \multirow[t]{11}{*}{2017} & 48 & September 4 & 175 \\
\hline & 49 & September 4 & 160 \\
\hline & 50 & September 4 & 150 \\
\hline & 51 & September 4 & 210 \\
\hline & 52 & September 4 & 148 \\
\hline & 53 & September 4 & 513 \\
\hline & 54 & September 4 & 167 \\
\hline & 55 & September 4 & 293 \\
\hline & 56 & September 4 & 170 \\
\hline & 57 & September 4 & 289 \\
\hline & 58 & September 4 & 37 \\
\hline
\end{tabular}

It's worth mentioning that flash characteristics of 58 optically recorded flashes clearly showed that all flashes contained initial-stage current, confirming that all flashes to CN Tower were upward initiated. Figure 6.5 presents the frequency distribution of initial-stage current durations for 58 flashes received in the last five years (Table 6.4). The figure shows that overwhelming majority (93\%) of initial-stage current durations, are within $400 \mathrm{~ms}$ and $6.8 \%$ of initial-stage current durations are within the range of $400 \mathrm{~ms}$ and $700 \mathrm{~ms}$, which can be categorized as, the initial-stage current duration within 400 ms accounts for: 100\% in 2013, 83.3\% in 2014, $100 \%$ in $2015,100 \%$ in 2016 , and $91 \%$ in 2017. The ISC duration within the range of $400 \mathrm{~ms}$ and 700 ms counts as $16.7 \%$ in 2014 and $9 \%$ in 2017. 


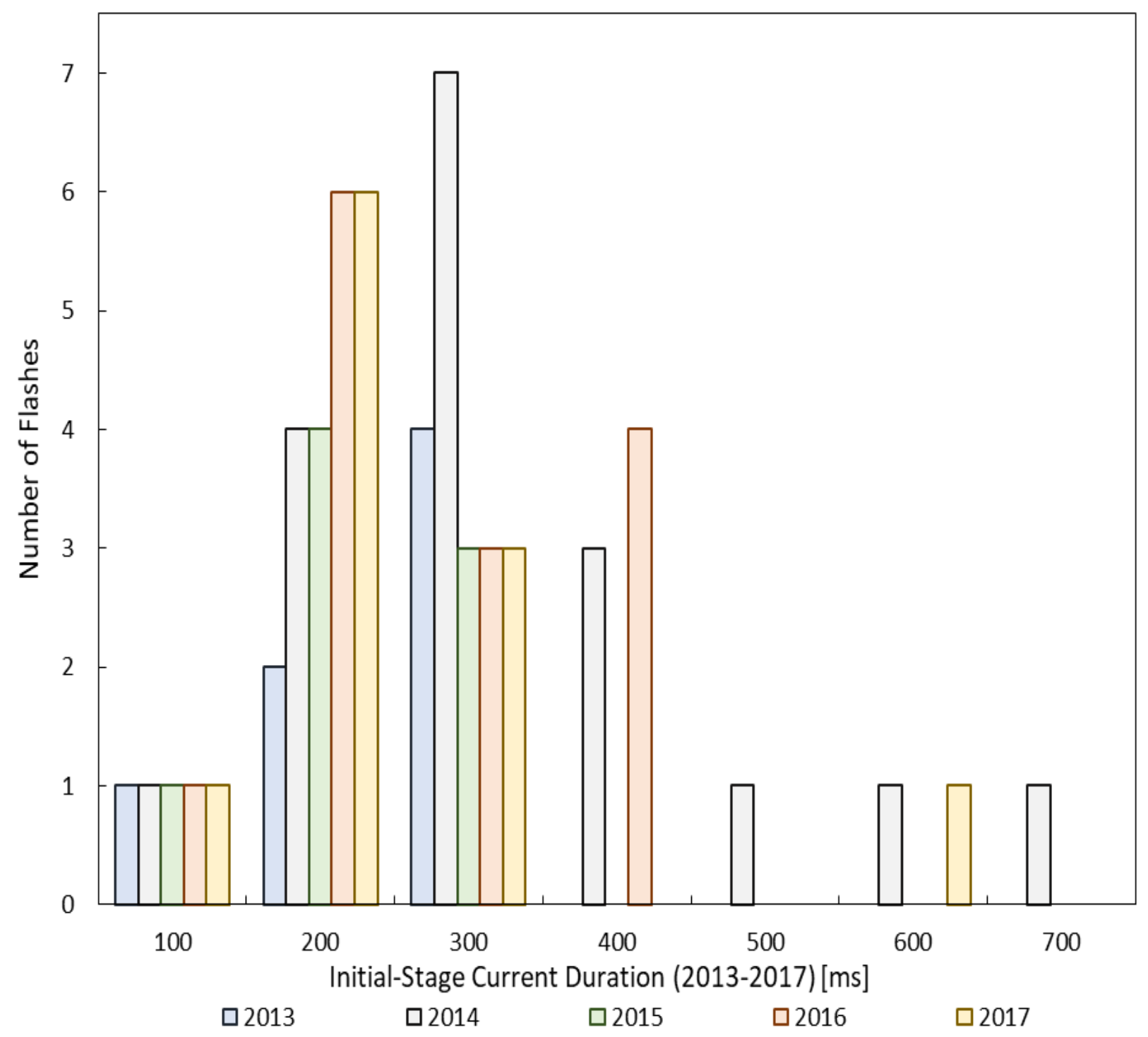

Figure 6.5 - Frequency distribution of initial-stage current durations (2013-2017).

Figure 6.6 presents the CPD of initial-stage current duration comprised by CN Tower flashes in each year, for comparison purpose. The figure and Table 6.5 clearly depict that year 2014 had minimum ISC duration of $99 \mathrm{~ms}$, an average ISC duration of $298 \mathrm{~ms}$ and 50\% CPD of $317 \mathrm{~ms}$, which clearly overweighs the other years. Though, ISC duration of 2015 varied between $32 \mathrm{~ms}$ and $225 \mathrm{~ms}$, with an overall average ISC duration of $170.5 \mathrm{~ms}$, reflecting the shortest minimum, maximum and average as compared to other years. 


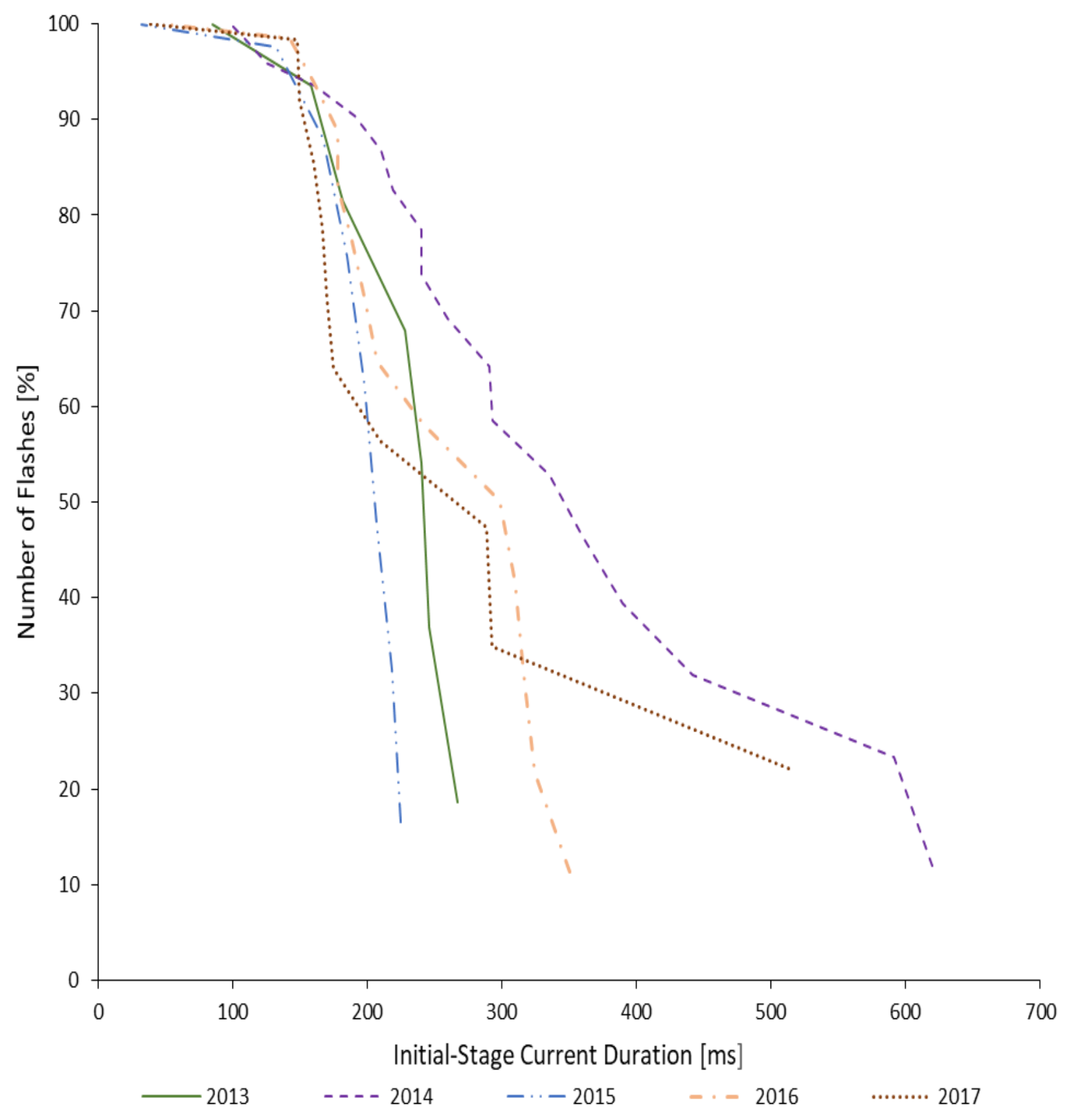

Figure 6.6 - Cumulative probability distribution of initial-stage current durations (2013-2017). 
Table 6.5 Statistics of initial-stage current durations based on video records (2013-2017).

\begin{tabular}{|c|c|c|c|c|c|}
\hline \multicolumn{7}{|c|}{ Initial-Stage Current Duration [ms] } \\
\hline & 2013 & 2014 & 2015 & 2016 & 2017 \\
\hline Minimum & 85 & 99 & 32 & 46 & 37 \\
\hline Maximum & 267 & 620 & 225 & 350 & 513 \\
\hline Mean & 200.6 & 288 & 170.5 & 224 & 210 \\
\hline 50\% Probability & 258 & 317 & 199 & 254 & 181 \\
\hline Standard Deviation & 63.6 & 149 & 63.5 & 86.14 & 122 \\
\hline
\end{tabular}

For comparison, it's worth mentioning that the maximum ISC duration of 2017 (513 ms) is $17 \%$ shorter as compared to the 2014 (620 ms) ISC duration, making it longest as compared to all other years. Also, maximum ISC duration of 2013 (267 ms) is 15.7\% longer than 2015 (225 ms) maximum ISC duration.

Based on the cumulative probability distribution (Figure 6.6), the 50\% CPD for the year 2015 (199 ms) is only 9\% longer than 2017 (181 ms), with 2014 (317 ms) ISC duration leading all other years. It's worth mentioning that 50\% CPD of ISC duration of 2013 (258 ms) and 2016 (254 ms) are close to each other. 


\subsection{Flash Multiplicity (2013-2017)}

During the last five years, $\mathrm{CN}$ Tower was struck 58 times, which was simultaneously recorded by two imaging systems. Out of 58 flashes received, only 27 (46.5\%) flashes contained a single or multiple return strokes. Flash multiplicity is defined as a number of return strokes per flash. More number of return strokes per flash can cause more damage, increasing the electromagnetic radiation in the area which causes interference in the electronic and communication systems. Table 6.6 demonstrates the detailed description of flash multiplicity and inter-stroke time duration for flashes received in the last five years.

Table 6.6 Flash multiplicity and inter-stroke time duration based on video records (2013-2017).

\begin{tabular}{|c|c|c|c|c|}
\hline \multicolumn{5}{|c|}{ Flash Multiplicity and Inter-stroke Time [ms] (2013-2017) } \\
\hline Year & Flash number & Date & Flash Multiplicity & Inter-Stroke Time Duration [ms] \\
\hline \multirow[t]{9}{*}{2013} & 1 & July 8 & - & - \\
\hline & 2 & July 8 & 1 & - \\
\hline & 3 & July 8 & - & - \\
\hline & 4 & July 19 & 1 & - \\
\hline & 5 & July 19 & 4 & 34 \\
\hline & & & & 58 \\
\hline & & & & 92 \\
\hline & 6 & September 11 & - & - \\
\hline & 7 & September 11 & 2 & 47 \\
\hline \multirow[t]{11}{*}{2014} & 8 & July 7 & - & - \\
\hline & 9 & July 7 & - & - \\
\hline & 10 & July 7 & - & - \\
\hline & 11 & September 1 & - & - \\
\hline & 12 & September 1 & - & - \\
\hline & 13 & September 5 & - & - \\
\hline & 14 & September 5 & - & - \\
\hline & 15 & September 5 & 1 & - \\
\hline & 16 & September 5 & 1 & - \\
\hline & 17 & September 5 & 3 & 110 \\
\hline & & & & 25 \\
\hline
\end{tabular}




\begin{tabular}{|c|c|c|c|c|}
\hline & 18 & September 5 & 2 & 126 \\
\hline & 19 & September 5 & 2 & 64 \\
\hline & 20 & September 5 & - & - \\
\hline & 21 & September 5 & - & - \\
\hline & 22 & September 5 & - & - \\
\hline & 23 & September 5 & 1 & - \\
\hline & 24 & September 5 & - & - \\
\hline & 25 & September 5 & - & - \\
\hline \multirow[t]{11}{*}{2015} & 26 & July 17 & - & - \\
\hline & 27 & July 17 & - & - \\
\hline & 28 & July 17 & 1 & - \\
\hline & 29 & September 8 & - & - \\
\hline & 30 & September 8 & - & - \\
\hline & 31 & September 12 & 5 & 29 \\
\hline & & & & 38 \\
\hline & & & & 56 \\
\hline & & & & 47 \\
\hline & 32 & September 12 & - & - \\
\hline & 33 & September 12 & 1 & - \\
\hline \multirow[t]{21}{*}{2016} & 34 & July 14 & 1 & - \\
\hline & 35 & July 14 & - & - \\
\hline & 36 & July 14 & 2 & 114 \\
\hline & 37 & July 14 & - & - \\
\hline & 38 & July 25 & 1 & - \\
\hline & 39 & July 25 & 3 & 92 \\
\hline & & & & 85 \\
\hline & 40 & July 25 & 9 & 18 \\
\hline & & & & 84 \\
\hline & & & & 14 \\
\hline & & & & 72 \\
\hline & & & & 22 \\
\hline & & & & 12 \\
\hline & & & & 20 \\
\hline & 41 & September 7 & 1 & - \\
\hline & 42 & September 7 & - & - \\
\hline & 43 & September 7 & - & - \\
\hline & 44 & September 9 & 1 & - \\
\hline & 45 & September 9 & 1 & - \\
\hline & 46 & September 9 & - & - \\
\hline & 47 & September 9 & 2 & 86 \\
\hline & & & & \\
\hline
\end{tabular}




\begin{tabular}{|l|l|l|l|c|}
\hline 2017 & 48 & September 4 & - & - \\
\hline & 49 & September 4 & - & - \\
\hline & 50 & September 4 & - & - \\
\hline & 51 & September 4 & - & - \\
\hline & 52 & September 4 & - & - \\
\hline & 53 & September 4 & 1 & - \\
\hline & 54 & September 4 & 1 & - \\
\hline & 55 & September 4 & 4 & 102 \\
\hline & & & & 58 \\
\hline & & & & 79 \\
\hline & 56 & September 4 & 2 & 49 \\
\hline & 57 & September 4 & 2 & - \\
\hline
\end{tabular}

Figure 6.7 presents the frequency distribution of all 27 flashes containing return strokes (Table 6.6). It can be clearly depicted from the figure that $77.8 \%$ of flashes contained one to two return strokes, $14.8 \%$ of flashes contained three to four return strokes and $7.4 \%$ of flashes constituted 5 to 9 return strokes, which can be categorized as 2013 - 75\% of flashes comprised one to two return strokes and $25 \%$ of flashes contained four return strokes, $2014-83.3 \%$ of flashes included one to two return strokes and $16.67 \%$ of flashes contained three to four return strokes, $2015-66.6 \%$ of flashes constituted one return stroke and $33.3 \%$ of flashes constituted five return strokes, $2016-77.7 \%$ of flashes comprised one to two return strokes and $22.2 \%$ of flashes contained three to nine return strokes, 2017 - $40 \%$ of flashes contained 1 to 2 return strokes and $20 \%$ of flashes contained four return strokes. 


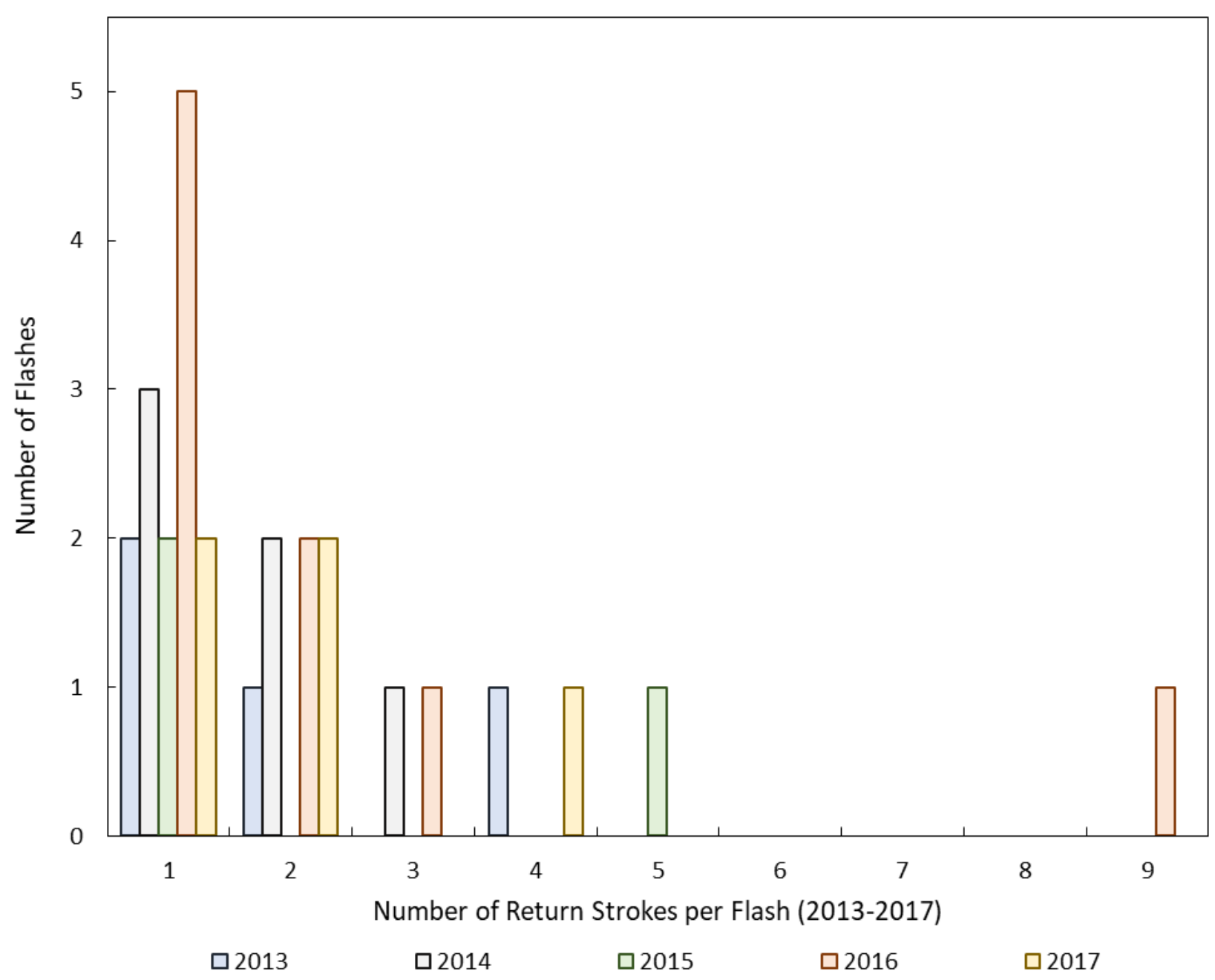

Figure 6.7 - Frequency distribution of flash multiplicity (2013- 2017).

Figure 6.8 illustrates the CPD of flash multiplicity comprised by CN Tower flashes in each year, for comparison purpose. The figure and Table 6.7 reveal that every year had at least one return stroke per flash. However, 2016 accounts for a maximum of nine return strokes, which is more in contrast with 2015, having only five return strokes as maximum, and 2013 and 2017 with a maximum of four return strokes each. 


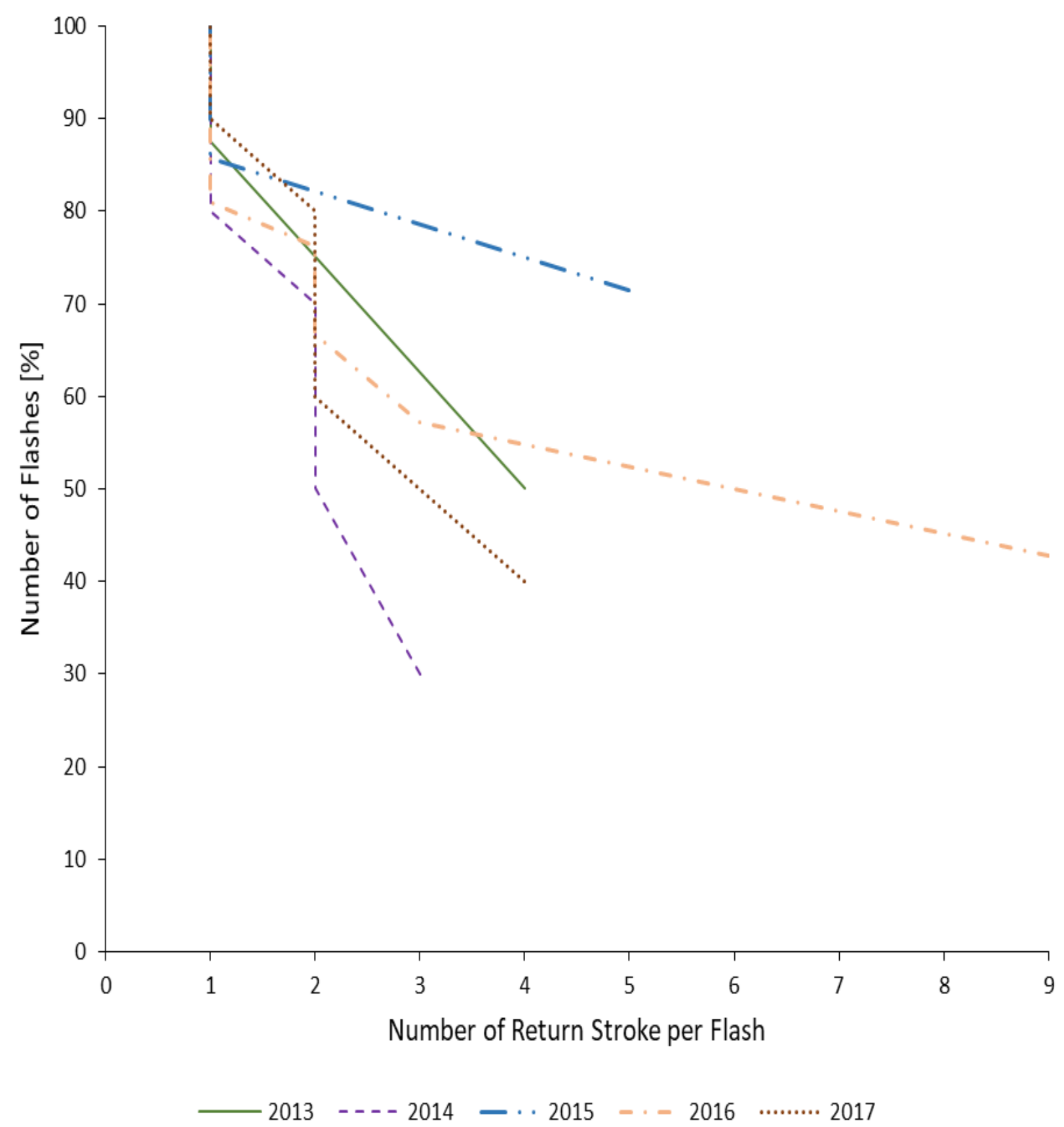

Figure 6.8 - Cumulative probability distribution of flash multiplicity (2013-2017). 
Table 6.7 Statistics of flash multiplicity for 27 flashes based on video records (2013-2017).

\begin{tabular}{|c|c|c|c|c|c|}
\hline \multicolumn{7}{|c|}{ Flash Multiplicity } \\
\hline & 2013 & 2014 & 2015 & 2016 & 2017 \\
\hline Minimum & 1 & 1 & 1 & 1 & 1 \\
\hline Maximum & 4 & 3 & 5 & 9 & 4 \\
\hline Mean & 2 & 1.67 & 2.33 & 2.33 & 2 \\
\hline $50 \%$ Probability & 2 & 2 & 1 & 2 & 2 \\
\hline Standard Deviation & 1.4 & 0.8 & 2.3 & 2.6 & 1.2 \\
\hline
\end{tabular}

For comparison, it's worth mentioning that the year 2016 had an overall average multiplicity of 2.33 , which is precisely similar to the average multiplicity of 2015 . Whereas, the other three years (2013, 2014 and 2017) had 18.9\% less average flash multiplicity.

It can also be noted from Figure 6.8 that 50\% CPD of 2015 is shortest as it's 50\% smaller than that of 2013, 2014, 2016 and 2017.

\subsection{Inter-Stroke Time Duration (2013-2017)}

The inter-stroke time (IST) duration is the time difference between the successive return strokes, comprised by multi-stroke flashes. The flashes with short time duration within successive return strokes poses more threat to tall structures. Figure 6.9 presents the frequency distribution of inter-stroke time durations for flashes received in the last five years (Table 6.6). The figure and Table 6.6 shows that data set of the last five years comprised 13 (22.4\%) multi-stroke flashes, containing 28 inter-stroke intervals. Furthermore, it was observed that the inter-stroke duration 
lied within the range of $12 \mathrm{~ms}$ and $126 \mathrm{~ms}$, with an overall average of $62.51 \mathrm{~ms}$. It's worth mentioning that $85 \%$ of IST duration lied within $100 \mathrm{~ms}$ and $14.2 \%$ of the total IST comprised duration ranging from $100 \mathrm{~ms}$ to $126 \mathrm{~ms}$, which can be summarized as the inter-stroke time duration within $60 \mathrm{~ms}$ were $75 \%$ in 2013, $50 \%$ in $2014,100 \%$ in 2015, $45 \%$ in 2016, and $40 \%$ in 2017. The inter-stroke time duration beyond $60 \mathrm{~ms}$ were $25 \%$ in $2013,50 \%$ in $2014,54.5 \%$ in 2016, and 60\% in 2017.

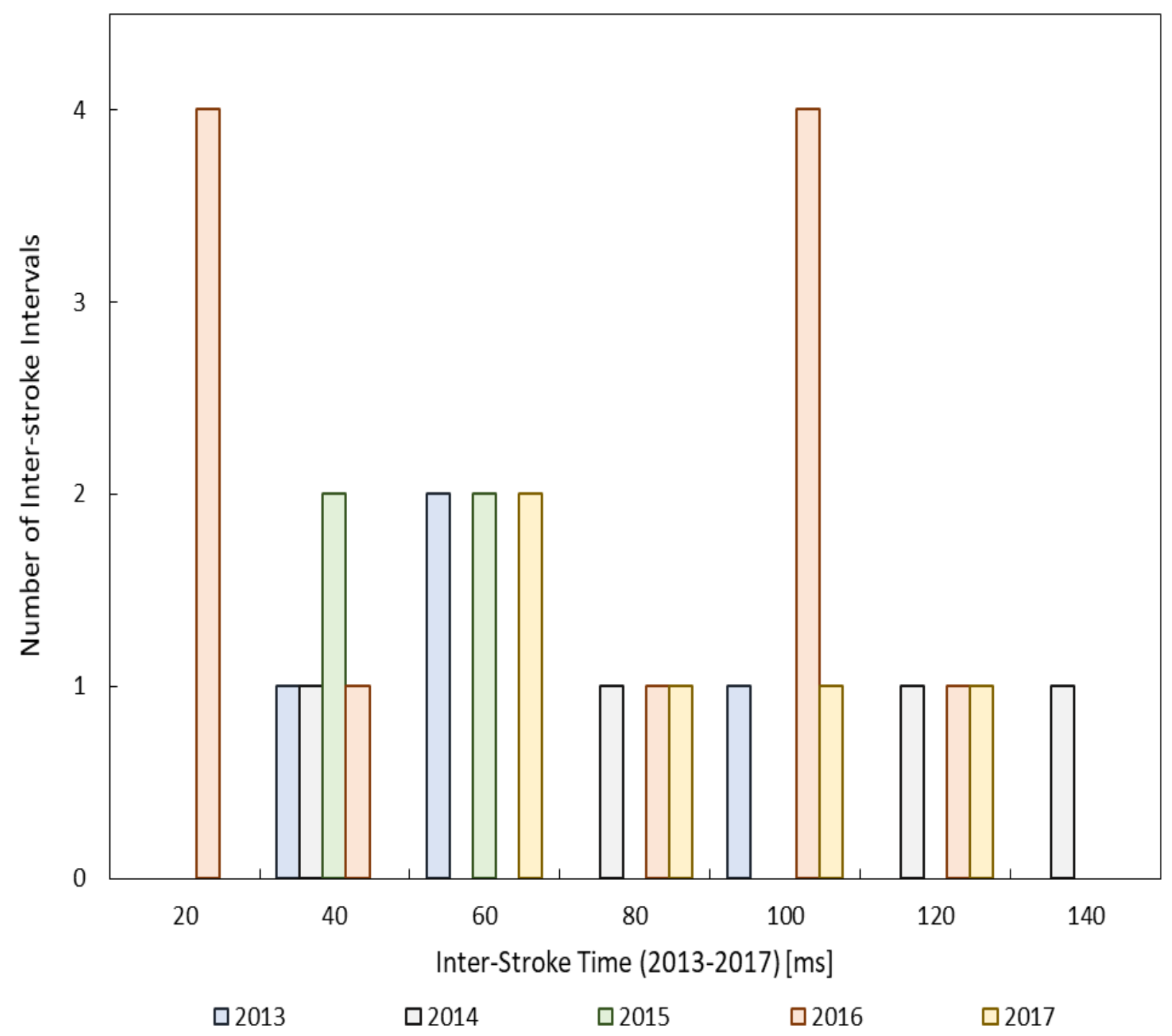

Figure 6.9 - Frequency distribution of inter-stroke time duration (2013-2017). 
Figure 6.10 illustrates the cumulative probability of inter-stroke time duration comprised by $\mathrm{CN}$ Tower flashes in the last five years, for comparison purpose. The figure and Table 6.8 demonstrate that the minimum inter-stroke time duration of previous five years varied between 12 $\mathrm{ms}$ and $49 \mathrm{~ms}$. However, the maximum inter-stroke time duration during the last five years ranged from $56 \mathrm{~ms}$ to $126 \mathrm{~ms}$.

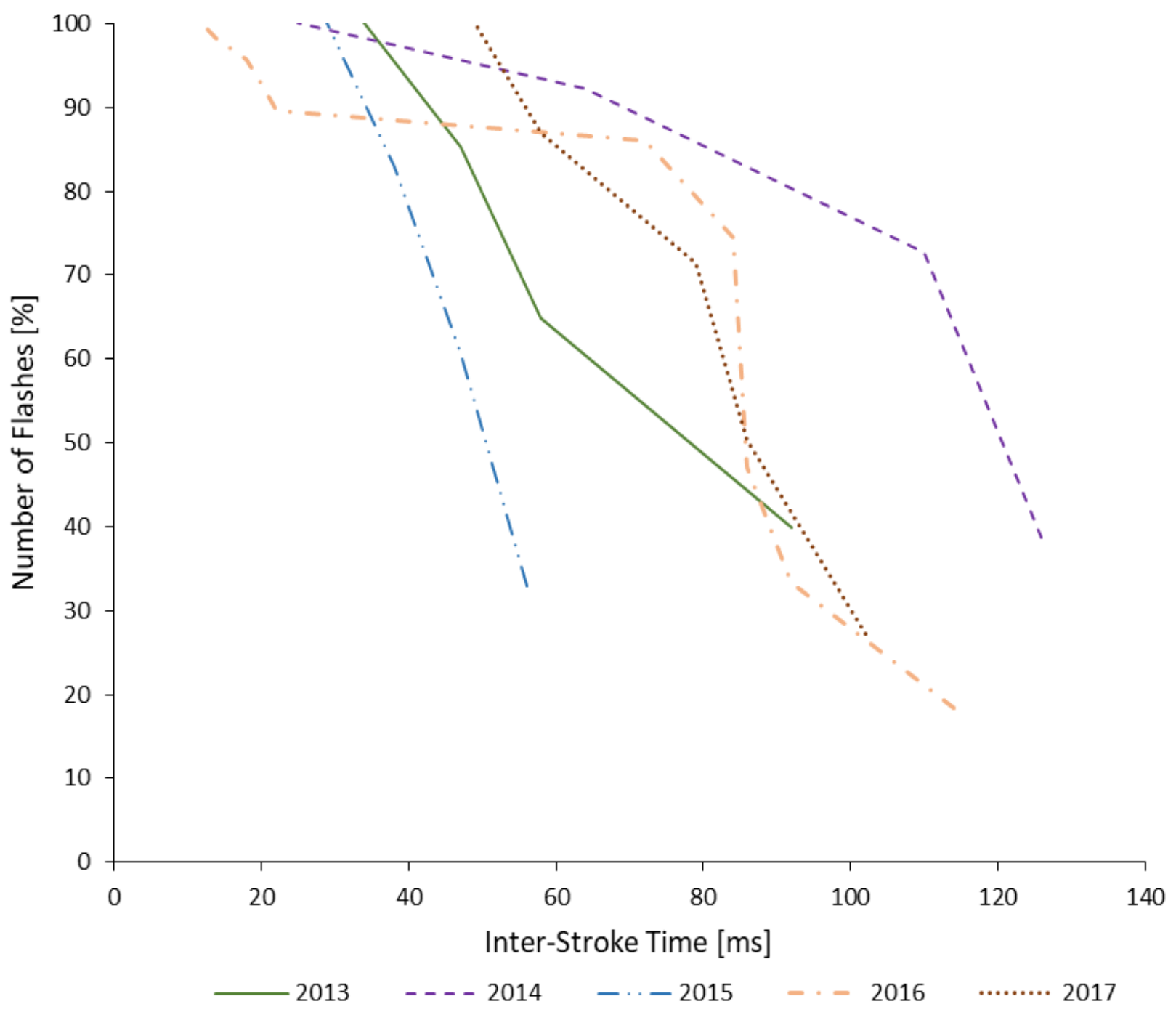

Figure 6.10 - Cumulative probability distribution of inter-stroke time (2013-2017). 
Table 6.8 Statistics of inter-stroke time durations based on video records (2013-2017).

\begin{tabular}{|c|c|c|c|c|c|}
\hline \multicolumn{7}{|c|}{ Inter-Stroke Time [ms] } \\
\hline & 2013 & 2014 & 2015 & 2016 & 2017 \\
\hline Minimum & 34 & 25 & 29 & 12 & 49 \\
\hline Maximum & 92 & 126 & 56 & 114 & 102 \\
\hline Mean & 57.75 & 81.25 & 42.5 & 56.27 & 74.8 \\
\hline 50\% Probability & 56 & 112 & 44 & 86 & 21.4 \\
\hline Standard Deviation & 24.8 & 45.8 & 11.6 & 38.8 & \\
\hline
\end{tabular}

It's also noted that all years (2013-2017) had an inter-stroke time interval within 126 ms. For comparison, it's observed that the average inter-stroke time durations for flashes received in $2014(81.25 \mathrm{~ms})$ was leading and 7.9\% longer as compared to the inter-stroke time average of 2017 (74.8 ms). Also, the inter-stroke time averages of $2013(57.75 \mathrm{~ms})$ and $2016(56.27 \mathrm{~ms})$ are almost close, with 2013 being $2.13 \%$ longer.

The cumulative probability distribution (Figure 6.10) demonstrates that a 50\% CPD of interstroke time duration for $2014(112 \mathrm{~ms})$ is only among other years, which is above $100 \mathrm{~ms}$. Whereas, 50\% CPD of 2015 (44 ms) which is the lowest among all other years (below $50 \mathrm{~ms}$ ).

\subsection{Continuing Current Duration (2013-2017)}

Continuing current is defined as the relatively low-level current of typically tens to hundreds of amperes that immediately follows a return stroke, in the same channel to ground, and usually lasts for tens to hundreds of milliseconds [3]. Table 6.9 demonstrates the detailed description of 
the continuing current contained by flashes received in the last five years. The continuing currents with longer time durations pose severe threat to the tall structures, and electrical and communication systems as the flow of steady amount of current for continuous duration of the time cause heating effects that could melt or damage the resistive equipment's.

Table 6.9 Continuing current time durations based on video records (2013-2017).

\begin{tabular}{|c|c|c|c|}
\hline \multicolumn{4}{|c|}{ Continuing Current Duration (2013-2017) [ms] } \\
\hline Year & Flash number & Date & Continuing Current [ms] \\
\hline 2013 & 1 & July 8 & - \\
\hline & 2 & July 8 & - \\
\hline & 3 & July 8 & - \\
\hline & 4 & July 19 & 12 \\
\hline & 5 & July 19 & 52 \\
\hline & 6 & September 11 & - \\
\hline & 7 & September 11 & 24 \\
\hline & & & 14 \\
\hline 2014 & 8 & July 7 & - \\
\hline & 9 & July 7 & - \\
\hline & 10 & July 7 & - \\
\hline & 11 & September 1 & - \\
\hline & 12 & September 1 & - \\
\hline & 13 & September 5 & - \\
\hline & 14 & September 5 & - \\
\hline & 15 & September 5 & 156 \\
\hline & 16 & September 5 & 79 \\
\hline & 17 & September 5 & 68 \\
\hline & & & 12 \\
\hline & & & 45 \\
\hline & 18 & September 5 & 120 \\
\hline & & & 72 \\
\hline & 19 & September 5 & 24 \\
\hline & 20 & September 5 & - \\
\hline & 21 & September 5 & - \\
\hline & 22 & September 5 & - \\
\hline & 23 & September 5 & 16 \\
\hline & 24 & September 5 & - \\
\hline & 25 & September 5 & - \\
\hline 2015 & 26 & July 17 & - \\
\hline
\end{tabular}




\begin{tabular}{|c|c|c|c|}
\hline & 27 & July 17 & - \\
\hline & 28 & July 17 & 62 \\
\hline & 29 & September 8 & - \\
\hline & 30 & September 8 & - \\
\hline & 31 & September 12 & 119 \\
\hline & & & 87 \\
\hline & 32 & September 12 & - \\
\hline & 33 & September 12 & - \\
\hline \multirow{15}{*}{2016} & 34 & Julv 14 & 32 \\
\hline & 35 & July 14 & - \\
\hline & 36 & July 14 & 97 \\
\hline & & & 48 \\
\hline & 37 & July 14 & - \\
\hline & 38 & July 25 & - \\
\hline & 39 & July 25 & 68 \\
\hline & 40 & July 25 & - \\
\hline & 41 & September 7 & - \\
\hline & 42 & September 7 & - \\
\hline & 43 & September 7 & - \\
\hline & 44 & September 9 & - \\
\hline & 45 & September 9 & - \\
\hline & 46 & September 9 & - \\
\hline & 47 & September 9 & 38 \\
\hline \multirow[t]{12}{*}{2017} & 48 & September 4 & - \\
\hline & 49 & September 4 & - \\
\hline & 50 & September 4 & - \\
\hline & 51 & September 4 & - \\
\hline & 52 & September 4 & - \\
\hline & 53 & September 4 & - \\
\hline & 54 & September 4 & 62 \\
\hline & 55 & September 4 & 67 \\
\hline & & & 114 \\
\hline & 56 & September 4 & - \\
\hline & 57 & September 4 & 33 \\
\hline & 58 & September 4 & - \\
\hline
\end{tabular}

Table 6.9 revealed that continuing currents followed 25 out of $56(45 \%)$ return strokes. Furthermore, $66.6 \%$ of flashes containing return strokes had return strokes followed by continuing currents, and $46 \%$ of multi-stroke flashes contained multiple strokes followed by continuing 
currents. Figure 6.11 presents the frequency distribution of continuing current time durations for flashes received in the last five years (Table 6.9). The figure and Table 6.9 demonstrate that $76 \%$ of flashes contained continuing currents within $80 \mathrm{~ms}$ and $24 \%$ of flashes comprised continuing currents within the range of $80 \mathrm{~ms}$ and $160 \mathrm{~ms}$, which can be further elaborated as, flashes with continuing current duration within $80 \mathrm{~ms}$ : $100 \%$ in $2013,77.7 \%$ in $2014,33.3 \%$ in $2015,8 \%$ in 2016, and 75\% in 2017. Also, flashes that contained the continuing current beyond $80 \mathrm{~ms}$, can be categorized as: $22.2 \%$ in $2014,66.6 \%$ in $2015,20 \%$ in 2016, and $25 \%$ in 2017.

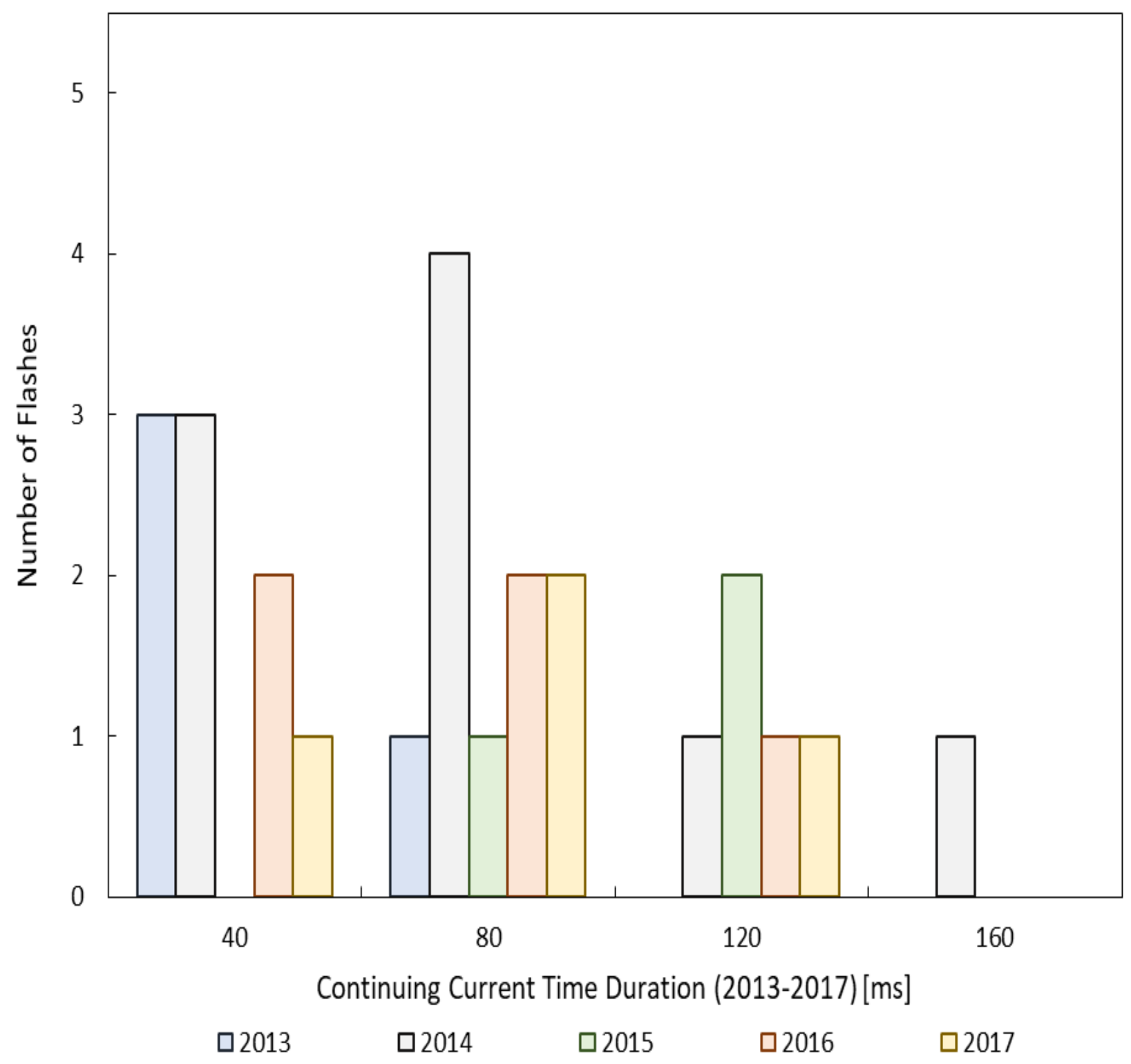

Figure 6.11 - Frequency distribution of continuing current time duration (2013-2017). 
Figure 6.12 illustrates the $\mathrm{CPD}$ of continuing current time duration comprised by $\mathrm{CN}$ Tower flashes in the last five years, for comparison purpose. The figure and Table 6.10 reveal that 2013 and 2014 had minimum continuing current duration of $12 \mathrm{~ms}$. Interestingly 2014 had the most extended continuing current duration of $156 \mathrm{~ms}$, leading all other years, those had maximum lying within $97 \mathrm{~ms}$ and $119 \mathrm{~ms}$.

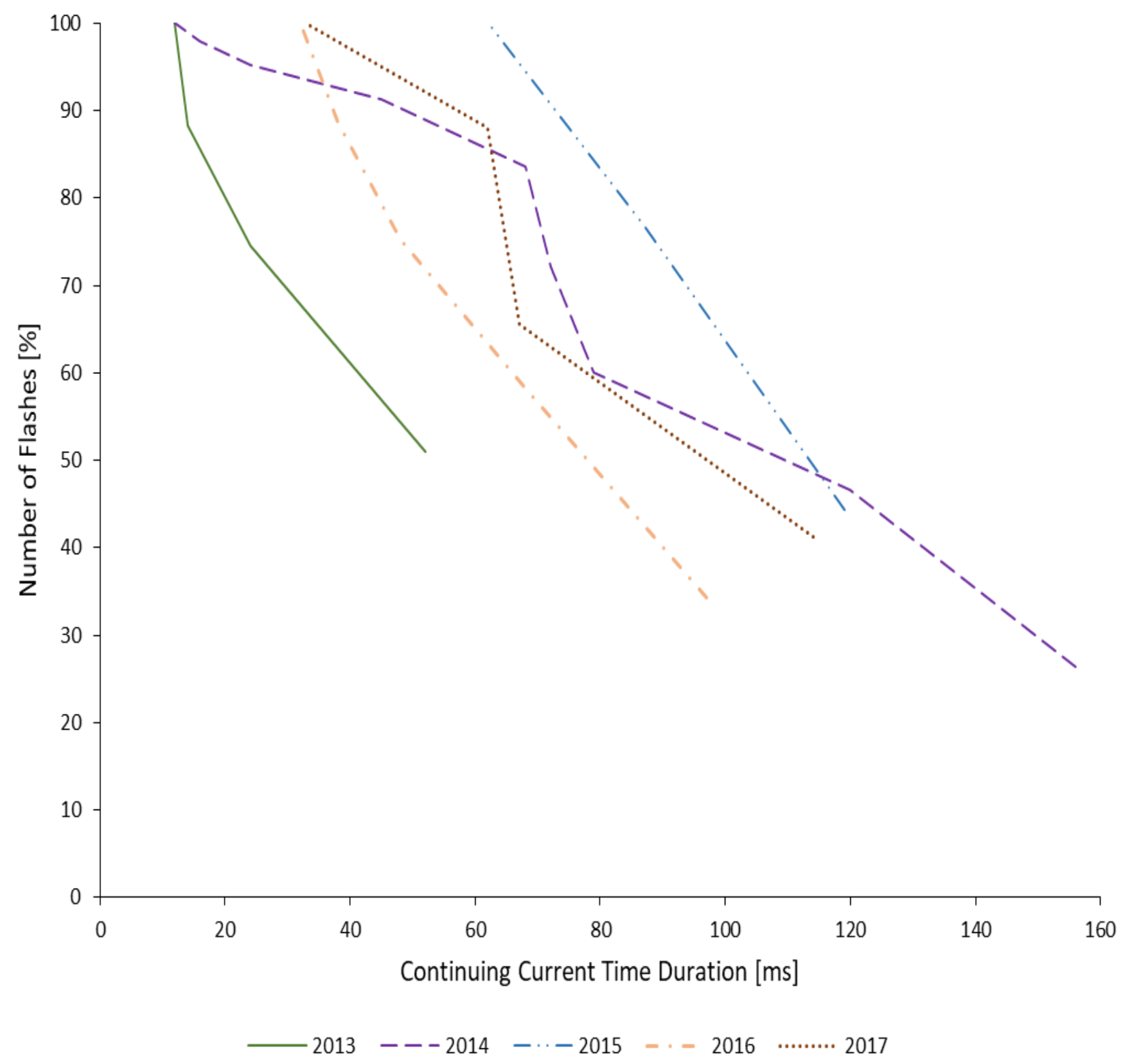

Figure 6.12 - Cumulative probability distribution of continuing current time duration (20132017). 
Table 6.10 Statistics of continuing current time durations based on video records (2013-2017).

\begin{tabular}{|c|c|c|c|c|c|}
\hline \multicolumn{7}{|c|}{ Continuing Current Time Duration [ms] } \\
\hline & 2013 & 2014 & 2015 & 2016 & 2017 \\
\hline Minimum & 12 & 12 & 62 & 32 & 33 \\
\hline Maximum & 52 & 156 & 119 & 97 & 114 \\
\hline Mean & 25 & 65.8 & 89.3 & 56.6 & 69 \\
\hline 50\% Probability & 22 & 76 & 89 & 58 & 66 \\
\hline Standard Deviation & 18.43 & 48.5 & 28.6 & 26 & 33.5 \\
\hline
\end{tabular}

The average continuing current duration of 2015 is $89.3 \mathrm{~ms}$, due to a small number of flashes received in that year, comprising longest time duration of continuing currents, which is on average $39 \%$ longer as compared to other years.

It's worth mentioning that 2013 comprised lowest average continuing current duration of $25 \mathrm{~ms}$, due to the short continuing current durations contained by all flashes received in that year (below $80 \mathrm{~ms}$ ).

\subsection{Comparison of CN Tower Major Storms}

During the night of September 5, 2014, the CN Tower imaging systems recorded 13 flashes, with average flash duration of $399 \mathrm{~ms}$. The storm started at 20:09:20 pm and lasted for $111.4 \mathrm{mins}$, and produced on an average a flash to tower every $556 \mathrm{~s}$. It's worth mentioning that all 13 flashes comprised initial-stage current with an average duration of $332 \mathrm{~ms}$. Also, 6 out of 13 flashes (46\%) contained return strokes, with an average multiplicity of 1.67 . 
Similarly, during the night of September 4, 2017, there was another storm at the CN Tower, captured by two imaging systems. The storm started at 20:14:58 pm and lasted for 49.35 mins. The storm comprised 11 flashes, with an average flash duration of $321.8 \mathrm{~ms}$, and produced on average a flash to tower every 291.9 s. It's worth mentioning that 5 out of 11 flashes (45\%) contained return strokes, with an average multiplicity of 2 . Also, all 11 flashes received during the storm contained initial-stage current with an average duration of $210 \mathrm{~ms}$.

Based on both imaging system records, the statistical analyses of significant storms were conducted, and also the flash parameters namely flash duration, inter-flash time duration, initialstage current duration, flash multiplicity, inter-stroke time duration, and continuing current duration are derived. The comparison of storms is conducted to obtain a better insight into the characteristics and to find various major differences between there flash parameters.

\subsubsection{Flash Duration}

Based on the analyses of 13 flashes recorded during 2014 storm and 11 flashes recorded during 2017 storm, by the two imaging systems, the flash time durations of flashes received during 2014 storm is found to vary between $99 \mathrm{~ms}$ and $767 \mathrm{~ms}$. Whereas, the flash time durations of flashes received during 2017 storm is observed to vary between $37 \mathrm{~ms}$ and $720 \mathrm{~ms}$.

Figure 6.13 presents the frequency distribution of flash time durations. The figure shows that the flash durations within $400 \mathrm{~ms}$ can be categorized as $69.2 \%$ in case of 2014 storm and $63.6 \%$ during 2017 storm. Furthermore, the flashes with the flash duration beyond $400 \mathrm{~ms}$ were $30.7 \%$ in 2014 and $36.3 \%$ in 2017. 


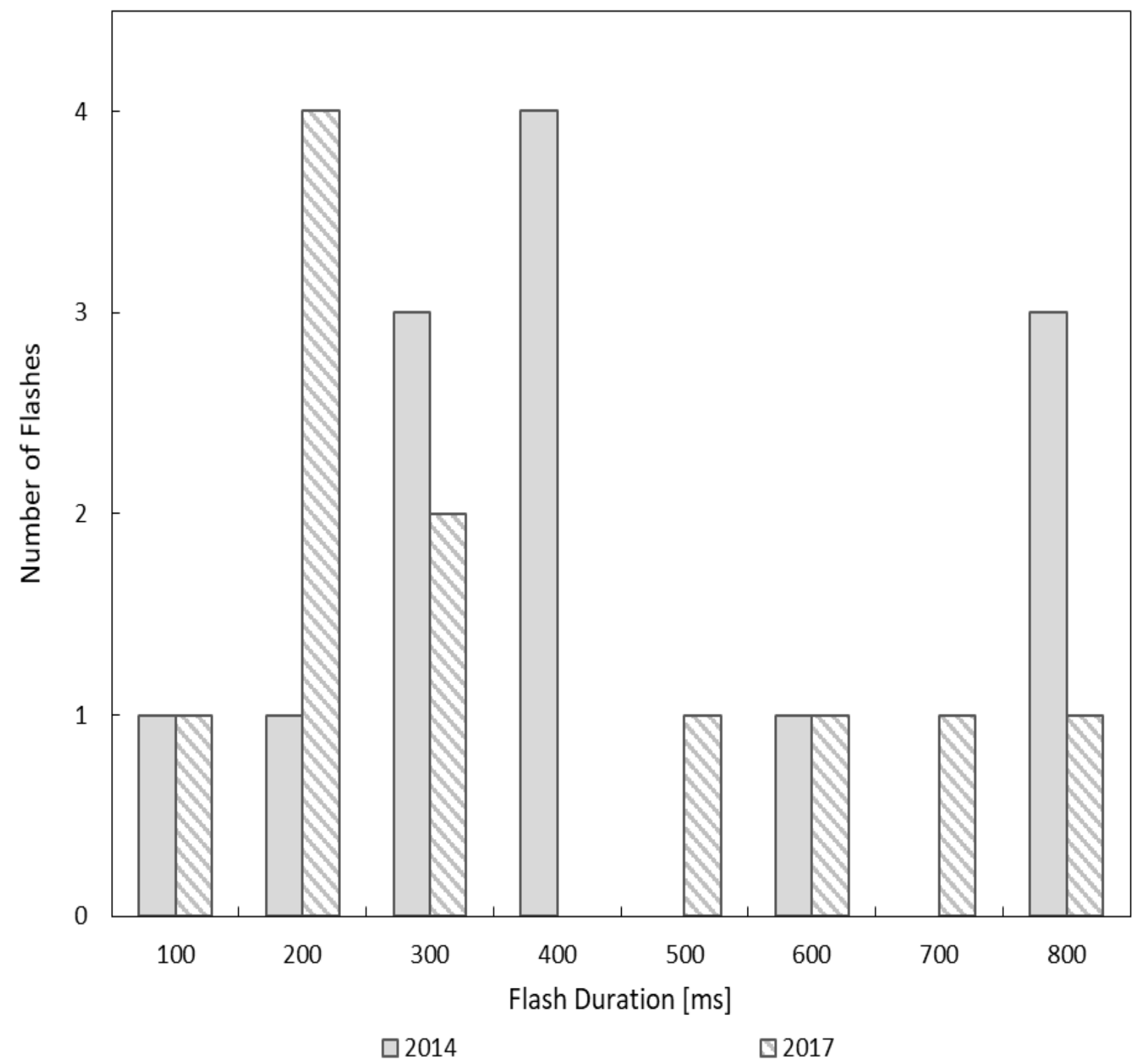

Figure 6.13 - Frequency distribution of the flash duration of flashes recorded during major storms (Sept. 5, 2014 and Sept. 4, 2017).

Table 6.11 reveals that the average flash duration of flashes received during 2014 storm is $20 \%$ longer as compared to the average flash duration of flashes received during $2017 \mathrm{storm}$. Also, Figure 6.14 presents that the 50\% CPD of flash durations of storm 2017 is about $26 \%$ longer as compared to flash durations of 2014 storm. 


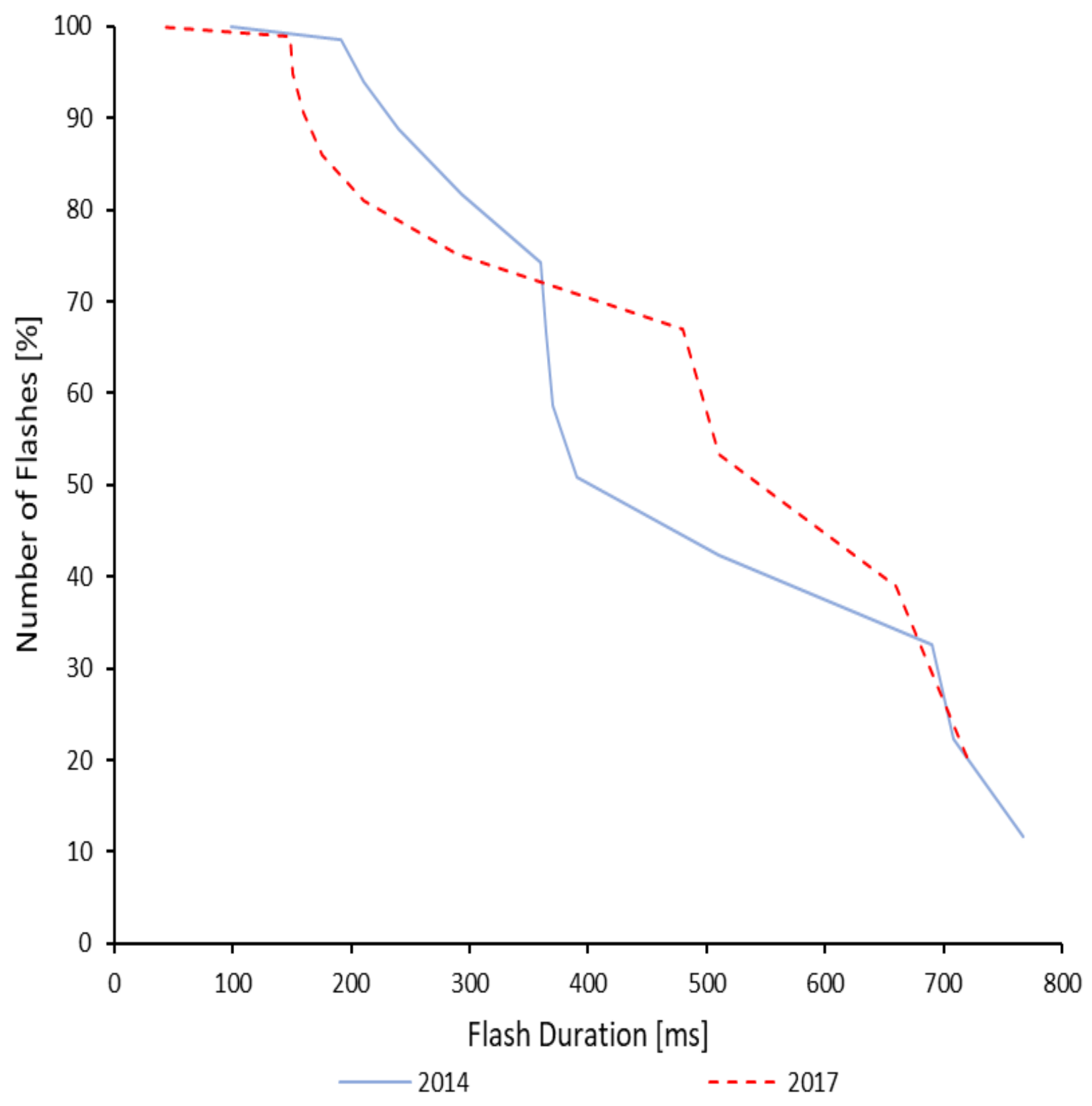

Figure 6.14 - Cumulative probability distribution of flash duration of flashes recorded during major storms (Sept. 5, 2014 and Sept. 4, 2017). 
Table 6.11 Statistical summary of flash durations of flashes recorded during major storms (Sept. 5, 2014 and Sept. 4, 2017).

\begin{tabular}{|c|c|c|}
\hline \multicolumn{2}{|c|}{ Flash Duration [ms] } \\
\hline & 2014 Storm & 2017 Storm \\
\hline Minimum & 99 & 37 \\
\hline Maximum & 767 & 720 \\
\hline Mean & 399.4 & 321.8 \\
\hline 50\% Probability & 367 & 497 \\
\hline Standard Deviation & 211.6 & 231 \\
\hline
\end{tabular}

It's worth mentioning that the 50\% CPD of flash durations of 2017 (497 ms) storm is $26 \%$ greater than that of 2014 (367 ms) storm, flash durations (Table 6.11). The difference in the size of the two data sets and possibly the $5.6 \%$ more flashes contained by 2017 storm, with flash durations above $400 \mathrm{~ms}$, may explain the discrepancies.

\subsubsection{Inter-Flash Time Duration}

Figure 6.15 shows the frequency distribution of inter-flash time duration of flashes captured during 2014 and 2017 storms. It's observed that the inter-flash time intervals of 2014 storm (16.67\%) and 2017 storm (80\%) are within 400 s. While, 83.3\% (2014) and 20\% (2017) of interflash time intervals are beyond $400 \mathrm{~s}$. 


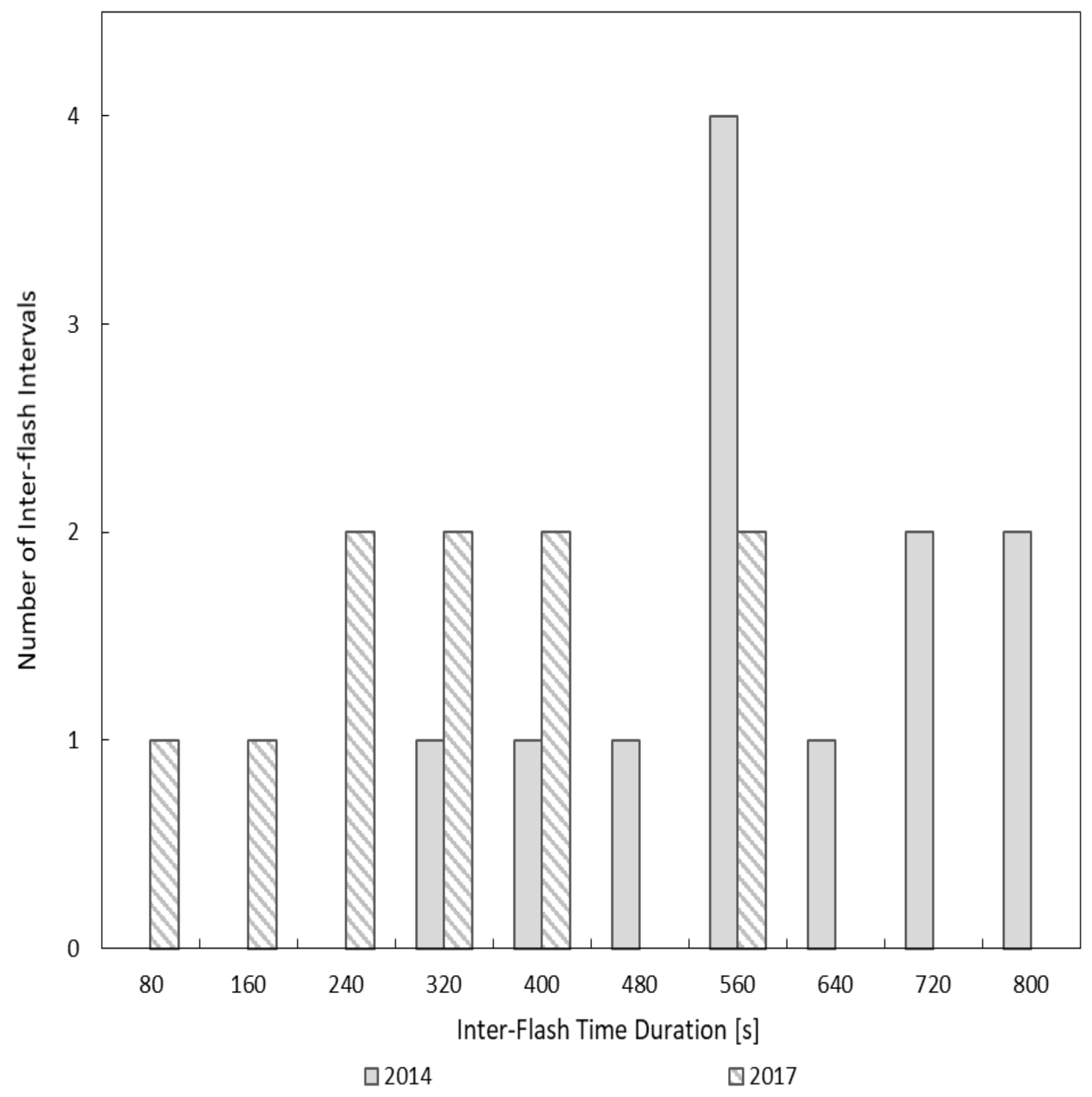

Figure 6.15 - Frequency distribution of inter-flash duration of flashes recorded during major storms (Sept. 5, 2014 and Sept. 4, 2017). 


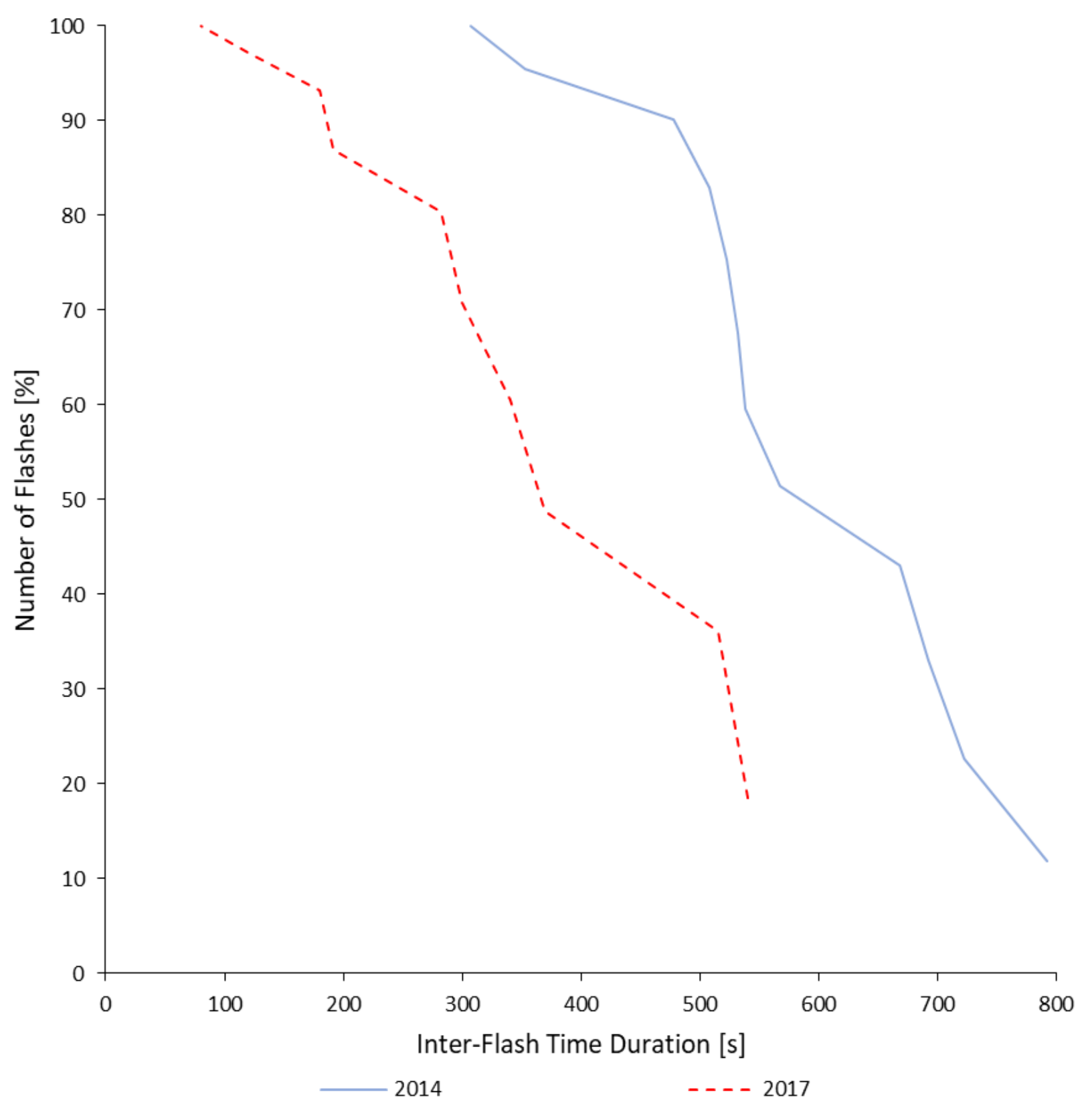

Figure 6.16 - Cumulative probability distribution of inter-flash time of flashes recorded during major storms (Sept. 5, 2014 and Sept. 4, 2017). 
Table 6.12 Statistical summary of inter-flash durations of flashes recorded during major storms (Sept. 5, 2014 and Sept. 4, 2017).

\begin{tabular}{|c|c|c|}
\hline \multicolumn{2}{|c|}{ Inter-Flash Time Duration [s] } \\
\hline Minimum & 2014 Storm & 2017 Storm \\
\hline Maximum & 307 & 80 \\
\hline Mean & 792 & 540 \\
\hline 50\% Probability & 556 & 291.9 \\
\hline Standard Deviation & 550 & 348 \\
\hline
\end{tabular}

Table 6.12 reveals that the inter-flash time durations for storm 2014 vary between $307 \mathrm{~s}$ and $792 \mathrm{~s}$, on the other hand, the inter-flash time durations for 2017 storm varies between $80 \mathrm{~s}$ and 540 S.

For comparison, it's noted that the minimum inter-flash time duration of 2017 storm is $73 \%$ shorter than the minimum inter-flash time duration 2014 storm. However, the maximum interflash time duration of 2014 storm is $31.8 \%$ longer, as compared to 2017 storm. It's also concluded from the Table 6.12 that the average inter-flash time duration of 2017 storm is $47 \%$ smaller as compared to the average inter-flash time duration of 2014 storm. The discrepancies in the data are due to the nature of two storms.

It can be inferred from Figure 6.16 that $50 \%$ CPD of the inter-flash time duration of 2014 storm (550 s) is more as compared to the 2017 storm (348 s). 


\subsubsection{Initial-Stage Current Duration}

During the 2014 and 2017 storms, the CN Tower optical recording systems captured 13 and 11 flashes respectively. Interestingly, all the flashes received during the storms contained initialstage current. Figure 6.17 presents the frequency distribution of initial-stage current time durations, which made possible to conclude that the majority of 2014 (77\%) and 2017 (90\%) flashes have an initial-stage current duration within 400ms. Whereas, a small amount of flashes contained initial-stage current duration between $400 \mathrm{~ms}$ and $650 \mathrm{~ms}$ constituting $23 \%$ (2014) and $10 \%$ (2017).

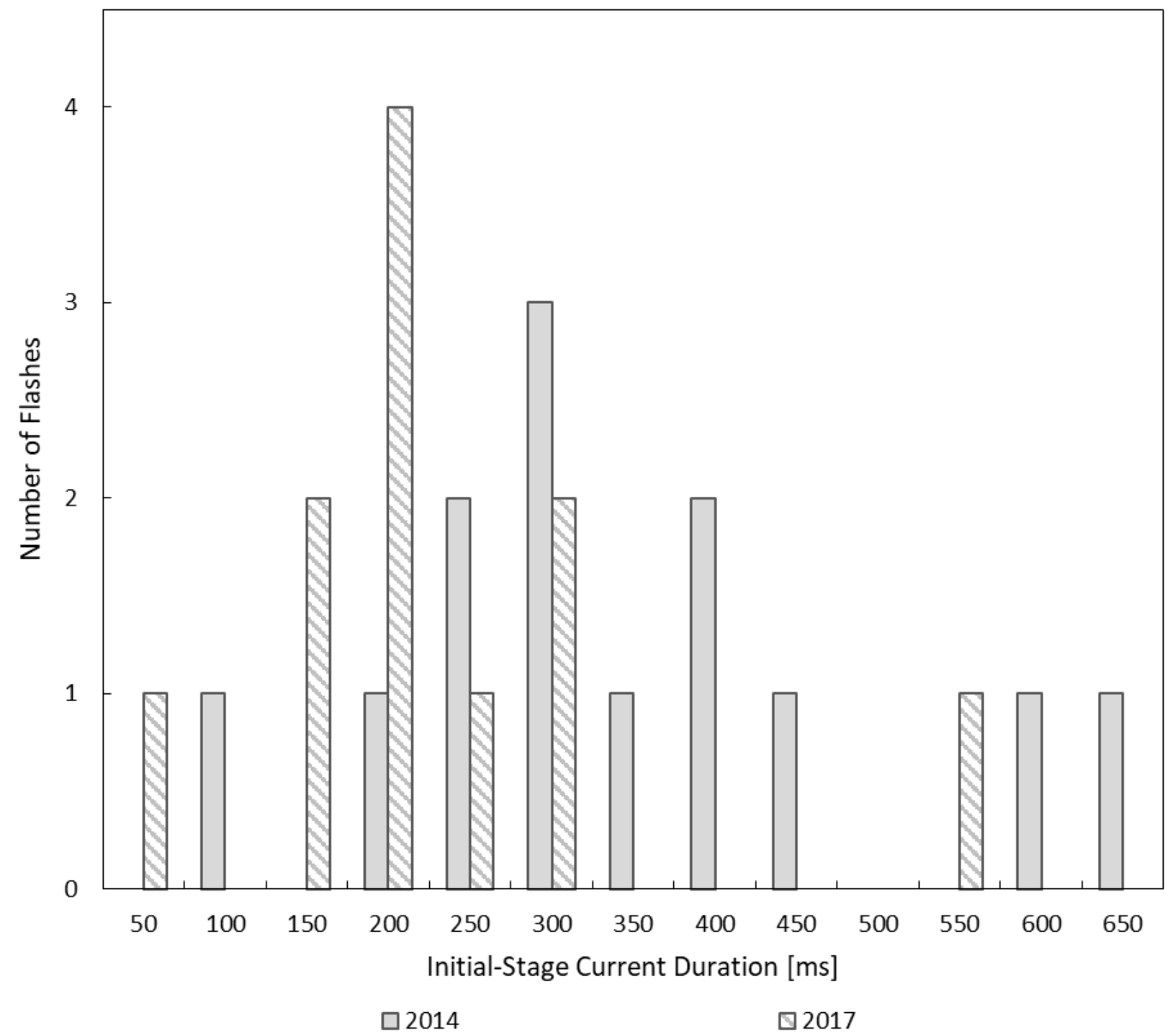

Figure 6.17 - Frequency distribution of initial-stage current duration of flashes recorded during major storms (Sept. 5, 2014 and Sept. 4, 2017). 


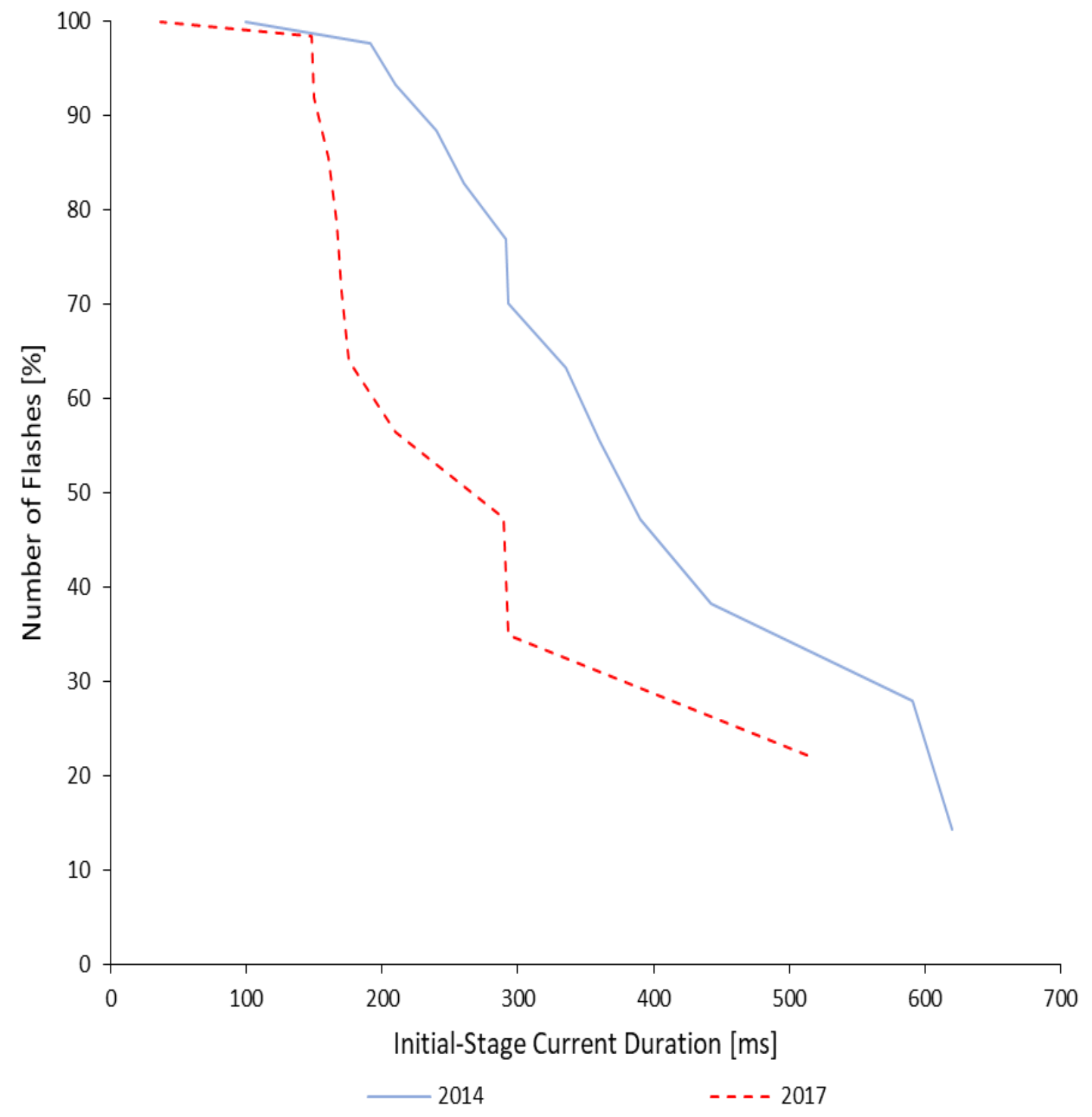

Figure 6.18 - Cumulative probability distribution of initial-stage current duration of flashes recorded during major storms (Sept. 5, 2014 and Sept. 4, 2017). 
Table 6.13 Statistical summary of initial-stage current durations of flashes recorded during major storms (Sept. 5, 2014 and Sept. 4, 2017).

\begin{tabular}{|c|c|c|}
\hline \multicolumn{2}{|c|}{ Initial-Stage Current Duration [ms] } \\
\hline Minimum & 2014 Storm & 2017 Storm \\
\hline Maximum & 99 & 37 \\
\hline Mean & 620 & 513 \\
\hline 50\% Probability & 332 & 210.2 \\
\hline Standard Deviation & 360 & 188 \\
\hline
\end{tabular}

Table 6.13 shows that minimum initial-stage current duration of 2014 (99 ms) is $62.6 \%$ longer than 2017 (37 ms), which is the markedly more substantial difference. Whereas, a maximum initial-stage current of 2014 (620 ms) is only 17\% longer as compared to 2017 (513 ms).

For comparison, Table 6.13 and Figure 6.18 clearly states that storm of 2014 had more considerable average initial-stage current duration (332 ms) and 50\% CPD (360 ms) as compared to the average initial-stage current duration $(210 \mathrm{~ms})$ and 50\% CPD (188 ms) of 2017 storm.

\subsubsection{Flash Multiplicity}

Based on the datasets of 2014 and 2017 storms, 46\% and $45 \%$ of flashes contained return strokes, respectively. Figure 6.19 illustrates the frequency distribution of flash multiplicity. The figure shows that $80 \%$ of flashes in both years had 1 or 2 return strokes. While only $16.6 \%$ of 
flashes received during 2014 storm had three return strokes and $20 \%$ of flashes received during 2017 storm had four return strokes.

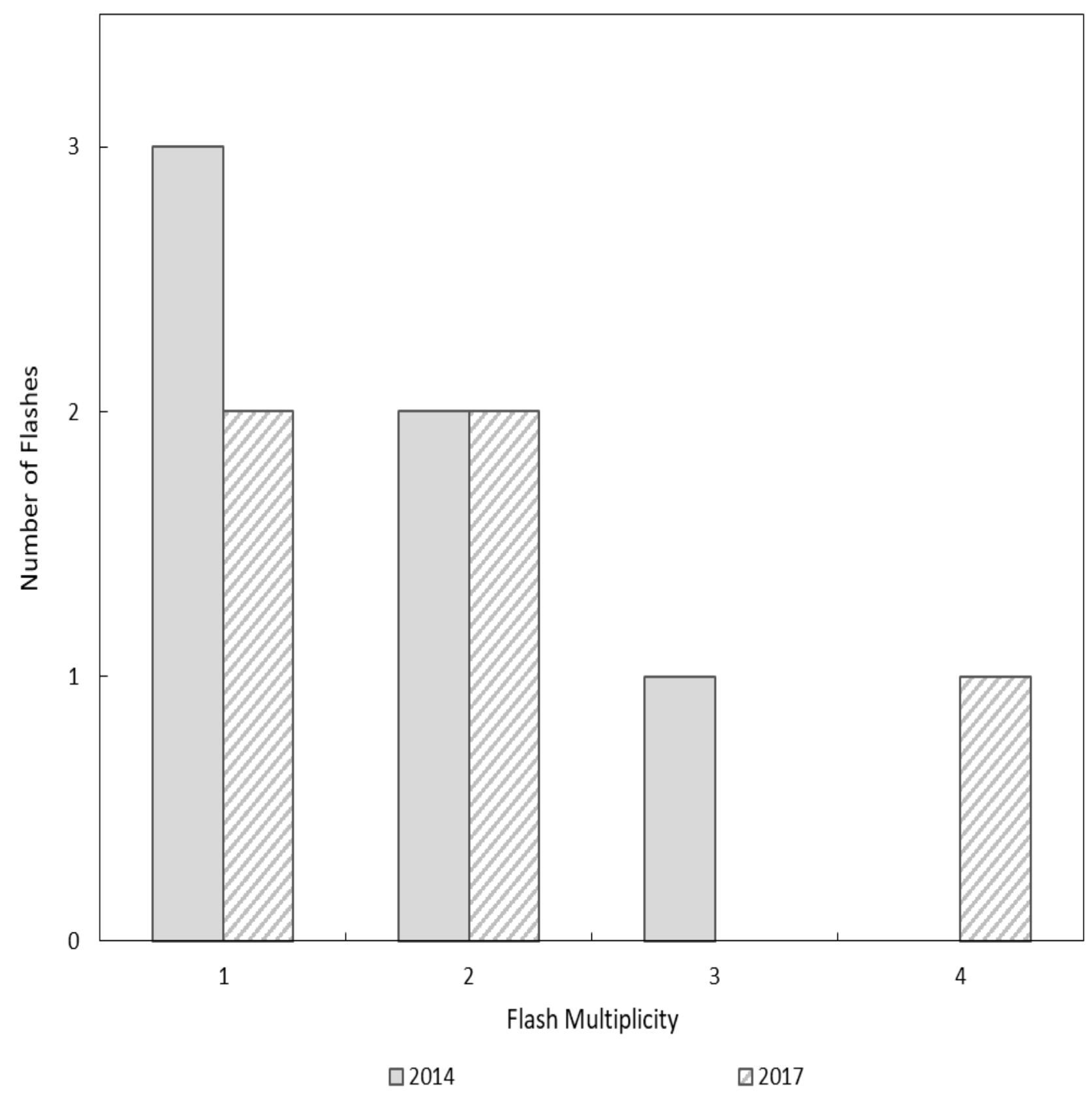

Figure 6.19 - Frequency distribution of flash multiplicity of flashes recorded during major storms (Sept. 5, 2014 and Sept. 4, 2017). 


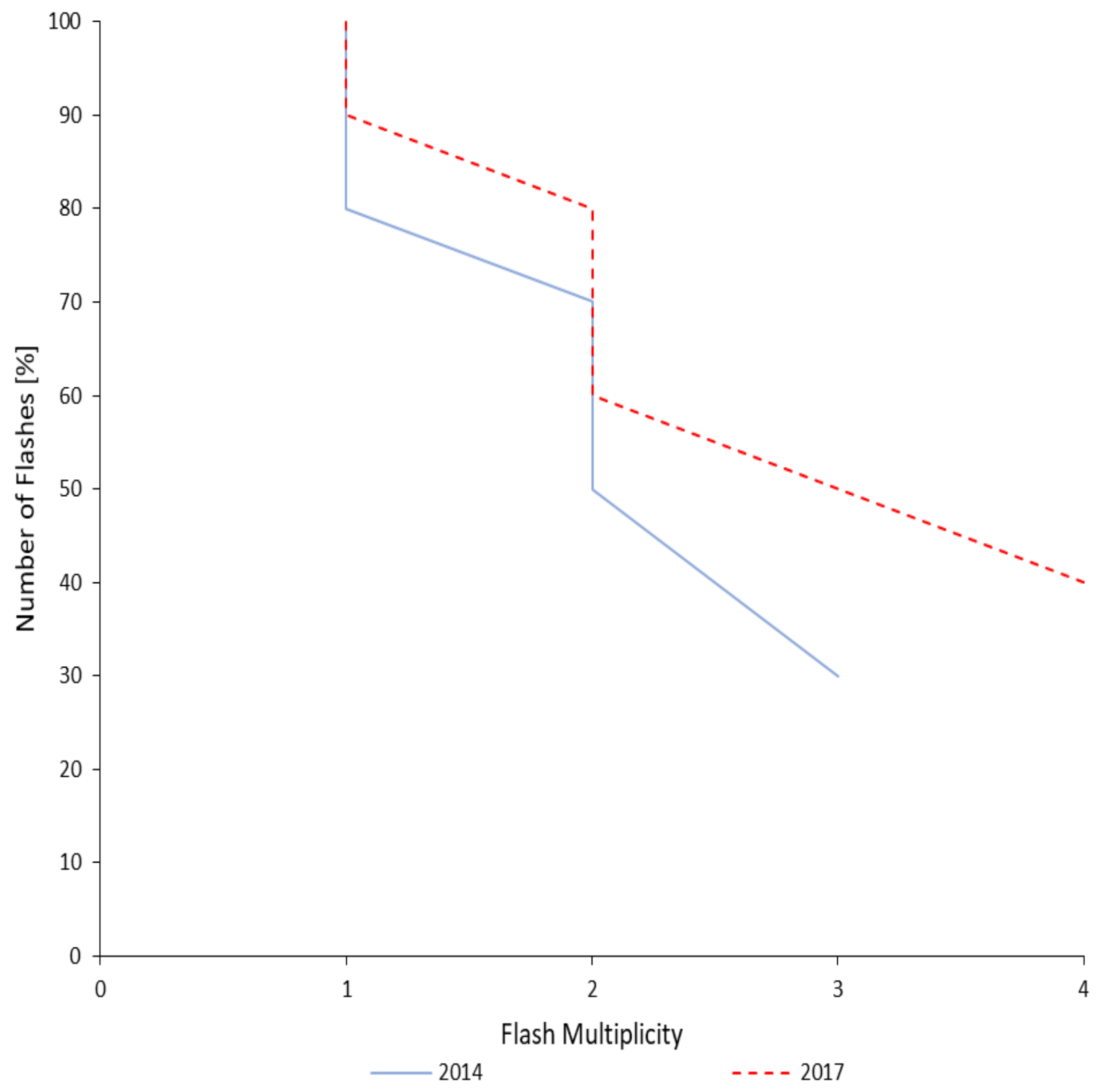

Figure 6.20 - Cumulative probability distribution of flash multiplicity of flashes recorded during major storms (Sept. 5, 2014 and Sept. 4, 2017). 
Table 6.14 Statistical summary of flash multiplicity of flashes recorded during major storms (Sept. 5, 2014 and Sept. 4, 2017).

\begin{tabular}{|c|c|c|}
\hline \multicolumn{2}{|c|}{ Flash Multiplicity } \\
\hline & 2014 Storm & 2017 Storm \\
\hline Minimum & 1 & 1 \\
\hline Maximum & 3 & 4 \\
\hline Mean & 1.67 & 2 \\
\hline 50\% Probability & 2 & 2 \\
\hline Standard Deviation & 0.81 & 1.22 \\
\hline
\end{tabular}

Table 6.14 clearly shows that storm of September 5, 2014, and storm of September 4, 2017, both had at least one return stroke. Whereas, 2017 had a maximum of 4 return strokes as compared to 2014 (3 return strokes), which has one less return stroke.

For the comparison purpose, it can be concluded from Table 6.14 and Figure 6.20, that both storms had similar average multiplicity with a modest difference. Also, 50\% CPD of the two storms is identical.

\subsubsection{Inter-Stroke Time Duration}

Based on the data sets of the two storms, the storm of 2014 contains four inter-stroke time intervals, and the 2017 storm constitutes five inter-stroke time intervals. Figure 6.21 demonstrates the frequency distribution of inter-stroke time intervals. Furthermore, it's also concluded from the figure that $50 \%$ of 2014 inter-stroke time durations are within the range of $20 \mathrm{~ms}$ and $80 \mathrm{~ms}$, and a similar percentage of flashes are within the range of $80 \mathrm{~ms}$ and $140 \mathrm{~ms}$. Whereas, $2017 \mathrm{storm}$ had $40 \%$ of inter-stroke intervals within $20 \mathrm{~ms}$ and $80 \mathrm{~ms}$ and $60 \%$ of flashes within $80 \mathrm{~ms}$ and 
$140 \mathrm{~ms}$, meaning $10 \%$ a smaller number of inter-stroke time intervals within $20 \mathrm{~ms}$ and $80 \mathrm{~ms}$ and $10 \%$ more number of inter-stroke time intervals within $80 \mathrm{~ms}$ to $140 \mathrm{~ms}$, as compared to the storm of 2014.

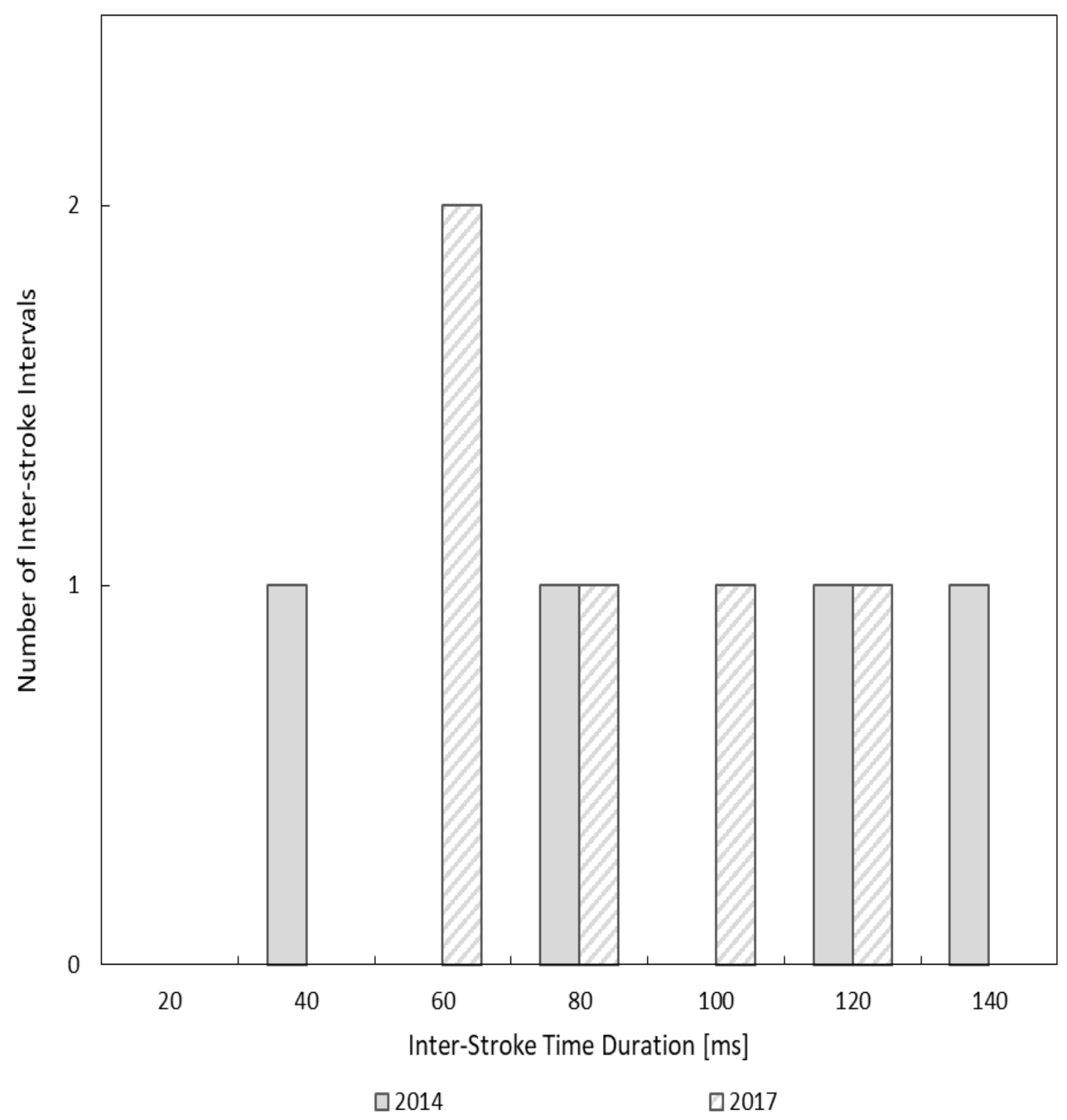

Figure 6.21 - Frequency distribution of inter-stroke time duration of flashes recorded during major storms (Sept. 5, 2014 and Sept. 4, 2017). 


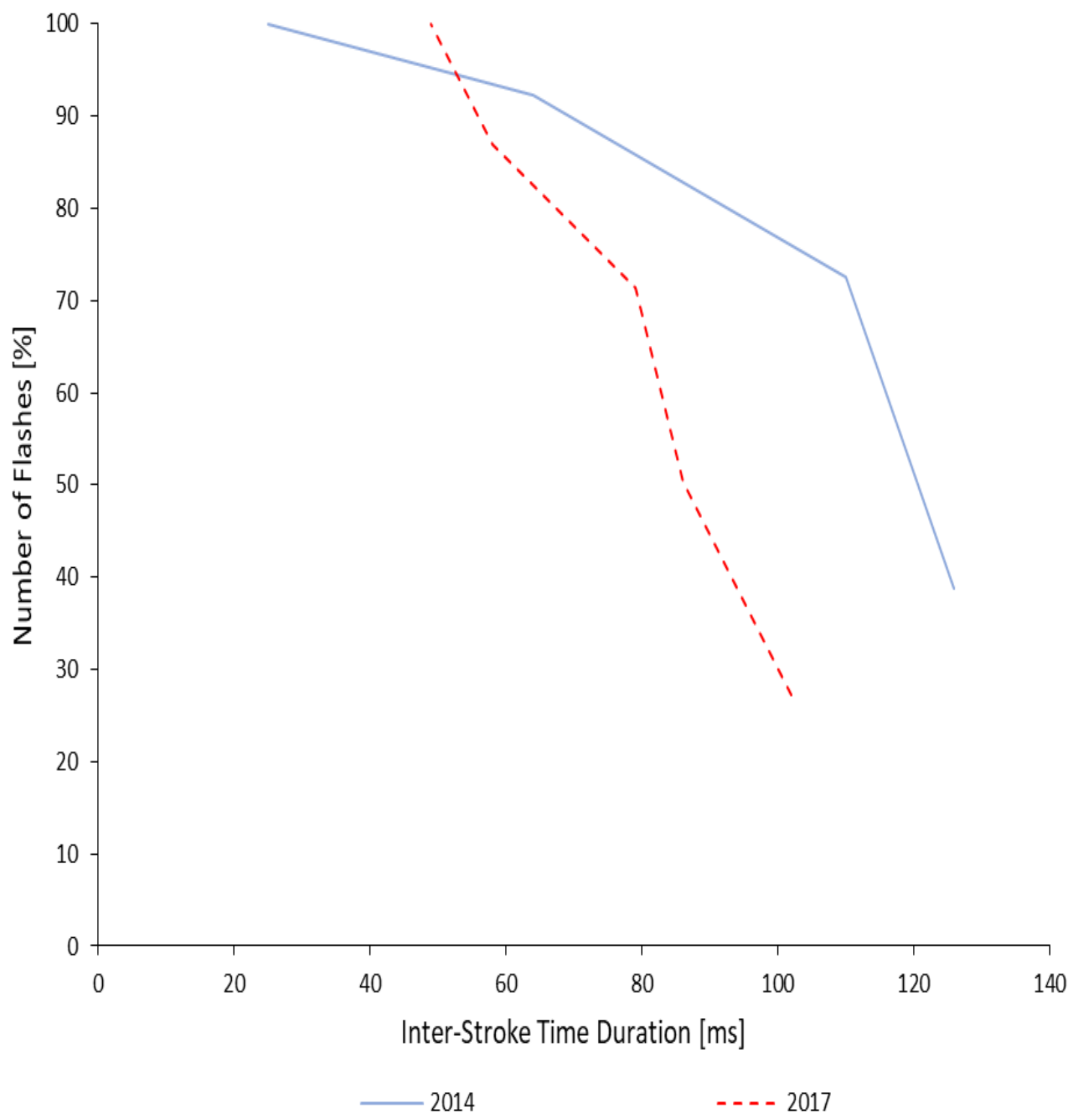

Figure 6.22 - Cumulative probability distribution of inter-stroke time duration of flashes recorded during major storms (Sept. 5, 2014 and Sept. 4, 2017). 
Table 6.15 Statistical summary of inter-stroke time durations duration of flashes recorded during major storms (Sept. 5, 2014 and Sept. 4, 2017).

\begin{tabular}{|c|c|c|}
\hline \multicolumn{2}{|c|}{ Inter-Stroke Time [ms] } \\
\hline & 2014 Storm & 2017 Storm \\
\hline Minimum & 25 & 49 \\
\hline Maximum & 126 & 102 \\
\hline Mean & 81.25 & 74.8 \\
\hline 50\% Probability & 112 & 83 \\
\hline Standard Deviation & 45.8 & 21.4 \\
\hline
\end{tabular}

Table 6.15 reveals that the inter-stroke time duration of 2014 storm is found to vary between $25 \mathrm{~ms}$ and $126 \mathrm{~ms}$ with an overall average of $81.25 \mathrm{~ms}$. On the other hand, the inter-stroke time duration of 2017 storm is found to vary between $49 \mathrm{~ms}$ to $102 \mathrm{~ms}$ with an overall average interstroke time duration of $74.8 \mathrm{~ms}$, which is $7.9 \%$ shorter than the average inter-stroke time duration of 2014 storm.

For the comparison, the Figure 6.22 shows that 2014 had greater $50 \%$ CPD as compared to 2017 storm.

\subsubsection{Continuing Current Duration}

Based on the data sets of the two storms it's observed that 2014 storm had six flashes (46\%) containing continuing currents, while 2017 storm had three flashes (27\%) containing continuing currents. 
Figure 6.23 presents the frequency distribution of 2014 and 2017 storms. It's possible to infer from the figure that $77 \%$ of continuing current durations falls within $80 \mathrm{~ms}$ for 2014 and 2017 storms. Whereas, only about $23 \%$ of continuing current durations falls within the range of $80 \mathrm{~ms}$ to $160 \mathrm{~ms}$ for the two storms.

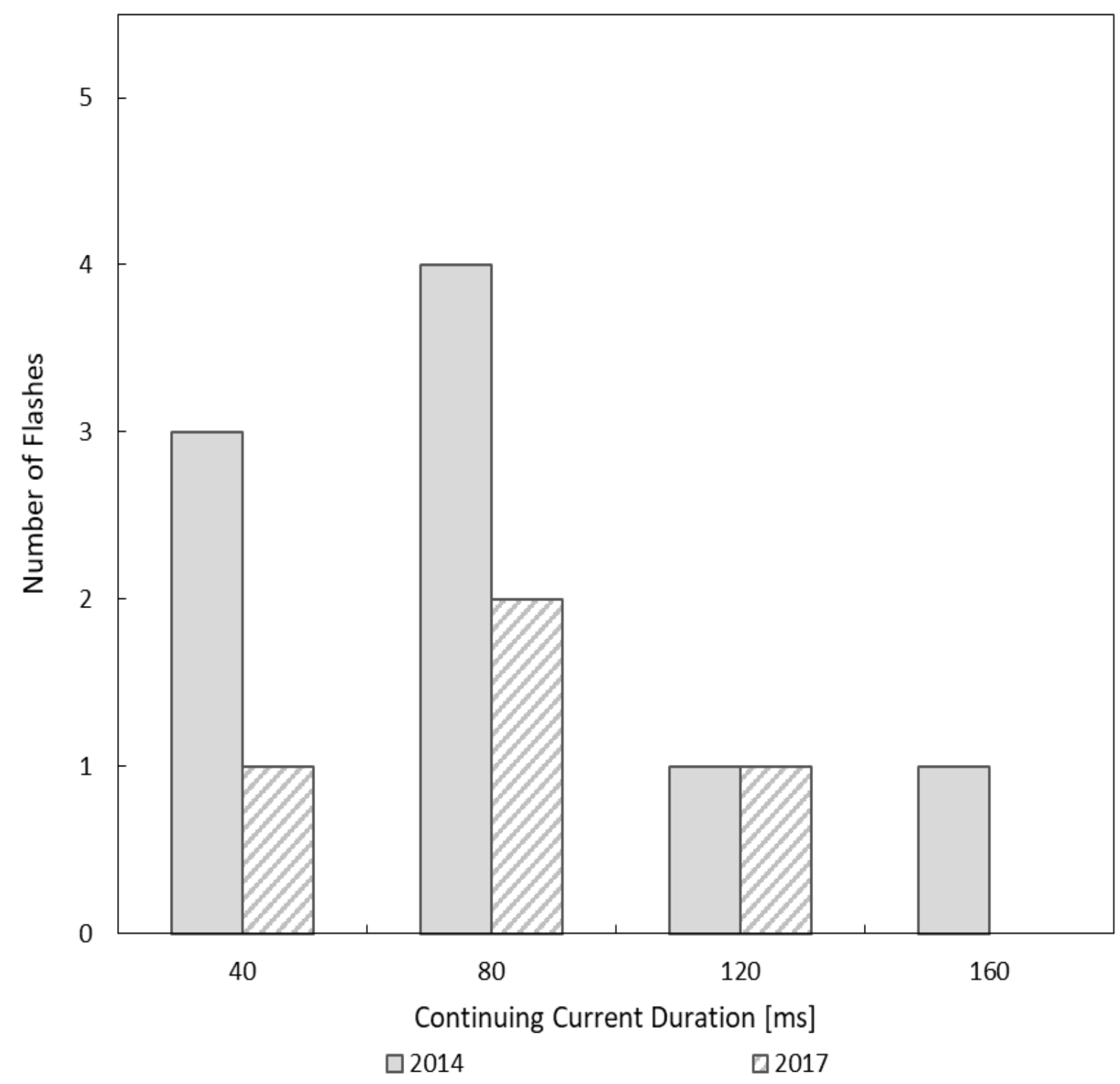

Figure 6.23 - Frequency distribution of continuing current duration of flashes recorded during major storms (Sept. 5, 2014 and Sept. 4, 2017). 


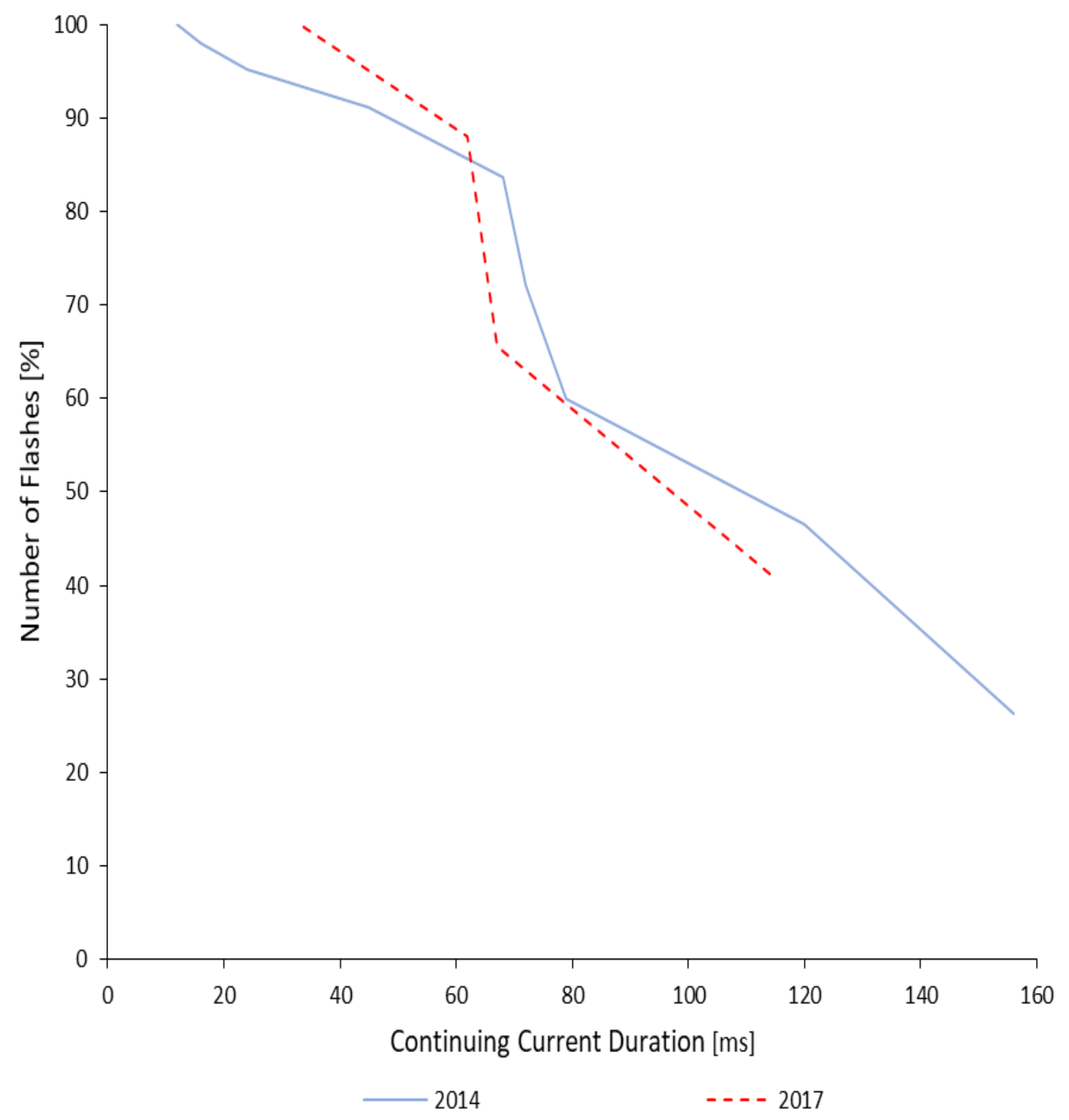

Figure 6.24 - Cumulative probability distribution of continuing current duration of flashes recorded during major storms (Sept. 5, 2014 and Sept. 4, 2017). 
Table 6.16 Statistical summary of continuing current durations of flashes recorded during major storms (Sept. 5, 2014 and Sept. 4, 2017).

\begin{tabular}{|c|c|c|}
\hline \multicolumn{2}{|c|}{ Continuing Current Time Duration [ms] } \\
\hline \multirow{2}{|c|}{ Minimum } & 2014 Storm & 2017 Storm \\
\hline Maximum & 12 & 33 \\
\hline Mean & 156 & 114 \\
\hline 50\% Probability & 65.8 & 69 \\
\hline Standard Deviation & 78 & 66 \\
\hline
\end{tabular}

Table 6.16 clearly shows that continuing current time durations of 2014 storm is found to vary between $12 \mathrm{~ms}$ to $156 \mathrm{~ms}$, with an overall average of $65.8 \mathrm{~ms}$. Whereas, the continuing current time duration of 2017 storm is found to vary between $33 \mathrm{~ms}$ to $114 \mathrm{~ms}$, with an overall average of $69 \mathrm{~ms}$, which is almost the same to the average continuing current duration of the 2014 storm.

Figure 6.24 shows that the 50\% CPD of 2014 storm is $15 \%$ longer as compared to that of the 2017 storm. 


\section{Chapter 7}

\section{Conclusions and Future Research}

\subsection{Conclusions}

The principal objective of the work completed in this thesis focused on the statistical analysis of CN Tower lightning flash characteristics, based on the video records of Phantom v5.0 digital high-speed camera and Sony HDR PJ790VB digital continuously recording camera, which were acquired over the past five years (2013-2017). The existence and characteristics of lightning flash components, namely, the initial-stage current, return strokes, M-components and continuing currents were determined by examining video records (luminosity vs. time analysis).

It is worth mentioning that the characteristics of 58 optically recorded flashes clearly show that every recoded flash contained an initial-stage current, confirming that all flashes were upward initiated. Also, it has been inferred that the duration of the initial-stage current varied from $32 \mathrm{~ms}$ to $620 \mathrm{~ms}$, with an overall average of $218.6 \mathrm{~ms}$. Also, 27 out of the 58 flashes contained return strokes ranging from 1 to 9 , with an average multiplicity of 2.16. It is important to mention that 56 return strokes were observed to hit the tower during the past five years. Furthermore, the flash time duration varied between $32 \mathrm{~ms}$ to $767 \mathrm{~ms}$, with an overall average of $296.8 \mathrm{~ms}$. Whereas, the inter-flash time duration ranged from $80 \mathrm{~s}$ to $792 \mathrm{~s}$, with an overall average of $324 \mathrm{~s}$. It is also important to say that the data set of the last five years only comprised 13 multi-stroke flashes, containing 28 inter-stroke intervals that varied between $12 \mathrm{~ms}$ to $126 \mathrm{~ms}$, with an overall average 
of $62.5 \mathrm{~ms}$. Moreover, 25 out of the 56 return strokes were followed by continuing currents, with durations ranging from $12 \mathrm{~ms}$ to $156 \mathrm{~ms}$, with an overall average duration of $61 \mathrm{~ms}$.

The second objective of this thesis was to compare the statistical analyses of each year (20132017). Based on the analysis of the 58 video recorded flashes, it was observed that in 2014 got the highest number of flashes with extended flash durations of up to $767 \mathrm{~ms}$, and the most substantial average flash duration as compared to all other years. However, 50\% cumulative probability distribution (CPD) of 2017 overweighs that for 2014 and all other years because the flash duration of most of the flashes comprised by 2017 dataset is in the higher range (above $400 \mathrm{~ms}$ ). Also, the 2014, we observed the highest inter-flash time duration of (792 s), with the largest overall average and 50\% CPD in comparison with all other years. Furthermore, the initial-stage current in 2014 had the longest initial-stage current duration (620 ms), largest average (288 ms) and 50\% CPD (317 ms), as compared with all other years. Moreover, the flash multiplicity of the 2016 data set accounts for the maximum of return strokes per flash, which clearly overweighs all other years. However, the average flash multiplicity of all years was almost identical (2).

The maximum inter-stroke time durations for all years varied between $102 \mathrm{~ms}$ and $126 \mathrm{~ms}$, with 2014 leading all other years. It was also noted that the average $(81.25 \mathrm{~ms})$ and 50\% CPD (112 $\mathrm{ms}$ ) of the inter-stroke time duration of 2014 dataset was longest among all other years. The comparison of the statistical analyses of the continuing current time duration clearly showed that the 2014 dataset had the longest continuing current time duration (156 ms). Whereas, the 50\% CPD of continuing current duration of 2015 was leading among all years.

Based on the analyses of video records for the last five years, it was noted that two significantly major storms were captured during the night of September 5, 2014, and September 4, 2017. During the storm of September 5, 2014, the CN Tower imaging systems recorded 13 flashes. The storm lasted for 111.4 mins, resulting in average a flash to the tower every 9 mins. Whereas, during the September 4, 2017 storm 11 flashes hit the tower and the storm continued for 49.35 mins, producing on an average a flash to tower every 4 mins and 48 s. However, interestingly during the storm of September 4, 2017, all eleven flashes were recorded by Sony continuouslyrecording camera, whereas the high-speed camera was only able to record four flashes out of storm's eleven flashes. The inter-flash times of the eleven flashes captured by the LSC were pivotal in time matching of the two data sets. The comparison between the lightning data recorded by 
HSC and LSC illustrated that the economical LSC turns out to be an extremely valuable imaging system. As the continuously recording imaging system (LSC) confirmed the operation or the failure of the HSC. However, LSC does not have an adequate frame rate (60 fps) to capture every subtle detail of a flash, including M-components.

The comparison of the statistical analyses of these two significant storms was one of the objectives of this work, to further study the nature of the two major storms. The statistical analyses of flash durations of both storms clearly showed that 50\% CPD in the 2017 storm was longer as compared to that 2014 storm, due to $6 \%$ more flashes from the 2017 storm having the flash duration above $400 \mathrm{~ms}$. Similarly, the overall average of the inter-flash time duration of 2014 storm was longer as compared to the 2017 storm. Likewise, the 2014 storm had longer overall average initial-stage current duration as compared to 2017 storm. Furthermore, the 50\% CPD of flash multiplicity of both storms were identical. Moreover, the overall average inter-stroke time duration of the 2014 storm was higher than that of the 2017 storm. Whereas, the 50\% CPD of the continuing current duration of 2014 storm was higher than that of the 2017 storm.

To summarize, flashes with longer flash durations contains higher number of return strokes, with short inter-stroke time can pose severe threat to tall structures and electrical and communication systems especially when inter-stroke times are short. Study of various flash components is pivotal to study the nature of flashes to build a sophisticated protections system for tall structures.

\subsection{Future Research and Recommendations}

Simultaneous measurements and recordings of all relevant lightning parameters should continue. More equipment should be installed at closer distance from the $\mathrm{CN}$ Tower to better record the characteristics of $\mathrm{CN}$ Tower flashes and non-CN Tower flashes in the vicinity of the tower.

The digital high-speed imaging system currently in use to record CN Tower lightning flashes was updated in 2006 from Phantom v2.0 to Phantom v5.0, which made it possible to record lightning flashes to the tower at 1000 frames per second (fps), with higher recording length (1300 
$\mathrm{ms}$ ), which is more than double the record length of the previous high-speed imaging system, which was necessary for studying in more detail the flash characteristics of flashes. Although, the present high-speed imaging system can be utilized and a new high-speed camera with much higher frame rates must be acquired which would help in analyzing the speed of propagation of return strokes. Also, the required high-speed camera must have a built-in trigger, which would allow the camera to avoid getting triggered by false information outside its recording window. Moreover, the operation of the two high-speed cameras will make it possible to record the 3-dimensional trajectory of the flash.

The current continuously-recording low-speed camera has no time stamps, which could be made possible by the addition of a new continuously recording camera with time stamps. The simultaneous operation of the continuously recording camera has proved to be crucial and should be continued for recording $\mathrm{CN}$ Tower lightning flashes because the continuous recording of the camera enables to confirm the operation or failure of the high-speed cameras, which depends upon the external triggering device. 


\section{References}

[1] Martin A. Uman, "The Lightning Discharge”, Florida: Academic Press, Inc., 1987.

[2] Martin A. Uman, “All About Lightning”, New York: Dover Publications, Inc., 1986.

[3] Vladimir A. Rakov, and Martin A. Uman, "Lightning: physics and effects". Cambridge University Press, August 2003.

[4] Martin A. Uman, Lightning, Pittsburg PA: McGraw Hill, 1969.

[5] The Structure of Cold Clouds - University of Arizona

http://www.atmo.arizona.edu/students/courselinks/spring15/atmo589/ATMO489.

[ accessed on July 17, 2018]

[6] Earle R. Williams, “The Electrification of Thunderstorms”, Scientific American, pp. 88-99, November 1988.

[7] G. Diendorfer, "Lightning initiated from tall structures-A review." In Lightning Protection (XI SIPDA), 2011 International Symposium on, pp. 298-303. IEEE, 2011.

[8] M. Megumu, Vladimir A. Rakov, Takatoshi Shindo, G. Diendorfer, M. Mair, F. Heidler, W. Zischank, M. A. Uman, R. Thottappillil, and D. Wang. "Initial stage in lightning initiated from tall objects and in rocket-triggered lightning." Journal of Geophysical Research: Atmospheres 110, no. D2 (2005).

[9] A.M. Hussein, M. Milewski, A. Abdelraziq, W. Janischewskyj, and F. Jabbar. "Visual characteristics of CN Tower lightning flashes." In 28th International Conference on Lightning Protection (ICLP), Kanazawa, Japan, pp. 18-22, 2006.

[10] A.M. Hussein, S. Jan, V. Todorovski, M. Milewski, K. L. Cummins, and W. Janischewskyj. "Influence of the $\mathrm{CN}$ Tower on the lightning environment in its vicinity." In Proceedings of the International Lightning Detection Conference (ILDC), pp. 1-19. 2010. 
[11] W. Janischewskyj, A.M. Hussein, V. Shostak, I. Rusan, J-X. Li, and J-S. Chang. "Statistics of lightning strikes to the Toronto Canadian National Tower (19781995)." IEEE Transactions on Power Delivery 12, no. 3 (1997): 1210-1221.

[12] W. Janischewskyj, A.M. Hussein, M. Wiacek, and J. S. Chang. "Details of CN Tower flashes utilizing a digital high-speed camera." In Proc. 24th International Conference on Lightning Protection, pp. 101-106. 1998.

[13] A.M. Hussein, and M. Milewski. "CN tower lightning flash components." In Lightning Protection (XI SIPDA), 2011 International Symposium on, pp. 7-13. IEEE, 2011.

[14] A. M. Hussein, S. Kazazi, M. Anwar, M. Yusouf, and P. Liatos. "CN Tower lightning characteristics based on current-recorded flashes." In Lightning Protection (ICLP), 2014 International Conference, pp. 2028-2034. IEEE, 2014.

[15] A. Lafkovici, A.M. Hussein, W. Janischewskyj, and Kenneth L. Cummins. "Evaluation of the performance characteristics of the North American Lightning Detection Network based on tall-structure lightning." IEEE Transactions on Electromagnetic Compatibility 50, no. 3 (2008): 630-641.

[16] M. Milewski, "Lightning Return-Stroke Transmission Line Modelling Based on the Derivative of Heidler Function and CN Tower Data, "Ph.D. Thesis, Ryerson University, Toronto, Ontario, Canada, 2009.

[17] N. Mansour, "Lightning Environment in the Vicinity of the CN Tower During Major Storms, “MASc Thesis, Ryerson University, Toronto, Ontario, Canada, 2017.

[18] A. M. Hussein, M. Milewski, and W. Janischewskyj. "Characterization of CN tower lightning flash components." In Proceedings of the International Conference on Ground \& 4 Lightning Physics and Effects, pp. 1-7. 2010. 
[19] S. Kazazi, P. Liatos, and A.M. Hussein. "Simultaneous recording of cn tower lightning current and channel luminosity." In Electrical and Computer Engineering (CCECE), 2014 IEEE 27th Canadian Conference on, pp. 1-6. IEEE, 2014.

[20] Phantom Technical Specifications, "Phantom v5.0, "Vision Research Inc., Wayne, New Jersey, USA, 2000.

[21] A.M. Hussein, S. Kazazi, M. Anwar, M. Yusouf, and P. Liatos. "Characteristics of the most intense lightning storm ever recorded at the $\mathrm{CN}$ Tower." Journal of Atmospheric and Solar-Terrestrial Physics 154 (2017): 195-206.

[22] I. Sra, A.M. Hussein and P. Liatos, "CN Tower Lightning Flash Characteristics Based on High-Speed Imaging," Proceedings, International Conference on Grounding and Lightning Physics \& Effects, pp. 18-21, May 20-25, 2018, Pirenópolis, Brazil.

[23] A.M. Hussein, W. Janischewskyj, J-S. Chang, V. Shostak, W. A. Chisholm, P. Dzurevych, and Z-I. Kawasaki. "Simultaneous measurement of lightning parameters for strokes to the Toronto Canadian National Tower." Journal of Geophysical Research: Atmospheres 100, no. D5 (1995): 8853-8861.

[24] P. Liatos, and A.M. Hussein. "Characterization of 100-kHz noise in the lightning current derivative signals measured at the $\mathrm{CN}$ tower." IEEE transactions on electromagnetic compatibility 47, no. 4 (2005): 986-997.

[25] I. Sra, A.M. Hussein, "Luminosity Characteristics of the CN Tower Lightning Components,"25 $5^{\text {th }}$ International Lightning Detection Conference (ILDC) and 7th International Lightning Meteorology Conference (ILMC), pp. 1-12, March 12-15, 2018, Fort Lauderdale, Florida, USA. 


\section{Glossary}

\begin{tabular}{ll} 
AGL & Above Ground Level \\
CC & Continuing Current \\
CG & Cloud-to-ground \\
CPD & Cumulative Probability Distribution \\
DL & Dart Leader \\
EMI & Electromagnetic Interference \\
HSC & High-Speed Camera \\
ISC & Initial-Stage Current \\
IST & Inter-stroke Time \\
LEMP & Lightning Generated Electromagnetic Pulse \\
LSC & Low-Speed Camera \\
RS & Return Stroke \\
\hline
\end{tabular}

